\title{
Pathways of Gastric Carcinogenesis, Helicobacter pylori Virulence and Interactions with Antioxidant Systems, Vitamin C and Phytochemicals
}

\author{
James W. T. Toh ${ }^{1}$ and Robert B. Wilson ${ }^{2, *}$ \\ 1 University of Sydney, UNSW, Westmead Hospital, Sydney, NSW 2145, Australia; \\ james.toh@health.nsw.gov.au \\ 2 Department of Upper Gastrointestinal Surgery, UNSW, Liverpool Hospital, Liverpool, NSW 2170, Australia \\ * Correspondence: robert.wilson@unsw.edu.au
}

Received: 1 August 2020; Accepted: 31 August 2020; Published: 3 September 2020

\begin{abstract}
Helicobacter pylori is a class one carcinogen which causes chronic atrophic gastritis, gastric intestinal metaplasia, dysplasia and adenocarcinoma. The mechanisms by which H. pylori interacts with other risk and protective factors, particularly vitamin $\mathrm{C}$ in gastric carcinogenesis are complex. Gastric carcinogenesis includes metabolic, environmental, epigenetic, genomic, infective, inflammatory and oncogenic pathways. The molecular classification of gastric cancer subtypes has revolutionized the understanding of gastric carcinogenesis. This includes the tumour microenvironment, germline mutations, and the role of Helicobacter pylori bacteria, Epstein Barr virus and epigenetics in somatic mutations. There is evidence that ascorbic acid, phytochemicals and endogenous antioxidant systems can modify the risk of gastric cancer. Gastric juice ascorbate levels depend on dietary intake of ascorbic acid but can also be decreased by $H$. pylori infection, $H$. pylori CagA secretion, tobacco smoking, achlorhydria and chronic atrophic gastritis. Ascorbic acid may be protective against gastric cancer by its antioxidant effect in gastric cytoprotection, regenerating active vitamin $\mathrm{E}$ and glutathione, inhibiting endogenous $\mathrm{N}$-nitrosation, reducing toxic effects of ingested nitrosodimethylamines and heterocyclic amines, and preventing $H$. pylori infection. The effectiveness of such cytoprotection is related to H. pylori strain virulence, particularly CagA expression. The role of vitamin $C$ in epigenetic reprogramming in gastric cancer is still evolving. Other factors in conjunction with vitamin $C$ also play a role in gastric carcinogenesis. Eradication of $H$. pylori may lead to recovery of vitamin $\mathrm{C}$ secretion by gastric epithelium and enable regression of premalignant gastric lesions, thereby interrupting the Correa cascade of gastric carcinogenesis.
\end{abstract}

Keywords: ascorbic acid; CagA; chronic atrophic gastritis; Correa pathway; dietary salt; gastric cancer; glutathione; Helicobacter pylori; nitrosamines; oxidative stress; phytochemicals; vitamin C

\section{Introduction}

The Global Cancer statistics 2018 (GLOBOCAN 2018) estimated that in 2018 there were $1,033,701$ new cases of gastric cancer in the world, with 782,685 deaths [1]. Behind lung cancer, this represented the second leading cause of cancer-related mortality worldwide, closely followed by hepatocellular/cholangio carcinoma [1-5]. There are marked global geographical variations in gastric cancer incidence, with the highest incidence in East Asian countries and the lowest incidence in North America and North Africa [1,2]. This is thought to be related to Helicobacter pylori prevalence and strain virulence, as well as additional gastric cancer risk factors [2-4].

Pathways for gastric cancer are complex and interrelated, including metabolic, environmental, epigenetic, genomic, infective, inflammatory and oncogenic. These involve risk factors such as 
Helicobacter pylori bacteria or Epstein Barr virus (EBV) infection, atrophic gastritis (AG), gastric intestinal metaplasia (IM), diet, high salt intake, tobacco smoking, alcohol consumption, obesity, racial background, ABO blood group, biological sex and family history of gastric cancer [6]. In 1994, the World Health Organization (WHO) and the International Agency for Research on Cancer classified H. pylori as a class 1 carcinogen [7].

This review provides an in-depth analysis of the molecular pathways to gastric cancer including the role of dietary and environmental risk factors $-H$. pylori, tobacco smoking, nitrosamines, heterocyclic amines, dietary salt and alcohol consumption amongst others. The inter-relationships between gastric cytoprotection, $H$. pylori virulence, epigenetics and gastric neoplasia are also examined. This includes the potential protective effect of endogenous antioxidant systems, vitamin C (ascorbic acid) and other ingested phytochemicals in the development of gastric cancer.

\section{Gastric Carcinogenesis}

\subsection{Correa Pathway and Sydney Classification of Intestinal Metaplasia}

Of the non-cardia gastric cancers, $89 \%$ are related to $\mathrm{H}$. pylori bacterial infection and $9 \%$ are EBV related. The Correa model of intestinal type gastric carcinogenesis is a multistep cascade of chronic active gastritis progressing to multifocal AG, IM, low grade dysplasia, high grade dysplasia and finally gastric adenocarcinoma [8]. The Modified Sydney System is an internationally recognized endoscopic and histological system of chronic gastritis classification, which was originally introduced in 1994. It involves targeted endoscopic biopsies of abnormal gastric mucosa and non-targeted biopsies of the gastric antrum, incisura and corpus. This increases the detection rate of gastric IM, AG and dysplasia and can guide future endoscopic surveillance with mapping biopsies. The European Society of Gastrointestinal Endoscopy guideline currently includes eradication treatment for patients with H. pylori, and then endoscopic surveillance every three years in those found to have gastric IM [9].

Gastric intestinal metaplasia is classified as either focal or extensive in distribution, and complete or incomplete histological appearance. Complete gastric IM has small intestinal glands with loss of gastric mucins (MUC1, MUC5AC and MUC6), eosinophilic enterocytes with brush borders, well-defined goblet cells, and occasional Paneth cells. Incomplete gastric IM contains colonic type glands with intracytoplasmic mucin droplets and absence of an absorptive brush border. Incomplete IM has a higher proliferative rate and, together with extensive IM, is associated with a 4- to 11-fold higher risk for intestinal-type gastric cancer than complete IM [9-11].

Intestinal type gastric cancer and IM are characterized by high levels of Caudal type homeobox-2 (CDX-2) expression, which is also expressed in sporadic diffuse gastric cancer (DGC) but absent in normal gastric epithelium and in autosomal dominant hereditary gastric cancer (HDGC) [12,13]. DGC appears to arise directly from chronic active gastritis, without the intermediate steps of AG and IM in intestinal type gastric cancer. DGC is characterized by poorly cohesive adenocarcinoma cells with signet ring cell appearance on histopathology, resulting from intracellular mucin vacuoles which displace the nucleus to the periphery of the cell [10].

\subsection{Helicobacter Pylori}

Helicobacter pylori is the first bacterial carcinogen described. It is usually acquired in childhood, with a long period of colonization and chronic gastritis eventually leading to non-cardia intestinal type gastric adenocarcinoma, sporadic diffuse gastric cancer or gastric B-cell lymphocyte mucosa associated lymphoid tissue (MALT) lymphoma [14]. Exposure to H. pylori toxins causes generation of gastric oxidative stress, reactive aldehyde formation, cellular DNA and RNA damage, hypermethylation of DNA promoter genes, host inflammatory response, chronic mucosal inflammation, achlorhydria, synergistic interactions with other carcinogens, and failure of antioxidant protection in the gastric mucosa. Such mechanisms involve: 
1. H. pylori toxins which damage gastric mucosal epithelial cells leading to chronic atrophic gastritis, decreased gastric mucosal secretion of ascorbic acid, parietal cell apoptosis, achlorhydria, hypergastrinaemia, gastric dysbiosis, intestinal metaplasia, dysplasia and intestinal type gastric cancer (Figure 1, pathways 1, 4, 8, 9).

2. Recruitment of inflammatory cells resulting in acute and/or chronic inflammation, activation of reactive oxygen species (ROS) pathways including neutrophil myeloperoxidase- hypochlorite ( $\mathrm{HOCl}$ )-hydrogen peroxide $\left(\mathrm{H}_{2} \mathrm{O}_{2}\right)$, macrophage nitric oxide $(\mathrm{NO})$ and epithelial cell hydrogen peroxide production (Figure 1, pathway 6, 12).

3. Oxidative stress due to reactive nitrogen species (RNS), ROS, lipid peroxidation and MDA/free radical formation overwhelming gastric antioxidant protection.

4. Promotion of gastric epithelial proliferation, oncogenes and DNA damage via various mechanisms, including H. pylori CagA, VacA, BabA, SabA, Hp-NAP, ROS, RNS, urease, DNA hypermethylation and cellular tyrosine kinases (Figure 1, pathways 1, 3, 4, 7, 8, 10, 11, 12).

5. Dysregulation of tyrosine kinase oncogenic pathways and loss of tumour suppressors (p53, CDH1/E-cadherin, APC, MGMT, MLH1, CDKN2A), leading to failure of apoptosis and Epithelial Mesenchymal Transition (EMT) (Figure 1, pathways 7, 8).

6. Synergy with ingested carcinogens (nitrosamines/heterocyclic amines/nitrites/dietary salt/alcohol/ tobacco smoke) and complex interactions with antioxidants resulting in decreased protective effects and promotion of carcinogenesis (Figure 1).

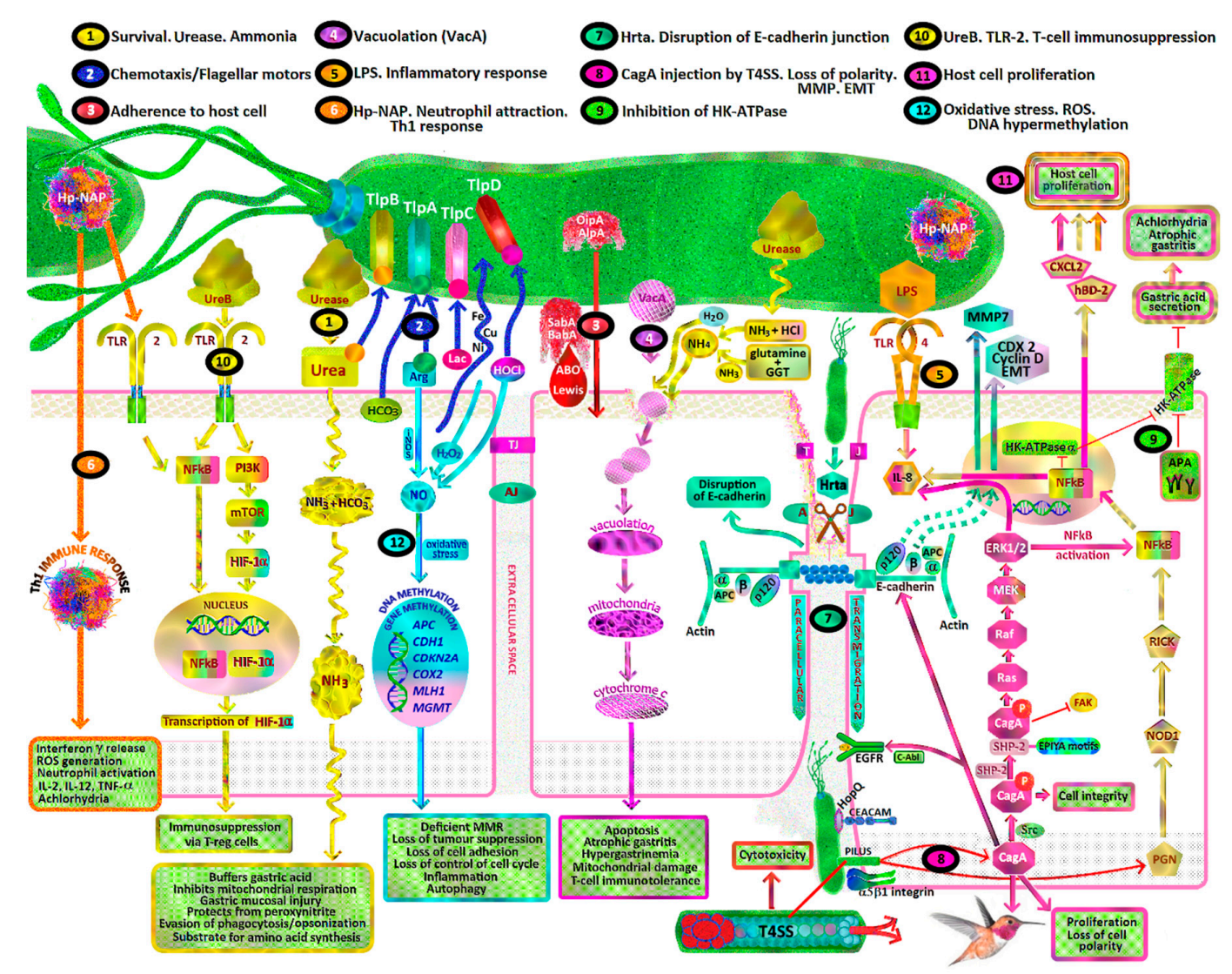

Figure 1. Pathways of $H$. pylori survival, chemotaxis, adhesion, colonization, virulence, inflammation, host immunotolerance, atrophic gastritis, oxidative stress, DNA methylation, cellular proliferation, EMT and oncogenesis in the gastric epithelium. H. pylori CagA injection causes disruption of E-cadherin and intercellular adhesion, loss of cell polarity, enhanced cell motility and development of the 'hummingbird' phenotype. 


\subsection{Epidemiology of Gastric Cancer}

At least half of the world's population is infected with $H$. pylori, but only $0.2-3 \%$ of those with H. pylori develop gastric cancer. From the GLOBOCAN 2018 data, the incidence of gastric adenocarcinoma is 3-12 times higher in East Asian countries (32.1/10 5 males, 13.2/10 females), Eastern Europe (17.1/10 5 males, $7.5 / 10^{5}$ females) and Andean Latin America (26.9/10 males, $10.3 / 10^{5}$ females) where virulent strains of $H$. pylori are endemic. This is compared to areas of lowest incidence in

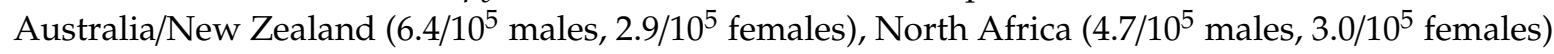
and North America (5.6/10 $0^{5}$ males, $2.8 / 10^{5}$ females). The highest rate of gastric cancer is in South Korea, with a national incidence of $60 / 10^{5}$ males and 25/10 females [1] (Figure 2). The fall in incidence of non-cardia gastric cancer and peptic ulcer disease in Western developed countries has occurred in parallel with declines in the incidence of $H$. pylori colonization in these countries, particularly in persons under 65 years of age [15]. H. pylori is transferred by the oral-oral and faecal-oral routes, leading to intergenerational spread in families. The prevalence of $H$. pylori in developing countries is closely related to socio-economic status, as poor nutrition, overcrowding, inadequate sanitation and close personal contact increase colonization rates [16].

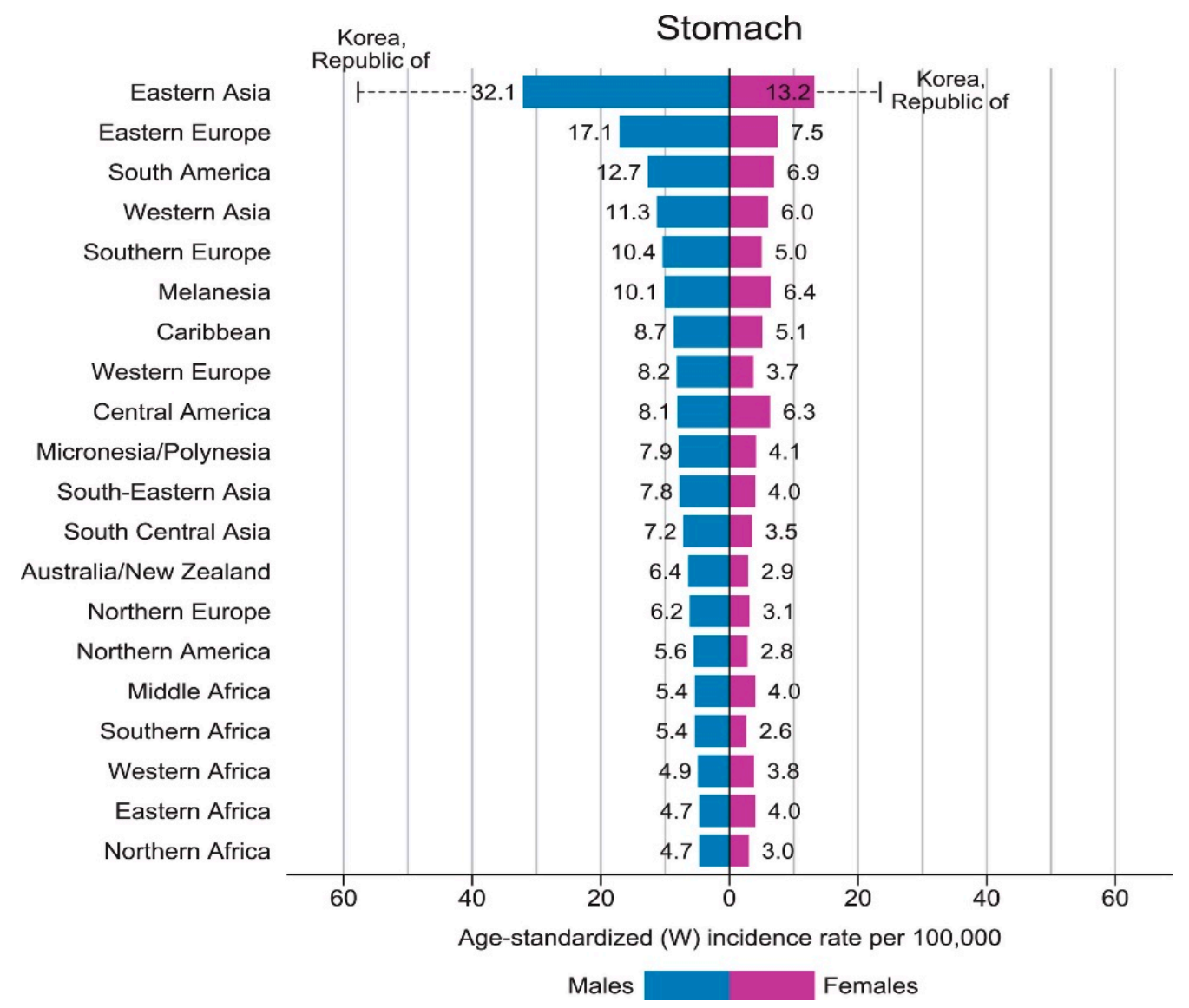

Figure 2. Age-standardized region-specific incidence (GLOBOCAN data) for gastric cancer in 2018. Adapted from Bray et al. (2018) with permission [1].

\subsection{Lauren Classification}

Since the Lauren classification was introduced in 1965, gastric cancer has been classified into intestinal, diffuse or mixed/indeterminate histological subtypes. Men are 2-4 times more likely to be diagnosed with intestinal-type non-cardia gastric cancer than females, whereas DGC is more common in women [14]. H. pylori is the main risk factor for non-cardia gastric adenocarcinoma and a diet rich in fresh fruits and vegetables is considered a protective factor $[17,18]$. Both diffuse and 
intestinal type gastric cancers share some dietary and environmental risk factors including H. pylori infection, as well as molecular abnormalities including DNA methylation, histone methylation and acetylation and chromosome recombination. The comparative risk of $H$. pylori causing intestinal type non-cardia gastric cancer (OR $=4.45 ; 95 \%$ CI: $2.74-7.24)$ versus DGC (OR $=3.39 ; 95 \%$ CI: $1.70-6.76)$ was equivalent $(p=0.50)$ in a pooled meta-analysis of 12 studies involving 1228 gastric cancer cases and 3406 controls $[19,20]$.

Genetic predisposition is more common in HDGC, due to E-cadherin (CDH1) gene germline mutations in $40 \%$ of cases. HDGC makes up only $1-3 \%$ of overall gastric cancer cases. It is characterized by autosomal dominant inheritance, and is associated with a 70\% lifetime risk of DGC [12,21]. The 'two hit' theory of gastric carcinogenesis suggests that loss of the second $C D H 1$ allele (by methylation, somatic mutations or loss of heterozygosity) is required for decreased E-cadherin glycoprotein expression and development of DGC. Sporadic DGC is associated with hypermethylation of the CDH1 promoter gene in $35-55 \%$ of cases. Other gene mutations found in DGC include those of Ras homologue gene family, member A (RhoA), claudin-18 and Rho GTPase activating protein 6 (CLDN18-ARHGAP6), and TGF $\beta 11$ [12,21].

Intestinal type non-cardia gastric cancers tend to affect male patients (M:F $=1.8: 1)$, older patients (Male mean age $=50.4$ years, Female mean age $=47.7$ years) and metastasize via lymphatic and vascular invasion, with an associated longer clinical course and better prognosis than diffuse subtypes. Diffuse-type gastric cancers tend to arise in the gastric body, affect younger patients, particularly females, with a predilection for diffuse invasion of the gastric submucosa and muscularis propria and subsequent peritoneal metastasis. Blood group A is also associated with DGC $[19,20]$.

\subsection{Gastric Cancer Molecular Subtypes}

In 2014, the Cancer Genome Atlas Research Network classified gastric carcinoma into four main molecular subtypes. These include:

1. Epstein Barr virus associated (EBV, 8.8\%) with hypermethylation of DNA promoters. EBV gastric cancer is characteristically found in the proximal stomach. It is a poorly differentiated adenocarcinoma with lymphocytic infiltration on histology, PD-L1 and PD-L2 overexpression and CDKN2A silencing [22].

2. Microsatellite instability (MSI, 21.7\%) due mainly to mutations of the hMLH1 gene promoter, leading to deficient mismatch repair of DNA (dMMR). MSI is associated with Lynch syndrome, distal gastric cancers and Lauren intestinal subtype on histology.

3. Chromosomal instability (CIN, 49.8\%) with intestinal type cancer and cytosine and guanine $(\mathrm{CpG})$ island methylator phenotype (CIMP). CIN gastric cancers arise more often in the gastro-oesophageal junction and gastric cardia (65\%).

4. Genomically stable (GS, 19.7\%) with DGC [23].

Subsequent transcriptomic and proteomic analysis has demonstrated that gastric cancer is a complex, heterogeneous disease, with substantial intra-tumoural, intra-patient and inter-patient variability [24-26]. The Lei classification (2013) is a biologically and therapeutically meaningful classification which divides gastric cancer into proliferative, metabolic and mesenchymal subtypes. In 2015, the Asian Cancer Research Group (ACRG) analysed the mRNA expression of 300 gastric cancers. Molecular subtypes were classified as:

1. MSI-high (23\%),

2. Microsatellite stable/epithelial mesenchymal transition (MSS/EMT, 15\%),

3. Microsatellite stable/TP53 intact (MSS/TP53+, p53 active, 26\%)

4. Microsatellite stable/TP53 loss (MSS/TP53-, p53 inactive, $36 \%$ ).

5. Each subtype was associated with distinct treatment options and prognostic outcomes [27]. 


\subsection{Cardia vs. Non-Cardia Gastric Cancer}

H. pylori appears not to be a significant risk factor for gastric cardia adenocarcinoma $(\mathrm{OR}=0.99$; 95\% CI: 0.72-1.35) as compared to non-cardia adenocarcinoma (OR $=2.97 ; 95 \%$ CI: 2.34-3.77) [19]. Interactions between host susceptibility, genomics, environmental carcinogens, tissue protective mechanisms, redox status, and epigenetics appear to determine the progression of gastric carcinogenesis in both groups. However, infection with a virulent $H$. pylori strain (i.e., CagA+, VacA s1+) is the most important risk factor in non-cardia type gastric cancers [6].

\subsection{Gastric Oxidative Stress}

The stomach, as a bioreactor, is constantly exposed to ingested carcinogens and reactive species, bacterial pathogens and oxidative compounds related to food digestion [28]. Gastric cytoprotection and prevention of oxidative stress is dependent upon intact endogenous antioxidant systems and ingested antioxidants and phytochemicals in food [29]. ROS such as superoxide, hydrogen peroxide and peroxyl can steal electrons from cell membrane lipids, leading to lipid peroxidation and formation of unstable fatty acid radicals (lipid hydroperoxides) [30]. These break down to produce cytotoxic ketones, epoxides and reactive aldehydes such as glyoxal, methyl-glyoxal, acrolein, 4-hydroxynonenal and malondialdehyde (MDA) in the stomach. These are then absorbed in the intestines with a resulting rise in plasma and urinary levels. Reactive aldehydes damage protein and DNA, form DNA adducts such as malondialdehyde-deoxyguanosine, and also react with low density lipoproteins (LDL) to form MDA-LDL [29]. The generation of advanced lipid peroxidation end products (ALEs) and advanced glycation end products (AGEs) by reactive aldehydes (e.g., MDA) has been shown to be mutagenic in bacterial and mammalian systems and carcinogenic in rats [29,31] (Figure 3). The interaction of AGEs with their receptor (RAGE) promotes the progression of gastric cancer [32].

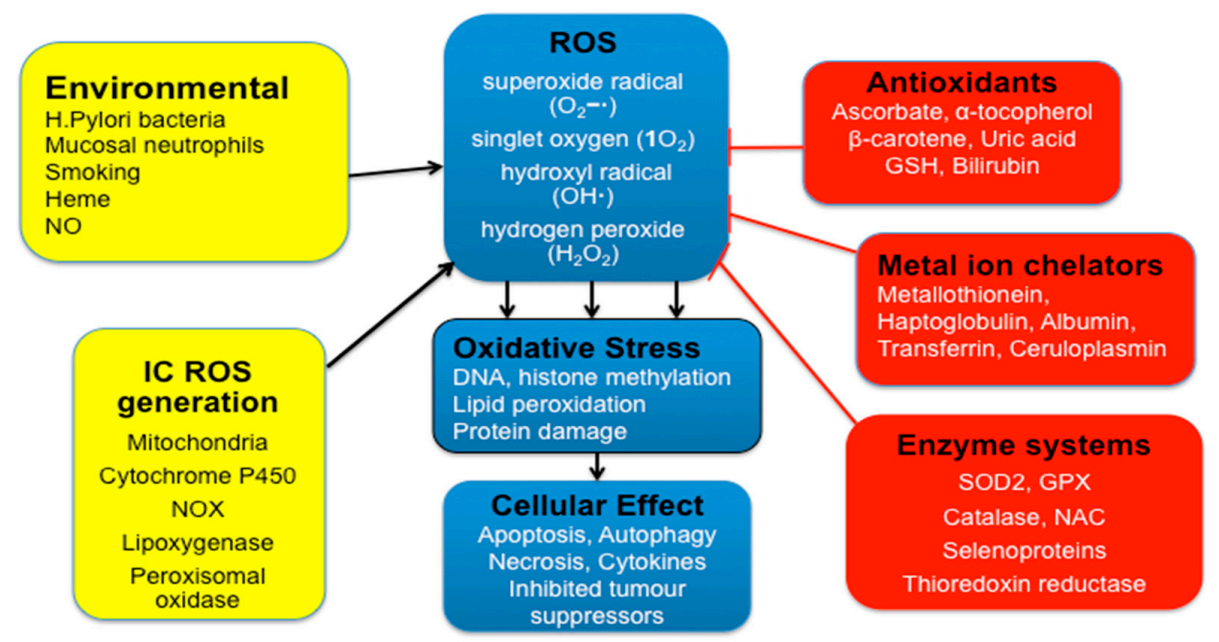

Figure 3. Contribution of environmental and intracellular (IC) sources of reactive oxygen species (ROS) with resulting oxidative stress and activation of oncogenes and inflammation. This can be modified by endogenous antioxidant systems, metal ion chelators and ingested phytochemicals including vitamin $\mathrm{C}$ (ascorbate) [30].

\subsection{Gastric Cytoprotection}

Gastric cytoprotection is reliant on antioxidant systems including:

1. Enzymatic antioxidants such as superoxide dismutase (SOD), catalase (CAT), thioredoxin reductase and glutathione peroxidase (GPX).

2. Small molecule antioxidants such as $\alpha$-tocopherol (vitamin E), ascorbic acid (vitamin $\mathrm{C}$ ), beta-carotene, bilirubin, glutathione (GSH) and uric acid. 
3. Metal ion chelators including metallothionein, haptoglobulin, albumin, transferrin and ceruloplasmin (Figure 3).

These counteract ROS formation and free radical damage. Selenium is an important component of the selenoprotein antioxidant enzyme family, which includes glutathione peroxidases (GPX1-GPX4 and GPX6), thioredoxin reductases (TXNRD1-2), and thioredoxin-glutathione reductase (TXNRD3). The selenoproteins have the unique property of being able to rapidly remove hydrogen peroxide $\left(\mathrm{H}_{2} \mathrm{O}_{2}\right)$ from the cell cytosol. This prevents $\mathrm{H}_{2} \mathrm{O}_{2}$ reacting with ferrous iron and forming hydroxyl radicals, which are the most reactive of oxygen derived free radicals. Selenium deficiency thus contributes to oxidative stress and enhanced inflammation [33].

Vitamin $C$ is important in the reduction of oxidative stress at the gastric mucosal/luminal surface. It also maintains the antioxidant defence system by regenerating urate, glutathione, beta-carotene, and $\alpha$-tocopherol (vitamin E). Glutathione can regenerate oxidised vitamin E (tocopheryl radical) or oxidised vitamin C (Dehydroascorbic acid; DHA), producing a thionyl radical (GS) in the process [34]. Vitamin $C$ may act as a pro-oxidant at supraphysiological levels or in the presence of transition metal ions such as iron or copper, where, by Fenton chemistry, hydroxyl radicals are generated. For example, high dose oral ascorbic acid can have a pro-oxidant effect on ingested red meat (heme iron), resulting in lipid peroxidation in the stomach. However, when ascorbic acid is combined with polyphenols (e.g., catechins), they have synergistic antioxidant effects, and lipid peroxidation is prevented. Polyphenols contained in sage or rosemary can inhibit the formation of ALEs in the stomach from red meat by as much as $100 \%$. One of the theories as to why individual oral antioxidant supplements may not be successful in large-scale human preventative studies is the widespread deficiency of dietary polyphenols or selenium. However, a diet rich in plant polyphenols and vitamin $\mathrm{C}$, such as the Mediterranean diet, helps to maintain redox homeostasis in the stomach during a meal [29,35].

The importance of fresh citrus fruit was demonstrated by the naval surgeon Dr. James Lind in 1747 on the HMS Salisbury, when he showed consumption of two oranges and a lemon per day cured scurvy in sailors [36]. Since then, the crucial role of vitamin C in collagen formation has been established, its deficiency leading to impaired hydroxylation of the amino acid proline to hydroxyproline by the $\mathrm{Fe}^{2+} / 2$-oxoglutarate (2-OG)-dependent dioxygenase prolyl hydroxylase. This redox ability also makes vitamin $C$ the major and essential water-soluble antioxidant in human serum and tissues. Vitamin $C$ can function as an electron donor to form DHA, via the intermediate ascorbyl radical. Vitamin $\mathrm{C}$ can thus scavenge the superoxide anion radical $\left(\mathrm{O}_{2}^{-} \cdot\right)$, singlet oxygen $\left(1 \mathrm{O}_{2}\right)$, hydroxyl radical $(\mathrm{OH} \cdot)$, neutralize hypochlorous acid $(\mathrm{HOCl})$, and prevent lipid peroxidation. Vitamin $\mathrm{C}$ cannot scavenge or neutralize hydrogen peroxide $\left(\mathrm{H}_{2} \mathrm{O}_{2}\right)$. Rather, vitamin $\mathrm{C}$ may potentiate its toxicity by inhibiting catalase activity. $\mathrm{HOCl}$ is produced from $\mathrm{H}_{2} \mathrm{O}_{2}$ and $\mathrm{Cl}^{-}$by myeloperoxidase (MPO) present in neutrophils $[37,38]$ (Figures 3 and 4).

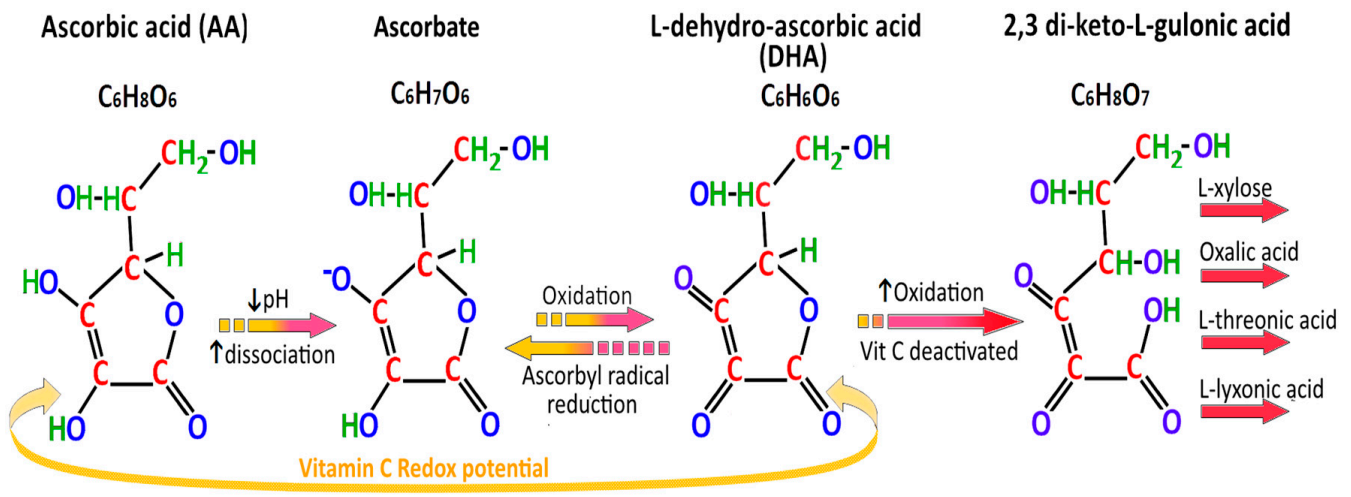

Figure 4. The redox potential of ascorbate. At the normal acidic gastric $\mathrm{pH}$, secreted gastric ascorbic acid dissociates into ascorbate. Ascorbate can act as an antioxidant by reversible oxidation to DHA, and then be regenerated by glutathione-dependent DHA reductase back to ascorbate. DHA can be irreversibly oxidized to 2,3 di-keto-L-gulonic acid and thence excreted in the urine as oxalate. 
Vitamin C can protect DNA from oxidant-mediated damage including CIMP and 8-hydroxy2-deoxyguanosine (8-OHdG) formation. It has been reported to neutralize phagocyte-derived oxidants, protecting the 1-protease inhibitor (API) from oxidant-mediated functional inactivation. Vitamin C is also important in the antioxidant protection of lipid-soluble environments such as cell membranes, mitochondria, and endoplasmic reticulum by regeneration of vitamin $E$. It does so by donating an electron to the vitamin E radical to regenerate the active form of vitamin E, alpha-tocopherol [34]. The preventative effect of vitamin $\mathrm{C}$ on $\mathrm{H}$. pylori generated malondialdehyde-deoxyguanosine is debated [29,31,39].

\subsection{Absorption and Secretion of Ascorbic Acid}

Humans, like other higher primates, fruit bats and guinea pigs do not have functional hepatic L-gulono-gamma-lactone oxidase (L-GULO), the enzyme which catalyzes the final step in the endogenous synthesis of ascorbic acid from glucose [40]. These particular mammals are thus at risk of scurvy (and oxidative stress) if oral vitamin $C$ ingestion is inadequate. As such, dietary vitamin $C$ intake, vitamin $C$ transporters and levels of oxidative stress determine the plasma and organ levels of ascorbic acid. The US Food and Nutrition Board recommended daily allowance (RDA) of vitamin C in men is $90 \mathrm{mg}$ and $75 \mathrm{mg}$ in women. Normal plasma levels of vitamin $C$ in humans are $30-90 \mu \mathrm{mol} / \mathrm{L}$, with marginal deficiency at $11-23 \mu \mathrm{mol} / \mathrm{L}$ and deficiency at $<11 \mu \mathrm{mol} / \mathrm{L}$. Vitamin $C$ is actively absorbed in the intestines via the two sodium-dependent vitamin C transporters (SVCT1 and SVCT2). DHA is absorbed via facilitated diffusion in the small intestines and also competes with glucose for active transport by enterocyte glucose transporters (GLUT2, GLUT8). Enterocytes (and also erythrocytes) contain GSH-dependent dehydroascorbate reductases which convert DHA to ascorbate, maintaining low intracellular DHA levels and a concentration gradient for continued DHA uptake [41]. The vitamin C renal threshold occurs above a plasma level of $80 \mu \mathrm{mol} / \mathrm{L}$ [41].

Vitamin $C$ is actively secreted into the gastric lumen by gastric epithelial cells under the influence of gastrin, cholecystokinin (CCK) and acetyl choline [16,42]. Various mechanisms for vitamin C secretion have been proposed, including gap-junction hemi-channels, $\mathrm{Ca}^{2+}$-dependent anion channels, cell membrane homo- and hetero-exchange systems or exocytosis of ascorbate containing secretory vesicles [43].

Ascorbic acid levels are normally 3-10 times higher in gastric glands than in the plasma of human subjects. The accumulation of ascorbic acid in gastric glands occurs against an 8-fold concentration gradient by SVCT2, located in the basolateral membrane of the gastric epithelium. Analysis of ascorbic acid levels in KATO III and AGS gastric epithelial cells demonstrated a high affinity, saturable transport system for ascorbic acid with a $\mathrm{K}_{\mathrm{m}}$ of 3-11 $\mu \mathrm{mol} / \mathrm{L}$. The concentration of gastric luminal ascorbate is decreased by $H$. pylori infection, poor oral vitamin $C$ intake, use of proton pump inhibitors, cigarette smoking, impaired secretory state of the gastric mucosa, autoimmune gastritis, achlorhydria and atrophic gastritis. The average intake of oral vitamin $\mathrm{C}$ was found to be lower in $H$. pylori positive subjects ( $35.9 \mathrm{mg}$ /day) as compared to $130.9 \mathrm{mg}$ /day in H. pylori negative subjects $(p<0.01)$, which may also contribute to diminished intragastric ascorbate levels [41].

The oxidization of luminal gastric ascorbate to the reversible product DHA and the irreversible product 2,3-diketo-L-gulonic acid is related to the increased $\mathrm{pH}$ in $\mathrm{H}$. pylori-associated corpus gastritis. In H. pylori positive patients with normal gastric $\mathrm{pH}$ of $\mathrm{pH}<2$, the mean gastric juice ascorbic acid level was $16.5 \mu \mathrm{mol} / \mathrm{L}$, but fell to $4.5 \mu \mathrm{mol} / \mathrm{L}$ in those with gastric $\mathrm{pH} 2-4$, and to zero in those with gastric $\mathrm{pH}>6$ [44]. Other mammals such as cats, rabbits, dogs, goats, rats and mice have preserved L-GULO function, and can markedly increase their vitamin C synthesis during oxidative stress [45,46] (Figure 4).

\section{Helicobacter pylori-Virulence Factors and Pathways to Gastric Cancer}

\subsection{Helicobacter pylori}

H. pylori is a microaerophilic, gram negative, flagellated, curved rod which infects half of the worldwide population. It has evolved to live in the acidic (luminal $\mathrm{pH}=1.2-3.5$ ) environment of the 
human stomach by its flagellar motility, chemotaxis signalling, urease activity, ammonia production, bacterial toxins and adhesin molecules. Once ingested, $H$. pylori bacteria penetrate the thick mucus layer $(100 \mu \mathrm{m})$ of the stomach by swimming with their $4-8$ unipolar flagella and digesting the viscous gastric mucus with ammonia. Their helical shape also enables penetration of the mucus layer by corkscrew-like, counterclockwise rotational movements. The ammonia is derived from $H$. pylori urease activity splitting urea into ammonia and $\mathrm{CO}_{2}$ gas, and $H$. pylori derived $\gamma$-glutamyl transpeptidase (GGT) hydrolyzing glutamine into ammonia [47].

\subsection{H. pylori Urease}

The H. pylori urease enzyme is initially intracytoplasmic, but, after gastric colonization commences, it can become surface associated. It may also be released into the extracellular space by secretion or by bacterial autolysis. The urease apoenzyme is assembled by a cytoplasmic histidine kinase, and is made up of two major subunits UreA and UreB. The dodecameric urease complex is then matured by the accessory proteins UreE/UreG and UreF/UreH, and activated by the insertion of two nickel ions $\left(\mathrm{Ni}^{2+}\right)$. For host-derived urea to reach the urease in the bacterial cytoplasm, it has to be moved across both the H. pylori outer and inner membranes. This process is facilitated by a specific proton-gated urea pore in the inner membrane (UreI). The urea is hydrolyzed into two ammonia molecules $\left(2 \mathrm{NH}_{3}\right)$ and carbonic acid $\left(\mathrm{H}_{2} \mathrm{CO}_{3}\right)$ by urease, and the carbonic acid is converted to $\mathrm{CO}_{2}$ gas by cytoplasmic $\beta$-carbonic anhydrase. UreI then enables movement of ammonia and $\mathrm{CO}_{2}$ back through the periplasm. An $\alpha$-carbonic anhydrase located on the periplasm/inner membrane can generate $\mathrm{HCO}_{3}{ }^{-}$from the returning $\mathrm{CO}_{2}$ for periplasmic buffering [48,49]. $\mathrm{NH}_{4}{ }^{+} / \mathrm{NH} 3(\mathrm{pKa}=9.3)$ and $\mathrm{HCO}_{3}{ }^{-} / \mathrm{CO}_{2}$ buffer gastric parietal cell derived $\mathrm{HCl}$ in the immediate external environment, but also in the bacterial cytoplasm and periplasm. By this mechanism, the $H$. pylori cytoplasmic $\mathrm{pH}$ is kept relatively neutral and periplasmic $\mathrm{pH}$ at around 6.1, even with an external $\mathrm{pH}\left(\mathrm{pH}_{\mathrm{e}}\right)$ as low as 2.5. This maintains H. pylori intracellular homeostasis and permits successful bacterial colonization of the stomach. Transcription of ure $A B$ is induced by the presence of acid and by nickel [50]. H. pylori urease activity increases exponentially as the external $\mathrm{pH}\left(\mathrm{pH}_{\mathrm{e}}\right)$ decreases-the availability of urea at $\mathrm{pH}_{\mathrm{e}}<4$ thus determines $H$. pylori survival in the stomach [51] (Figure 1, pathway 1). In conditions where host derived urea is limited, H. pylori arginase can endogenously produce urea and l-ornithine from l-arginine [52].

\subsection{H. pylori-Derived Ammonia}

Being a gas, ammonia readily diffuses across lipid membranes and reacts to form $\mathrm{OH}^{-}$and $\mathrm{NH}_{4}{ }^{+}$ in the interior of the membrane. This raises the internal $\mathrm{pH}$ of intracellular organelles and can thus affect phagosome-lysosome fusion in mucosal macrophages and the function of epithelial cell mitochondria. The gastric juice of $H$. pylori positive subjects contains significantly higher concentrations of ammonia $(0.01-0.02 \%)$ than that of $H$. pylori negative subjects $(<0.005 \%)$. Such levels of ammonia in the gastric juice of $H$. pylori positive subjects are able to:

1. buffer gastric acid

2. inhibit gastric epithelial mitochondrial and isolated cellular respiration

3. induce cytotoxicity in gastric epithelial cells

4. contribute to gastric mucosal injury

5. enable H. pylori to evade host phagocytosis and opsonisation

6. provide protection to $H$. pylori from host generated peroxynitrite

7. provide a substrate for H. pylori from which to synthesise amino acids [47,53] (Figure 1, pathway 1).

\subsection{H. pylori and Hypochlorhydria}

Other mechanisms for the acute and profound hypochlorhydria which occurs within three days of initial $H$. pylori infection include: 
1. Increased Thelper type 1 (Th1) cell secretion of Interleukin-1 $\beta$ (from mucosal neutrophils and monocytes), which inhibits gastric proton pump $\left(\mathrm{H}^{+} / \mathrm{K}^{+}\right.$-ATPase) activity (Figure 1 , pathway 6$)$.

2. Release of $H$. pylori fatty acids (tetradecanoic acid and cis 9,10-methyleneoctadecanoic acid), which inhibit proton pump $\mathrm{H}^{+} / \mathrm{K}^{+}$-ATPase and dissipate proton $\left(\mathrm{H}^{+}\right)$transport in parietal cell secretory vesicles [54].

3. H. pylori cag pathogenicity island (PAI) gene products repress the nuclear transcription of the catalytic alpha subunit of the parietal cell proton pump (HKalpha) and decrease the expression of $\mathrm{H}^{+} / \mathrm{K}^{+}$-ATPase [55] (Figure 1, pathway 9).

4. Suppression of acid secretion by neural inhibition of enterochromaffin cell histamine secretion and antral G-cell gastrin secretion [56].

5. H. pylori VacA disrupts the incorporation of tubulovesicles (which contain $\mathrm{H}^{+} / \mathrm{K}^{+}$-ATPase) into the gastric parietal cell apical membrane [54].

Acute hypochlorhydria or "epidemic hypochlorhydria" in children was first described by Sir William Osler in 1910. This occurs during initial H. pylori infection but is not due to loss of parietal cells. Parietal cell loss only occurs later in established H. pylori induced chronic atrophic gastritis, with associated compensatory G-cell hyperplasia and hypergastrinaemia. The mechanisms behind parietal cell apoptosis in $H$. pylori related chronic atrophic (corpus) gastritis include Th1 cytokines (TNF- $\alpha$, IL-1 $\beta$ ), Th17 immune responses involving IL-17A cytokine-ligand induced caspase activation, and anti-parietal cell antibody (APA) generation [57].

\subsection{H. pylori and Chemotaxis}

Chemotaxis is essential for $H$. pylori organisms to find a niche and survive in the hostile environment of the stomach. Chemotaxis for acidity, bicarbonate, urea, energy, amino acids (arginine, glutamine, histidine) and transition metals (iron, zinc, copper, nickel) occurs via H. pylori chemosensing and flagellar motor switches. Thus $H$. pylori are able to sense these agents in the gastric microenvironment and swim towards nutrients and away from acidic areas. There are four known $\mathrm{H}$. pylori chemoreceptors or transducer like proteins (Tlp), three of which are membrane localized (TlpA, TlpB, TlpC), and one (TlpD), which is wholly cytoplasmic [50-56].

1. TlpA is able to sense gastric mucosal arginine/amino acids, acidic $\mathrm{pH}$ and bicarbonate

2. TlpB senses urea and bacterial quorum (via auto-inducer (AI-2))

3. TlpC senses lactate

4. TlpD senses ROS, alkaline $\mathrm{pH}$, neutrophil derived $\mathrm{HOCl}$ and inhibitors of electron transport (Figure 1, pathway 2).

Chemoreceptors and flagellar rotation enable $H$. pylori to rapidly and preferentially colonize the antral and body mucosal glands within $14 \mathrm{~h}$ of ingestion, but also areas of injured gastric epithelium and neutrophil activity where nutrients may be more available. H. pylori appear to target specific gastric epithelial cell types via chemotaxis, including LGR5+ adult stem cells located in antral glands. This preference for colonization of gastric glands under the gastric mucus is related to the higher $\mathrm{pH}$ in the glands, due to buffering by epithelial bicarbonate excretion. By transducing the level of gastric acidity, and being repulsed from areas of low $\mathrm{pH}$ (gastric lumen) and attracted toward bicarbonate (gastric glands), H. pylori are able to survive, whereas other enteric bacterial pathogens such as Salmonella and Vibrio spp. cannot [58,59]. After ingestion and colonization of an acid secreting stomach, the majority of $\mathrm{H}$. pylori can be found swimming in the first $15 \mu \mathrm{m}$ of the antral mucus, with $30 \%$ of $H$. pylori bacteria in the $1-5 \mu \mathrm{m}$ of the mucus adjacent to the antral epithelium. Only about $2 \%$ of $H$. pylori are adherent to the epithelial cells. There are negligible numbers found in the middle or luminal sections of the gastric mucus. In conditions of chronic achlorhydria induced by AG or PPI use, $H$. pylori bacteria are able to colonize the stomach more widely, including the gastric body and fundus [60-64] (Figure 1). 


\subsection{Non-Enzymatic Effects of H. pylori Urease}

H. pylori urease is a virulence factor with separate and independent effects to its enzymatic activity. Extracellular UreB is able to bind to epithelial cell receptor CD74 (MHCII), which activates pro-survival genes and inflammatory pathways. These include increased:

1. release of IL-8, a chemokine for inflammatory cells including monocytes and neutrophils

2. activation of NF- $\mathrm{kB}$ pro-inflammatory pathways

3. activation of primary mucosal macrophages

4. release of gastric epithelial cell Th1 cytokines (IL-1 $\beta$, IL-6, TNF- $\alpha$, IL-8)

5. disruption of gastric epithelial tight junctions

6. release of IL-4 and antibody production by splenic lymphocytes

7. platelet aggregation [53].

UreB also binds to TLR-2 receptors on the gastric epithelial apical membrane which is independent of $H$. pylori lipopolysaccharide (LPS) binding. This activates both NF- $\mathrm{KB}$ and PI3K/AKT/mTOR/HIF- $1 \alpha$ pathways. The induction of gastric epithelial HIF- $1 \alpha$ under normoxic conditions by UreB has effects on cell cycling via Cyclin D1 and immune tolerance via Treg cells, and does not appear to involve the usual canonical transcriptional targets of HIF-1 $\alpha$ (LDH, VEGF, GLUT1) [48] (Figure 1, pathway 10).

\subsection{H. pylori Induction of HIF}

Reactive oxygen species accumulation and vitamin $C$ deficiency related to Helicobacter gastritis are further mechanisms for the normoxic stabilization of HIF- $1 \alpha$, as ascorbate is a required co-enzyme for the activity of the HIF- $\alpha$ prolyl hydroxylase family (PHD). Specific HIF- $\alpha$ proline residues are hydroxylated by HIF- $\alpha$-PHD, which increases the affinity of the HIF- $1 \alpha$ peptide for the von Hippel-Lindau protein (pVHL)-elonginB-elonginC (VBC) complex. HIF-1 $\alpha$ is ubiquinated by the VBC complex and then degraded by the $26 \mathrm{~S}$ proteasome. During normal physiological conditions, there is minimal cellular HIF- $1 \alpha$. However, under hypoxia, ROS or succinate accumulation, HSP activation, mitochondrial dysfunction, vitamin C or iron deficiency, PHD2 is inhibited. HIF- $1 \alpha$ is thus stabilized and accumulates within the cytoplasm. HIF- $1 \alpha$ is then translocated to the nucleus where it binds with HIF- $\beta$ to form the HIF heterodimer. HIF activates the transcription targets of the hypoxia response element (HRE), including proliferation (Caveolin-1, CTGF, IGFBP3, MET), angiogenesis (EPO, PDGF $\beta$, VEGF), redox homeostasis (GPX3, HMOX1, SOD2), glucose transport and metabolism (GLUT, HKII, LDHA, PDK1, PGK1, PKM2), epithelial mesenchymal transition (SNAIL, SLUG, VM, ZEB), and metastasis and invasion (CXCL12, CXCR4, LOX, MMP1, MUC-1, S100A4, TWIST1) [38,65].

\subsection{H. pylori and Correa Pathway}

In 1892, the Italian pathologist Guilio Bizzozero reported his observation of spiral shaped bacteria present in the gastric mucosa of dogs. His findings were largely ignored due to the pervasive belief that bacteria could not survive in the acidic milieu of the stomach [66]. In 1975, Paleyo Correa originally proposed the histological pathway for intestinal-type gastric cancer. After the rediscovery of H. pylori by Marshall and Warren in 1984 and further research by Correa and others, he incorporated positive risk factors ( $H$. pylori infection, dietary salt, $\mathrm{N}$-nitroso compounds) and negative risk factors (vitamin $\mathrm{C}$, $\beta$-carotene) for gastric cancer into this pathway in 1992 [6] (Figure 5). The H. pylori bacterium was then classified by the WHO in 1994 as a class 1 carcinogen for gastric cancer [7]. Much of the evidence for the role of $H$. pylori in gastric carcinogenesis comes from epidemiological studies in endemic areas. 


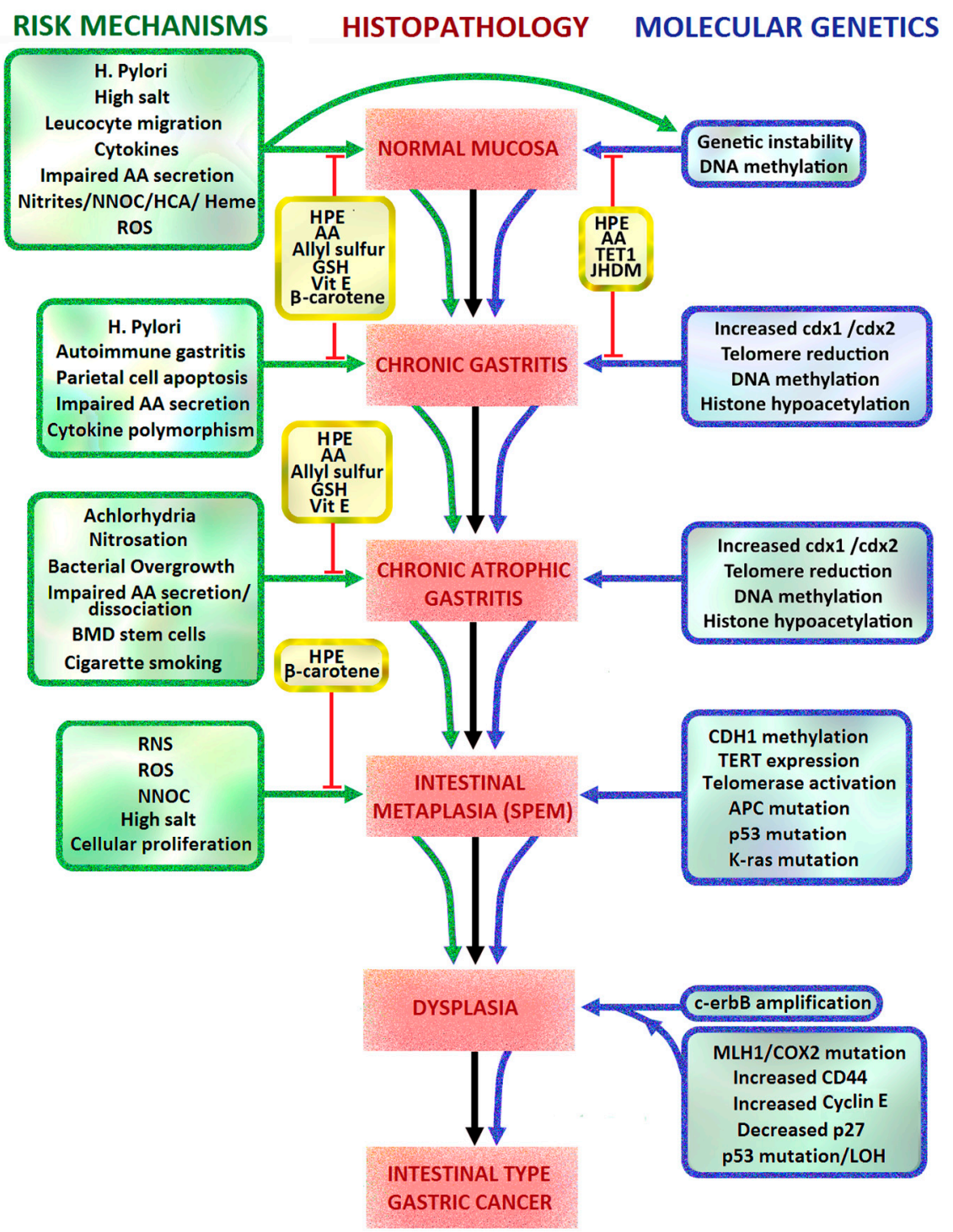

Figure 5. Modern Correa pathway of intestinal-type gastric carcinogenesis, with risk factors and host mechanisms in green, molecular genetics in blue, and preventive factors in yellow. As histological changes progress, antioxidant systems and DNA repair mechanisms become less effective and the epigenetic effects of Helicobacter pylori infection and environmental carcinogens more difficult to reverse. AA: ascorbic acid; BMD: bone marrow derived; cdx: caudal type homeobox gene; c-erbB: human epidermal growth factor oncogene; CDH1: E-cadherin gene; GSH: glutathione; HPE: Helicobacter pylori eradication, LOH: loss of heterozygosity; SPEM: spasmolytic polypeptide-expressing metaplasia; TET1: ten eleven translocation methylcytosine dioxygenase $1[6,19,26]$.

For example, Uemura et al. conducted a prospective study of 1526 Japanese patients who had duodenal ulcers, gastric ulcers, gastric hyperplasia, or non-ulcer dyspepsia at the time of enrolment [67]. After a mean of 7.8 years of follow-up, 2.9\% (36/1246) of those with H. pylori and 0\% (0/280) of H. pylori negative patients developed gastric cancer. Gastric cancers developed in:

1. $21(4.7 \%, p<0.001)$ of the 445 patients with non-ulcer dyspepsia,

2. $10(3.4 \%, p=0.002)$ of the 297 with gastric ulcers,

3. $5(2.2 \%, p=0.02)$ of the 229 with gastric hyperplastic polyps, and

4. 0 of the 275 with duodenal ulcers. 
Abnormalities at initial endoscopy associated with future development of gastric cancer included severe grade of gastric atrophy $(R R=4.9)$, pangastritis $(R R=15.6)$, corpus predominant gastritis $(R R=34.5)$ and intestinal metaplasia $(R R=6.4)$ [67]. Duodenal ulcer patients have corpus sparing, antral specific Helicobacter gastritis with high gastric acid secretion, whereas gastric ulcer and gastric cancer patients have fasting hypochlorhydria, low pepsinogen I levels $(\leq 70 \mathrm{ng} / \mathrm{mL})$ and pepsinogen $\mathrm{I} / \mathrm{II}$ ratios $(\leq 3)$, and severe, corpus predominant atrophic gastritis [68,69]. Eslick et al. found H. pylori conferred a 2-fold risk of developing gastric cancer [70], which correlated with the results from the European Prospective Investigation into Cancer and Nutrition (EPIC)-EURGAST study [71].

\subsection{H. pylori-Induced Inflammatory Response}

H. pylori causes gastric mucosal damage by its production of urease, protease, phospholipase, peptidoglycans, ammonia, Hp-NAP, VacA, CagA, BabA, SabA, GGT and acetaldehyde. It also generates reactive oxygen species, reactive nitrogen species and nitric oxide synthase (NOS) by initiating a host inflammatory reaction [72]. This includes a severe host inflammatory response triggered by tumour necrosis factor apoptosis inducing ligand (TRAIL), phosphorylation of IL-1 receptor-associated kinases (IRAK-1) and NF- $\mathrm{kB}$ activation [73]. The magnitude of the inflammatory response to H. pylori infection is increased by polymorphisms in host cytokine expression, with IL1RN, IL1 $\beta-511$ and TNFA-308 genotypes being more highly associated with achlorhydria, chronic atrophic gastritis, intestinal metaplasia and gastric cancer [74] (Figure 5).

\subsection{H. pylori and ROS}

Once a virulent strain of $H$. pylori is established in the stomach, Helicobacter pylori neutrophil activating protein (Hp-NAP) and chemokine release (IL-8) promote neutrophil, macrophage and $\mathrm{T}$ lymphocyte migration into the gastric mucosa. This induces a cascade of further inflammation, respiratory bursts of ROS formation, mucosal injury, DNA damage, parietal cell apoptosis and potential gastric carcinogenesis. DNA can be damaged by depurination, deamination, methylation or oxidation by ROS [33]. The induction of ROS release from gastric mucosal neutrophils by H. pylori is 10 times greater than that of $S$. aureus or E. coli [75]. The four oxidative agents produced by neutrophils are $\mathrm{NO}^{\bullet}$, $\mathrm{O}_{2}^{-\bullet}, \mathrm{H}_{2} \mathrm{O}_{2}$ and $\mathrm{HOCl}$, which interact with each other to form peroxynitrite $\left(\mathrm{ONOO}^{-}\right)$and hydroxyl radicals $(\mathrm{OH} \cdot) . \mathrm{HOCl}$ is an effective killing agent of most human pathogenic organisms, including spore and non-spore forming bacteria. However, the oxidative molecules released by neutrophils and macrophages against $H$. pylori organisms attached to the gastric mucosa cause collateral damage to the epithelial cells (Figure 1 pathway 6, Figure 6).

Initially, $\mathrm{O}_{2}^{-\bullet}$ is generated by cellular NADPH-oxidase (NOX) in response to phagocytosis of bacterial pathogens, which is then released into the extracellular space and converted to $\mathrm{H}_{2} \mathrm{O}_{2}$ by superoxide dismutase (SOD). $\mathrm{H}_{2} \mathrm{O}_{2}$ is easily diffusible across membranes, and can form $\mathrm{OH} \cdot$ by Fenton reactions. Neutrophil myeloperoxidases use much of the generated $\mathrm{H}_{2} \mathrm{O}_{2}$ to catalyse the reaction of $\mathrm{Cl}^{-}+\mathrm{H}_{2} \mathrm{O}_{2} \rightarrow \mathrm{HOCl}+\mathrm{OH}^{-}$. $\mathrm{HOCl}$ can also react with $\mathrm{O}_{2}^{-\bullet}$ to form hydroxyl radicals. $\mathrm{NO}$ (produced from arginine and oxygen by iNOS) can react with $\mathrm{O}_{2}{ }^{-\bullet}$ to form peroxynitrite, which subsequently generates $\mathrm{OH} \cdot$ and $\mathrm{NO}_{2}$. formation. $\mathrm{OH} \cdot$ causes much of the DNA base damage in mammalian cells, as well as peroxynitrite. $\mathrm{HOCl}$ is known to produce DNA damage such as pyrimidine oxidation products, DNA-protein cross-links and chlorination of DNA bases (e.g., 5-chlorouracil) [76,77] (Figure 1 pathway 12, Figure 6). To evade host inflammatory cell derived ROS damage to H. pylori proteins and DNA, $H$. pylori bacteria express DNA and protein repair enzymes and at least 14 antioxidant proteins (e.g., catalase, SOD, thioredoxin reductase) after colonization. 


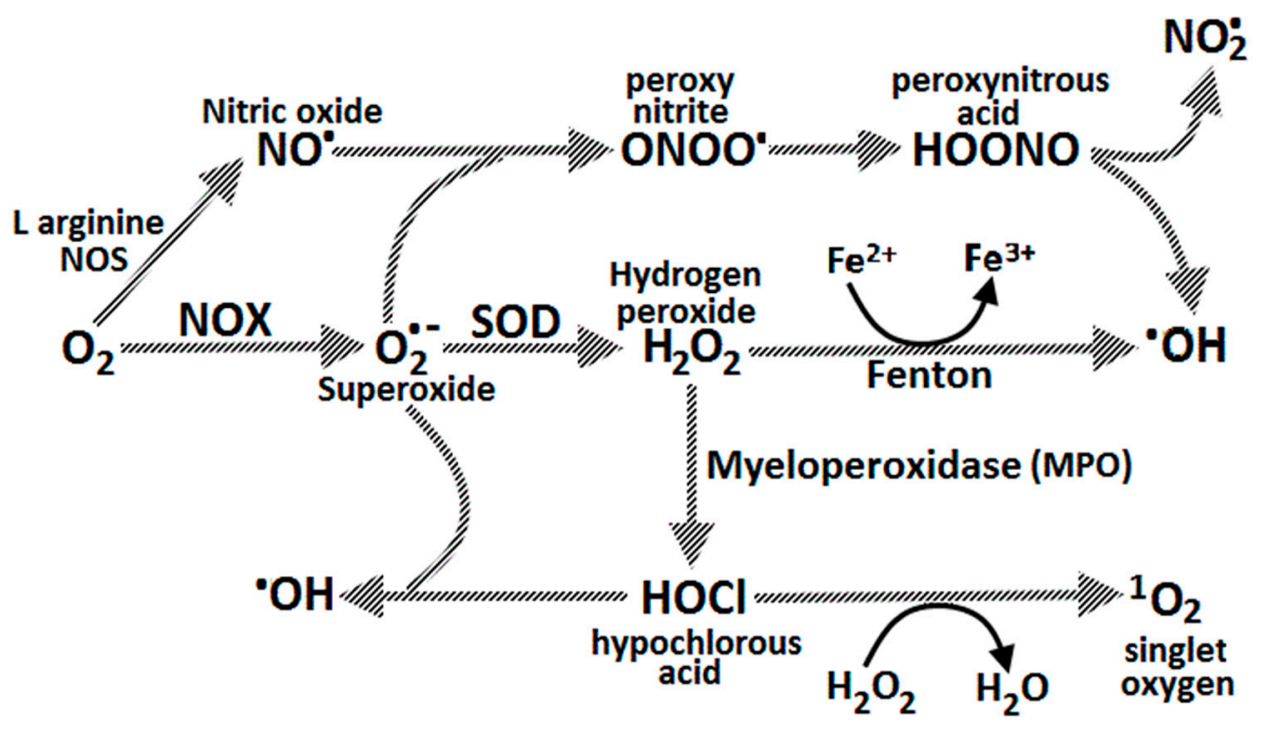

Figure 6. The three sources of DNA damaging hydroxyl radicals; from nitric oxide (NO) reacting with superoxide radicals to form peroxynitrite, from Fenton reactions with hydrogen peroxide $\left(\mathrm{H}_{2} \mathrm{O}_{2}\right)$ and ferrous iron, or from superoxide reacting with hypochlorous acid $(\mathrm{HOCl})$ from neutrophils. Nitric oxide synthase (NOS), Superoxide dismutase (SOD), NADPH oxidase (NOX), hydroxyl radical $(\mathrm{OH} \cdot)$. Adapted from Knaapen et al. with permission [76].

\subsection{H. pylori and Evasion of Immunosurveillance}

The H. pylori lipopolysaccharide endotoxin lipid A can be modified to resist host cationic antimicrobial peptides and evade Toll-like receptor 4 (TLR-4) recognition (Figure 1, pathway 5). There are also fucosylated oligosaccharides contained in the $\mathrm{O}$-antigen of $H$. pylori lipopolysaccharide that mimic human Lewis antigens. This assists in H. pylori evasion of host $\mathrm{T}$ cell immunosurveillance and persistent gastric colonization. The expression of these Lewis type antigens can also be extensively varied by H. pylori to permit adaptation to different gastric host environments [78]. Similarities also exist between human heat shock protein 60 (Hsp60) and H. pylori Hsp60, leading to generation of anti-Hsp60 autoantibodies. These are associated with diffuse gastric cancers and B-cell lymphocyte mucosa associated lymphoid tissue (MALT) lymphoma [79].

\subsection{H. pylori and DNA Damage}

H. pylori causes chronic oxidative stress and MDA formation in the stomach, leading to single and double DNA strand breaks, failure of DNA repair and DNA adducts [80,81]. DNA adducts include 8-hydroxydeoxyguanosine, thymine glycol and 5-hydroxymethyl uracil, which in themselves can cause DNA methylation, common mutations, epigenetic alteration and contribute to gastric carcinogenesis [75].

\subsection{H. pylori, iNOS, ROS and DNA Hypermethylation}

Inducible nitric oxide synthase (iNOS) is the enzyme that synthesizes NO from the amino acid arginine. NOS is inducible in gastric mucosa and neutrophils by $H$. pylori infection, resulting in a significant increase in local NO. Nitric oxide reacts with $\mathrm{O}_{2}{ }^{-\bullet}$ and metals to form peroxynitrite which, together with epithelial derived $\mathrm{H}_{2} \mathrm{O}_{2}$, can create DNA oxidative adducts. $\mathrm{NO}$ also prevents the repair of DNA by 8-oxoguanine glycosylase. Oxidative stress related to $H$. pylori activates oncogenes and inactivates tumour suppressor genes, via hypermethylation of $\mathrm{CpG}$ island promoter genes and increased activity of DNA methyltransferase [14]. Ding et al. (2010) outlined the multiple oncogenic pathways induced by H. pylori. These include NF- $\mathrm{B}$, activator protein-1 (AP-1), PI3K, beta-catenin, E-cadherin ( $C D H-1)$, Runt-related transcription factor 3 (RUNX3) and cyclooxygenase 2 (COX-2) by 
modification of chromatin protein and DNA methylation, leading to epithelial proliferation and gastric cancer [82]. Other promoter genes that are affected by H. pylori induced methylation include those of:

1. DNA repair [O-6-methylguanine DNA methyltransferase enzyme (MGMT)],

2. DNA mismatch repair [MutL Homologue 1 (MLH1)],

3. Cell cycle [Cyclin Dependent Kinase Inhibitor 2A (CDKN2A)],

4. Inflammation [Trefoil factor 2 (TFF-2)],

5. Transcription factors [Forkhead Box D3 (FOXD3), upstream stimulatory factors (USF1 and USF2), GATA4],

6. Autophagy (ATG16L1),

7. Tumour suppression [Adenomatous polyposis coli (APC), Phosphatase And Tensin Homolog (PTEN), lysyl oxidase gene (LOX)] [83] (Figure 1, pathway 12).

\subsection{H. pylori, NF- $\kappa B$, STAT3, TNF- $\alpha$, Vitamin $C$ and $\beta$-carotene}

Vitamin $C$ has been shown to inhibit the H. pylori mediated activation of NF- $\mathrm{kB}$ and STAT3, and promote tumour suppression in AGS cells in vitro by upregulating transmembrane protein with epidermal growth factor (EGF)-like and two follistatin motifs 2 (TMEFF2); and AGS apoptosis by mitochondrial mediated pathways [84]. In vitro studies have shown $\beta$-carotene reduces $H$. pylori induced NF- $\mathrm{KB}$ activation and ROS levels in AGS cells by its antioxidant activity, thereby inhibiting tumour necrosis factor receptor-associated factor (TRAF) induced gastric epithelial hyperproliferation. The decrease in ROS generation was mediated by $\beta$-carotene inhibition of NADPH oxidase. $\beta$-carotene was able to block the $H$. pylori induced degradation of $I \kappa B \alpha$, thereby retaining NF- $k B$ in the cytoplasm, preventing its nuclear translocation and activation of nuclear transcription targets, including TRAF1 and TRAF2 gene expression. Clinical prevention studies have suggested oral intake of $\beta$-carotene may decrease the risk of gastric cancer in $H$. pylori endemic areas by as much as $48 \%$ [85].

\section{Helicobacter CagA+/VacA+}

\section{1. $\operatorname{Cag} A+/ \mathrm{Vac} A+$}

H. pylori is geographically distributed into seven distinct populations and subpopulations. The East Asian H. pylori strain is more pathogenic with differing cytotoxin associated gene A (CagA) and vacuolating toxin A (VacA) expression than European or African strains [86,87]. Carriage of cag-PAI varies from an almost universal presence in the strains hpEastAsia and hpAfrica1, through an intermediate presence (hpEurope) to complete absence (hpAfrica2) [86,87]. VacA and CagA positivity doubles the odds ratio of gastric cancer. This may explain, in part, the African enigma: high rates of H. pylori infection but low incidence of gastric cancer in Northern and East African populations [86,87]. There are epidemiological differences in $H$. pylori strains, including increased prevalence of host colonization, bacterial virulence and subsequent atrophic gastritis and gastric cancer [86,87].

\subsection{CagA and EPIYA Carriage}

Pathogenic CagA positive H. pylori strains are more prevalent in high gastric cancer risk countries such as Japan, South Korea, China (90-95\%), Colombia (70\%) and lower in North Africa and other low gastric cancer risk areas (USA, Western Europe, Australia $(40 \%)$ ). Induction of gastric carcinogenesis may be related to variations in CagA tyrosine phosphorylation motifs (glutamate-proline isoleucinetyrosine-alanine, (EPIYA)). There are four current CagA EPIYA motifs (A, B, C, D), EPIYA A and $B$ being ubiquitous across the world and EPIYA-C mainly found in $H$. pylori strains from Western countries. Most Western H. pylori isolates contain only one EPIYA-C motif (EPIYA-ABC genotype), whilst some have two or three EPIYA-C repeats (EPIYA-ABCC and EPIYA-ABCCC). H. pylori strains carrying extra EPIYA-C motifs are more closely associated with gastric cancer. This is in part related to the CagA EPIYA-ABCCC motif inducing increased transcription of erbB2, HGF-R, FGFR4 and TGF- $\beta$ 
growth factor genes and expression of $\beta$-catenin, mmp7 and etv4 genes, and decreased APC gene expression in host cells [88]. EPIYA-ABD is found almost exclusively in the virulent East Asian H. pylori strain (China, Korea, Japan), which induces higher levels of IL-8 release from gastric epithelium than EPIYA A, B or C expressing strains [86,87]. CagA related IL-8 release increases the host inflammatory response, by attracting inflammatory cells via chemotaxis [89] (Figure 1, pathway 8).

\subsection{CagA and Type IV Bacterial Secretion System (T4SS)}

The oncoprotein CagA is a marker for the H. pylori cag-pathogenicity island (cag-PAI), which contains 31 genes including $\operatorname{cag} A, \operatorname{cag} B, \operatorname{cag} C, \operatorname{cag} L, \operatorname{cag} M, \operatorname{cagI}, \operatorname{cag} Y$, encoding the type IV bacterial secretion system (T4SS). The T4SS is used for the translocation of bacterial products directly into the host epithelial cell cytoplasm, including heptose 1,7-bisphosphate from LPS, chromosomal DNA, peptidoglycan and the cagA gene product. This is achieved by H. pylori excretion of the serine protease high temperature requirement A (HtrA), which disrupts epithelial cell-to-cell tight junctions (TJ) by fragmentation of junction proteins occludin and claudin 8 , and cleavage of E-cadherin-based cell-to-cell adherens junctions (AJ). Paracellular transmigration of $H$. pylori then enables the T4SS needle-like bacterial pilar binding of the $\alpha 5 \beta 1$ and $\alpha 5 \beta 6$ integrins in the basolateral cell membrane, and injection of CagA into gastric epithelial cells. The T4SS can also deliver CagA products by interacting with the carcinoembryonic antigen-related cell adhesion molecule family (CEACAM) on host cell membranes via the HopQ adhesin. HtrA is associated with a $40 \%$ decrease in E-cadherin levels in $H$. pylori infected epithelial cells, representing a severe disruption to the normal gastric mucosal barrier [90] (Figure 1, pathway 7).

Injected H. pylori peptidoglycan is recognized as a pathogen associated molecular pattern (PAMP) by cytosolic nucleotide binding and oligomerization domain 1 (NOD1). NOD1 then associates with the receptor-interacting protein serine-threonine kinase 2 (RICK). This results in activation of NF- $\mathrm{kB}$, translocation of NF- $\mathrm{kB}$ to the nucleus, and triggering of a pro-inflammatory response via IL-8 and Chemokine (C-X-C motif) ligand 2 (CXCL2) release (Figure 1, pathway 8). Cellular proliferation is also activated by nuclear NF- $\kappa$ B via human $\beta$-defensin-2 (HBD-2) and CXCL2. HBD-2 is a cationic antimicrobial peptide which interacts electrostatically with the negatively charged phospholipid cell membranes of Gram-negative bacteria including H. pylori, leading to increased bacterial cell membrane permeability and bacterial death. The antimicrobial activity of HBD-1 and HBD-2 can be completely inhibited by high salt conditions, which may influence H. pylori colonization [91] (Figure 1, pathway 11).

\subsection{CagA and Src}

Once H. pylori CagA is injected into the gastric epithelial cell cytoplasm, the EPIYA motif is phosphorylated by tyrosine kinases (Abelson murine leukemia viral oncogene homolog 1 (c-Abl) or Src family tyrosine kinase (SFK)). The phosphorylated EPIYA-A or B forms a binary complex with C-terminal Src kinase (Csk), which then phosphorylates and inactivates SFK. Thus, only the EPIYA-C or D motifs are able to activate the Src-Homology 2 (SH2) domain inositol phosphatase (SHIP2), which results in downstream Ras/MEK/ERK signaling, NF- $\mathrm{KB}$ nuclear translocation, focal adhesion kinase (FAK) inactivation and re-organization of the cellular actin cytoskeleton. This leads to transformation of gastric epithelial cells from a uniform polygonal shape to an elongated state with needle like projections (hummingbird phenotype), EMT, expression of mesenchymal markers (SNAIL, vimentin, and ZEB1) and stem cell (CD44) markers, uninhibited proliferation and reduced apoptosis [86,87,92] (Figure 1, pathway 8).

\subsection{CagA, Vitamin $C$ and Epigenetic Programming}

CagA positivity is strongly associated with hypermethylation of genes responsible for cell adhesion and cell cycle control, such as E-cadherin (CDH-1), PTEN, and CDKN2A [93]. Methylation of DNA cytosine, which involves $\mathrm{CpG}$ dinucleotides (CIMP), and also histones results in epigenetic silencing of key suppressor genes. Eradication of $H$. pylori has been shown to reduce oxidative stress and 
DNA methylation levels, including that of $\mathrm{CDH}-1$ [94]. DNA demethylation involves conversion of 5-methylcytosine (5-mCyt) to 5-hydroxymethylcytosine (5-hmCyt), which requires the ten-eleven translocation (TET) family of $\alpha$-ketoglutarate-dependent dioxygenases ( $\alpha$-KGDDs). CagA positivity is strongly associated with loss of TET methylcytosine dioxygenase 1 (TET1) and decreased expression of PTEN [95]. The TET DNA hydroxylases require 2-ketoglutarate and ferrous iron $\left(\mathrm{Fe}^{2+}\right)$ for their catalytic activity. Ascorbic acid reduces the inactive ferric $\left(\mathrm{Fe}^{3+}\right)$ form of iron to ferrous iron $\left(\mathrm{Fe}^{2+}\right)$ in the $\alpha$-KGDD complex, in a similar way to the prolyl hydroxylase and lysyl hydroxylase dioxygenase enzymes, required for collagen production. Hydroxylation of 5-mCyt by TET thus requires ascorbic acid as a critical co-factor. Both pharmacological and physiological vitamin $\mathrm{C}$ administration has been shown to enhance DNA demethylation in haematological malignancies (AML) and solid cancers such as gastric and colorectal cancer [96-98]. Ascorbate is also required for the continued function of Jumonji-C domain-containing histone demethylases (JHDMs), as well as other $\alpha$-KGDDs which regulate metabolism, DNA repair and DNA/RNA de-methylation. By removing the methyl groups on the methylated lysines in the tail of histone H3, JHDMs can reprogram the epigenetic effects of oxidative stress on chromatin regulation, somatic cells, and gastric carcinogenesis [98,99] (Figure 5).

\subsection{CagA, E-Cadherin and EMT}

H. pylori CagA is known to promote carcinogenesis by the induction of EMT, inhibition of apoptosis and the acquisition of stem cell properties by transformed gastric epithelial cells. This is achieved by the effects of chronic inflammation on TGF- $\beta$ and NF- $\mathrm{KB}$ release, and the dysregulation of tumour suppressor pathways (p53, CDH1/E-cadherin, APC, MGMT, MLH1, CDKN2A) and canonical tyrosine kinase signaling pathways. These include receptor associated tyrosine kinases (EGFR/ErbB, HGFR/c-MET) and non-receptor kinases (Abl, JAK, FAK, c-src/Ras/MEK/ERK) [100]. Such pathways are normally involved in the regulation of organogenesis, tissue homeostasis, apoptosis and wound healing, but can be 'hijacked' by the CagA oncoprotein, resulting in gastric neoplasia [101-103].

E-cadherin is the major transmembrane glycoprotein of the adherens junction, and is bound to the catenins $(\alpha-, \beta-, \gamma-$ and p120), APC protein and cytoskeletal actin. E-cadherin maintains intercellular adhesion, tissue architecture, cellular polarity and acts as a tumour suppressor by inhibiting EMT. Unphosphorylated CagA directly interacts with E-cadherin, resulting in disruption of the E-cadherin/catenin/actin cytoskeleton/APC complex, and thence aberrant $\beta$-catenin and p120 catenin translocation to the cytoplasm and nucleus. This process is independent of Src related tyrosine phosphorylation of CagA (Figure 1, pathway 7). APC is associated with the adherens junction and normally acts as a tumour suppressor by degrading free $\beta$-catenin and preventing its nuclear translocation. Nuclear translocation of $\beta$-catenin in gastric epithelial cells leads to the transactivation of $\beta$-catenin dependent carcinogenesis pathways (cyclin D1, c-MYC, CDX1). Stimulation of $c d x 1$ gene by nuclear $\beta$-catenin induces expression of CDX1, the intestinal differentiation marker MUC1, stem cell proteins CD44, SOX2, Oct4, and Nanog, and EMT markers (vimentin, SLUG). This results in transformation of gastric mucosa into a stem cell like phenotype with intestinal metaplasia, progression to intestinal type gastric cancer, spheroid formation and chemotherapy resistance to 5-FU and cisplatin $[104,105]$.

Nuclear translocation of p120 catenin promotes increased expression of matrix metalloproteinase-7 (MMP7) or "matrilysin". MMP7 is a zinc dependent endopeptidase which degrades the extracellular matrix and basement membrane by proteolytic cleavage of type IV collagen, casein, gelatins, proteoglycans and fibronectins. This enables epithelial cells to detach and migrate from the basement membrane. MMP7 also directly promotes angiogenesis and progression of gastric cancer. Cytoplasmic p120 catenin interacts with Rho GTPases, which are involved in re-organisation of the cytoplasmic actin cytoskeleton, promoting gastric epithelial cell motility and the ability to metastasize. Release of soluble E-cadherin from the adherens junction can also activate EGFR/ErbB membrane receptors and the Ras/MEK/Erk pathway [106-108] (Figure 1, pathway 7). 
CagA affects promoter genes important in initiation of gastric carcinogenesis. This includes promotion of EMT via ZEB1 transcription and disruption of the normal homeostatic control of gastric epithelial stem cell differentiation via the Hippo/LATS2/YAP1/TEAD pathway [109]. Cation transport regulator 1 (CHAC1) overexpression in human gastric epithelial (AGS) cells infected with CagA-positive H. pylori has been shown to degrade glutathione via glutamylcyclotransferase activity, leading to accumulation of ROS [110]. CagA also interferes with the tumour suppressor apoptosis-stimulating protein of p53 2 (ASPP2), also known as Bcl2-binding protein (Bbp)/tumor suppressor p53-binding protein 2 (p53 BP2), and CHAC1 causes loss of function somatic mutations in the TP53 tumour suppressor gene [101-103,110,111]. CagA can increase the degradation of TP53 by E3 ubiquitin ligases, ARF-BP1 (ARF-binding protein 1) and HDM2 (human double minute 2), leading to failure of apoptosis, resistance to anoikis, EMT and gastric stem cell generation [101].

A fraction of CagA is localized to the AGS mitochondria, where it generates ROS production by mitochondrial electron transport complex I and III. These ROS are not able to be scavenged by such antioxidants as the GSH precursor N-acetyl-cysteine (NAC), catalase, allopurinol, or desferrioxamine. Buildup of ROS results in decreased PHD activity; increased stabilization and transcription of HIF- $1 \alpha$; and degradation of SIRT3. This leads to activation of hypoxia response element (HRE) downstream targets, including expression of VEGF, LDHA and PDK1, even under normoxic conditions, which promotes the initiation and progression of gastric neoplasia [112].

\subsection{CagA and Inflammation}

CagA induces activation and migration of T cells into the gastric mucosa [113] as well as increasing the release of inflammatory mediators such as TNF- $\alpha$, NADH oxidase (NOX 1), pathogen inducible nitric oxide synthase (iNOS), IL-1 $\beta$, IL-8 and IL-10 [114]. Increased release of gastric mucosal TNF- $\alpha$ and IL- $1 \beta$ is associated with suppression of parietal cell $\mathrm{HCl}$ release and gastric achlorhydria. Because of this enhanced inflammation, immunogenicity and cytotoxicity, CagA positive H. pylori strains are associated with a significantly increased risk of chronic atrophic gastritis and intestinal metaplasia (OR, 3.48; 95\% CI, 1.02 to 12.18); and progression to gastric cancer (OR, 1.64; 95\% CI, 1.21 to 2.24) [6]. Helicobacter induced chemotaxis for neutrophils appears to be independent of CagA, and more related to Hp-NAP binding to host epithelial cell membrane TLR-2, which induces activation of a Th1 immune response [115]. Tumour associated neutrophils (TANs) induce EMT in gastric epithelium by the release of IL-17a and activation of IL-17a/JAK2/STAT3 signaling [116] (Figure 1, pathway 6).

\section{8. $\operatorname{Vac} A$}

VacA, produced by most $H$. pylori, is a pore forming toxin which increases cell membrane permeability, stimulates cell membrane tyrosine kinase receptors and decreases glutathione levels. Glutathione has several important actions including free radical scavenging properties, detoxifying toxins such as heterocyclic amine (HCA) metabolites and reducing DHA back to its active form ascorbate $[117,118]$. There are numerous gastric epithelial cell surface receptors for VacA including:

1. Receptor-like protein tyrosine phosphatase $\alpha(\mathrm{RPTP} \alpha)$,

2. Receptor-like protein tyrosine phosphatase $\beta$ (RPTP $\beta)$,

3. Epidermal Growth Factor Receptor (EGFR),

4. Lipid raft/glycosylphosphatidylinositol-anchored proteins (GPI-AP),

5. Sphingomyelin (SM),

6. Fibronectin (FN),

7. Heparin $(\mathrm{H})$ and heparan sulfate (HS),

8. Low-density Lipoprotein Receptor-related Protein-1 (LRP1),

9. and one T lymphocyte receptor: CD18 [119]. 


\subsection{VacA and Vacuolation}

VacA induces the formation of cytoplasmic vacuoles in gastric mucosal cells, which makes plasma membranes more permeable and thus susceptible to injury. VacA can be internalized into the gastric epithelial cell by pinocytic-dependent and clathrin-independent endocytosis and cause mitochondrial dysfunction by reducing the transmembrane potential and releasing cytochrome $\mathrm{C}$. This leads to oxidative stress and mitochondrial mediated apoptosis in gastric epithelial cells. After internalization of VacA, vacuolation of gastric epithelial cells occurs due to the accumulation of ammonium ions and water influx via osmosis into the gastric cell endosome. Thus, the pathogenicity of VacA is dependent on the production of ammonia by H. pylori urease and GGT [58] (Figure 1, pathway 4).

\subsection{VacA and $\operatorname{Cag} A$}

VacA contributes to an immunotolerant gastric microenvironment by blocking T-lymphocyte proliferation and reducing IL-2 production [119]. VacA also activates protein kinases including p38/MAPK, ERK1/2 and downstream activation of VEGF. VacA is not part of the cag-PAI but may act synergistically with CagA to enable persistent colonization and iron extraction from gastric mucosal cells, as well as the activation of AP-1. AP-1 regulates the expression and recruitment of cytokines such as IL-8, IL-6, TNF- $\alpha$ and NF- $\mathrm{BB}$. Variations in $v a c A$ expression also influence $H$. pylori virulence-the $s 1$ or $m 1$ genotypes being more significantly associated with AG and IM $[6,119,120]$. Most CagA positive H. pylori strains carry the toxigenic s1 VacA form and OipA adhesin, while CagA negative strains carry the non-toxigenic s2 vacA form without OipA. There is also some evidence that VacA and CagA can have reciprocal antagonism, with CagA inhibiting VacA induced vacuolation and apoptosis, and VacA inhibiting the CagA induced hummingbird proliferative phenotype in gastric epithelial cells [119,121].

\section{Helicobacter Adhesins, Blood Group and Vitamin C}

The Helicobacter pylori outer membrane proteins (OMP) comprise five gene family members. The first and largest family member includes the H. pylori outer membrane porin (HOP) adhesin molecules, which adhere to host cell membrane receptors with differing affinity. There are 21 HOP adhesins, including adherence associated lipoprotein A (AlpA), outer inflammatory protein A (OipA), HopQ, HopZ, blood group antigen binding adhesin (BabA) and sialic acid-binding adhesin (SabA) [86]. $\mathrm{BabA}$ is encoded by the $B a b A 2$ gene, of which there are numerous variations. BabA binds to $\mathrm{H}$, Lewis $\mathrm{b}$ (Leb) and fucosylated ABO blood group antigens, which are expressed not only on erythrocytes but also gastric epithelium. Sialyl-Lewis $\mathrm{x}$ and sialyl-Lewis antigens expressed on gastric epithelium are recognized by SabA [122]. Adherence of $H$. pylori via BabA to the gastric mucosa aids in more effective delivery of VacA and CagA by H. pylori to gastric epithelial cells via the T4SS. Apical membrane adherence also prevents shedding of $H$. pylori into the gastric lumen and provides a stable nutrient supply to the bacteria from the damaged host epithelium. Blood group $\mathrm{O}$ patients with $\mathrm{H}$ antigens, and subjects with Leb antigen have a higher incidence of peptic ulcer disease, suggesting enhanced adherence of $H$. pylori to $\mathrm{H}$ and Leb antigen on the gastric epithelium. Su et al. found the combination of OipA, BabA, and SabA antibodies gave a 77.3\% positive predictive rate in the diagnosis of gastric cancer, suggesting the carcinogenicity of $H$. pylori strains was closely related to expression of adhesin proteins [123] (Figure 1, pathway 3).

Lewis antigens expressed on the surface of red blood cells, endothelium, kidneys, genitourinary and gastrointestinal tract include Le $(a+, b-)$, Le $(a-, b+)$, Le $(a-, b-)$. As well as better binding affinity of BabA to Leb, Lewis antigens are closely interlinked with secretion of ABH antigens. Le $(a-, b+)$ and Le $(a-, b-)$ genotype is associated with $\mathrm{ABH}$ secretion, whereas Le $(a+, b-)$ is a non-secretor (i.e., Lewis a patients do not secrete $\mathrm{ABH}$ antigens via mucous glands of the gastrointestinal tract). This means that blood group $\mathrm{O}$ patients with $\mathrm{H}$ antigens but also with Lewis a do not have $\mathrm{H}$ antigens on gastric mucosa, and H. pylori BabA cannot effectively adhere. Whereas patients with blood group $\mathrm{O}$ 
have excessive bleeding and duodenal ulcer disease due to improved binding with $H$. pylori adhesins, blood group A patients are at greater risk of gastric cancer [124-126].

Blood group O patients have greater pro-inflammatory cytokine IL-6 and TNF-alpha response to H. pylori, but not anti-inflammatory cytokine IL-10 [127]. A study of 703 patients with gastric cancer and 1465 non-cancer patients by Nakao et al. [128] demonstrated a statistically significant increased risk of gastric cancer in patients with blood group $\mathrm{A}$ and a risk reduction associated with blood group $\mathrm{B}$ and $\mathrm{O}$ patients. Blood group A patients are also more susceptible to pernicious anaemia and chronic atrophic gastritis, and thus more prone to gastric cancer. Furthermore, immune response to tumours in blood group A patients are lower than blood group $\mathrm{O}$ patients. This is related to the similarities between blood group A carbohydrate antigens and gastric cancer A-like Thompsen-Friedenreich (TF) antigen, with a resulting lowered host TF agglutinin response [127,129]. Jaff et al. showed in Korean patients that blood group B were least susceptible to H. pylori infections, and blood group O patients most susceptible to $H$. pylori induced ulcers [130]. Even before the association between H. pylori and chronic atrophic gastritis was discovered, it was known that blood group O patients had greater production of free $\mathrm{HCl}$ in the stomach $(86 \%)$ and higher levels of serum pepsinogen $(564 \mathrm{U} / \mathrm{mL})$ as compared respectively to blood group A patients $(73 \%)$ and $494 \mathrm{U} / \mathrm{mL}$ [131]. Wang et al. (2012) showed individuals with type A blood are more prone to being infected by $H$. pylori than blood group B [117]. By means of a wide range of imaging techniques, the study demonstrated enhanced H. pylori attachment to erythrocytes with type A antigen.

Patients with blood group A are at increased risk of atrophic gastritis which impairs gastric secretion of vitamin $\mathrm{C}$ levels, compared to patients with blood group $\mathrm{O}$ without atrophy who tend to have normal luminal vitamin $\mathrm{C}$ levels and gastric $\mathrm{pH}$. Diffuse antral gastritis and duodenal ulceration are associated with normal intragastric vitamin $C$ levels compared to patients with pangastritis, body atrophic gastritis or intestinal metaplasia who have low gastric juice vitamin $C$ and achlorhydria. This may explain the observation that patients with $H$. pylori related duodenal ulceration rarely develop gastric cancer $[70,114]$. Gastric ascorbic acid secretion in patients with severe gastric atrophy $(0.56 \mathrm{~mL} / \mathrm{min}, 0.27-1.20)$ was markedly lower than those in patients with no atrophy $(1.51 \mathrm{~mL} / \mathrm{min}$, $0.59-3.30)$ or with mild $(1.43 \mathrm{~mL} / \mathrm{min}, 0.53-3.78)$ and moderate $(1.31 \mathrm{~mL} / \mathrm{min}, 0.47-3.16)$ atrophy $(p<0.005)$. There was a significant negative correlation between ascorbic acid secretion and severity of atrophy (correlation coefficient $=-0.43, p<0.005$ ) [42].

Tight adherence to erythrocyte blood group or gastric mucosal carbohydrate antigens also allows iron to be extracted from the host to be utilized by H. pylori [117]. This may explain the phenomenon of refractory iron deficiency anaemia in chronic $H$. pylori gastritis, which is most marked in blood group A patients and least in blood group O patients. Iron can also be utilized by $H$. pylori to cause the Fenton reaction-ferrous iron catalyzes hydrogen peroxide and superoxide to form hydroxyl radicals and cause lipid peroxidation and DNA damage:

Fenton reaction: $2 \mathrm{Fe}^{2+}+2 \mathrm{H}_{2} \mathrm{O}_{2} \rightarrow 2 \mathrm{Fe}^{3+}+2 \mathrm{OH} \cdot($ hydroxyl radical $)+2 \mathrm{OH}^{-}$[112].

Akatsuka et al. showed in rats that the Fenton chemical reaction generates hydroxyl radicals, which causes significant genomic alterations (particularly deletions), contributing to carcinogenesis [132] (Figure 6).

\section{Vitamin C and H. pylori}

\subsection{Chronic Atrophic Gastritis, H. pylori and Vitamin C}

H. pylori can cause non-atrophic gastritis or chronic atrophic gastritis. Corpus-predominant chronic atrophic gastritis is associated with loss of parietal cells, hypergastrinaemia, anti-parietal cell antibody (anti- $\mathrm{H}^{+} / \mathrm{K}^{+}$ATPase $\mathrm{Ab}$, anti-intrinsic factor $\mathrm{Ab}$ ) generation, increased proliferation by gastric stem and progenitor cells, and replacement of normal gastric epithelium by complete or incomplete IM. This is also referred to as "antralization" or "pseudopyloric metaplasia" of the corpus or fundus. Hypergastrinaemia leads to increased expression of COX-2, and of anti-apoptotic proteins, such as Bcl-2 and survivin. This can promote carcinogenesis and angiogenesis in areas of 
gastric mucosal atrophy and incomplete metaplasia [133] (Figure 1). It is proposed that some of the metaplastic cells arise from zymogenic chief cells recruited back into the cell cycle, which is involved in spasmolytic polypeptide-expressing metaplasia (SPEM). Spasmolytic peptide is a trefoil peptide which is characteristically expressed in normal intestinal mucosa $[57,134,135]$. Loss of chief cells in AG and IM is reflected by low serum pepsinogen I levels and pepsinogen I/II ratios [114]. Later in the course of the disease, some of the metaplastic cells are derived from bone marrow derived stem cells which have migrated into the gastric mucosa [118] (Figure 5).

Cag-A positive H. pylori strains are strongly associated with chronic atrophic gastritis and IM, and are more likely to cause gastric cancer [6]. This may be in part due to chronic achlorhydria, reduced active secretion of vitamin $C$, unopposed free radical damage in chronic atrophic gastritis, and persistent hypermethylation of promoter genes [114]. Vitamin C is a bi-acid, with two different $\mathrm{pKa}$ of dissociation, 4.17 and 11.6. This means that in the acidic environment of the normal stomach $(\mathrm{pH}<4)$, a greater proportion of vitamin $\mathrm{C}$ is dissociated to its anion, ascorbate, which is a more powerful antioxidant than its oxidised form DHA $[6,136]$. In the more alkaline environment of gastric achlorhydria $(\mathrm{pH}>4)$, there is less dissociation to ascorbate and therefore less effective antioxidant protection (Figure 4).

Vitamin $C$ is a relatively strong acid and contributes to the overall acidity of the human stomach (fasting $\mathrm{pH}=2$ ). This is important in host gastric cytoprotection from pathogenic enteric organisms. Vitamin C also helps to protect the gastric epithelium from colonization by $H$. pylori or physical injury by increasing the synthesis of prostaglandin E2 (PGE2) by $90-100 \%$, which stimulates mucus secretion into the gastric lumen. Apart from thiol oxidation of the sulfylhydryl rich urease enzyme by DHA-metal ion complexes, ascorbic acid also reacts with $\mathrm{Ni}^{2+}$ found at the centre of $H$. pylori urease enzyme. Ascorbic acid is oxidised to DHA-Ni ${ }^{2+}$ complexes which reduces the dimeric nickel centre and irreversibly inactivates the urease enzyme (Figure 7). This results in the urease molecule becoming unstable and the H. pylori organism being unable to create an alkaline environment in which to survive. H. pylori is not an acidophile, and if its urease enzymes are inactivated, it can only survive at a gastric $\mathrm{pH}$ of 4.0-8.0. Vitamin C has also been shown to improve the eradication rate of H. pylori in combination with quadruple therapy (bismuth, metronidazole, amoxicillin, omeprazole), in comparison to standard quadruple therapy ( $78 \%$ vs. $48.8 \%, p<0.0001)$. Thus, vitamin $C$ may protect the stomach against initial colonization by $H$. pylori organisms, but may also be useful in eradication therapy for established H. pylori gastritis [137].

\section{Urease Enzyme}

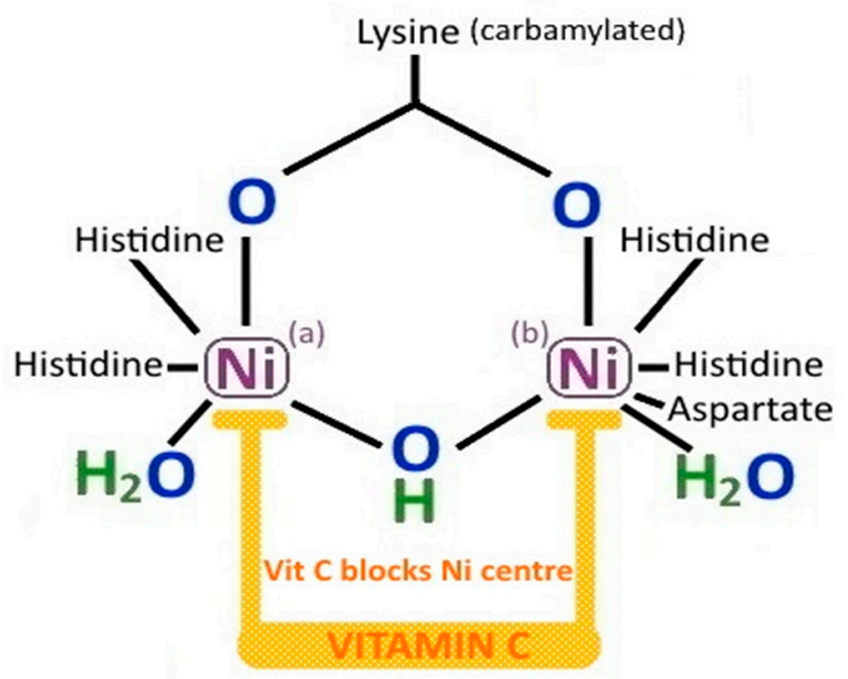

Figure 7. Inhibition of H. pylori urease by vitamin C [137]. 


\subsection{H. pylori and Gastric Ascorbic Acid Secretion}

H. pylori associated chronic atrophic gastritis substantially lowers gastric juice ascorbic acid secretion [138]. Waring et al. showed that, whilst plasma and gastric mucosal concentrations of ascorbic acid were unaffected by the presence of chronic gastritis, the gastric luminal concentration of ascorbic acid was significantly lower [139]. This was particularly so in vitamin C unsupplemented patients with hypochlorhydria (gastric $\mathrm{pH}>4$ ). These patients had a very low median ascorbic acid gastric juice level $(9 \mu \mathrm{mol} / \mathrm{L}$, range $0-82 \mu \mathrm{mol} / \mathrm{L}, p<0.05)$, as compared to unsupplemented patients without hypochlorhydria (gastric $\mathrm{pH}<4$ ), who had a much higher median level $(39 \mu \mathrm{mol} / \mathrm{L}$, range $0-483 \mu \mathrm{mol} / \mathrm{L}$ ). Oral vitamin C supplementation was less effective in improving luminal gastric ascorbate levels in patients with chronic gastritis than those with normal gastric mucosa [139]. Patients with $H$. pylori infection have a gastric juice ascorbic acid concentration significantly lower than those uninfected (19.3 $\mu \mathrm{mol} / \mathrm{L}$ (interquartile range (IQR) 10.7-44.5) versus $66.9 \mu \mathrm{mol} / \mathrm{L}$ (IQR 24.4-94.2), $p=0.003$ ). H. pylori CagA positive patients have lower gastric juice ascorbic acid concentrations than CagA negative $H$. pylori infected patients (14.8 $\mu \mathrm{mol} / \mathrm{L}$ (IQR 7.9-52.2) versus $39 \mu \mathrm{mol} / \mathrm{L}$ (IQR 19.9-142.2), $p=0.05)[114]$.

\subsection{H. pylori Eradication and Vitamin C}

H. pylori contributes to diminished gastric luminal ascorbic acid due to consumption by Helicobacter phospholipases, proteases and cytochrome c oxidases; increased release of ROS by migrating inflammatory cells; increased gastric $\mathrm{pH}$ and impaired active secretion of ascorbic acid due to damaged gastric epithelium. Eradication of $H$. pylori has been shown to improve gastric juice levels of ascorbic acid [140,141]. Sobala et al. [142] showed a significant recovery in intragastric ascorbic acid levels in patients who achieved successful $H$. pylori eradication versus those who failed eradication. The rise in gastric juice ascorbic acid levels was higher in H. pylori eradicated patients with final plasma vitamin C levels $>30 \mu \mathrm{mol} / \mathrm{L}$ compared to those who were deficient, with plasma levels $<30 \mu \mathrm{mol} / \mathrm{L}$. It was also found that oral vitamin $C$ supplementation alone was unable to increase gastric juice ascorbate levels in the presence of persistent H. pylori infection [142]. Annibale et al. (2003) reported $H$. pylori eradication in patients with chronic superficial $H$. pylori gastritis achieved a decrease in intragastric $\mathrm{pH}$ (4 to 2) and an increase in gastric juice ascorbic acid levels (9.02 to $14.48 \mathrm{mcg} / \mathrm{mL}$ ), but there was no change in patients with existing $H$. pylori related gastric atrophy who achieved H. pylori eradication [143]. In atrophic gastritis, H. pylori infection also results in gastric achlorhydria, favouring an overgrowth of nitrite-forming bacteria and increasing the formation of nitrite and $\mathrm{N}$-nitroso compounds and the oxidation of ascorbate [144].

\subsection{Phytochemicals, CagA and Prevention of Gastric Cancer}

The effect of CagA induced chronic atrophic gastritis and decreased secretion of vitamin C into the gastric lumen may explain, in part, the variable efficacy of dietary phytochemicals from fruit and vegetables in prevention studies of gastric dysplasia and adenocarcinoma. There have been positive [85,145-147], negative and equivocal results [148-153], some of which relate to study power and design, H. pylori virulence, endoscopic assessment, baseline histology, heterogeneity, controlling for other risk factors, assessment of plasma vitamin C status, dietary recall and length of follow-up [146-149]. For example, a pooled analysis was performed of 810 prospectively collected non-cardia gastric cancer cases and 1160 matched controls from East Asian countries (Korea, Japan, China), with associated H. pylori CagA status, demographic, lifestyle, smoking and dietary data. Higher fruit intake was associated with decreased risk of non-cardia gastric cancer $(\mathrm{OR}=0.71,95 \% \mathrm{CI}$ : $0.52-0.95, p$-trend $=0.02)$. High-fruit consumers without evidence of $H$. pylori antibodies had the lowest odds for gastric cancer incidence $(\mathrm{OR}=0.12,95 \% \mathrm{CI}$ : 0.06-0.25) when compared to low-fruit consumers who were infected with CagA-positive H. pylori. However, the inverse association with high-fruit consumption was lost in individuals infected with CagA positive $H$. pylori $(\mathrm{OR}=0.82$, 
95\% CI: 0.66-1.03). The overall low percentage of CagA negative subjects, and the non-smoking status of higher fruit consumers were potential confounding factors in the study [154].

\section{Probiotics and Helicobacter Eradication}

The emergence of antibiotic resistance in $H$. pylori bacteria has stimulated interest in the use of probiotics to enhance Helicobacter eradication rates. Live organisms such as L. acidophilus and L. bulgaricus have been shown to enhance the gastric mucus protection barrier, inhibit $H$. pylori adhesion to gastric epithelial cells, stimulate host immunity, compete with $\mathrm{H}$. pylori for nutrients and produce bactericidal agents (SCFA and bacteriocins). Probiotics may increase H. pylori eradication rates when used in conjunction with triple therapy, and prevent the loss of microbial diversity in the gastrointestinal tract and thus the side effects of antibiotic treatment. Lactobacillus spp. may be able to decrease oxidative stress in the stomach and the initiation of gastric neoplasia by their production of antioxidants which scavenge superoxides and hydroxyl radicals, and also decrease gastric inflammation by inhibition of $H$. pylori mediated activation of NF- $\mathrm{kB}$, STAT3 and cytokine release (TNF- $\alpha$, IL-8, iNOS, COX-2). There is some evidence that probiotic therapy may inhibit gastric carcinogenesis by decreasing polyamine synthesis, as polyamines are required for rapid cellular proliferation [155-160].

\section{Dietary and Environmental Risk Factors for Gastric Cancer}

Epidemiological studies have shown a diet of pickled, fermented, processed or smoked foods high in nitrites and nitrosamines [161], cooking methods involving high heat such as grilling, broiling and deep frying resulting in heterocyclic amine release [118,162], or diets high in salt, heme iron, red meat [163], or saturated fats can contribute to gastric cancer [164]. Tobacco smoking and alcohol consumption are also risk factors for gastric neoplasia, and may synergistically interact with dietary risk factors and $H$. pylori infection. Increased fruit and vegetable intake is preferable over synthetic vitamin $C$ supplementation as it is likely that ascorbic acid, carotenoids, polyphenols, flavonoids and other phytochemicals act synergistically to prevent gastric neoplasia [36,147] (Figure 8).

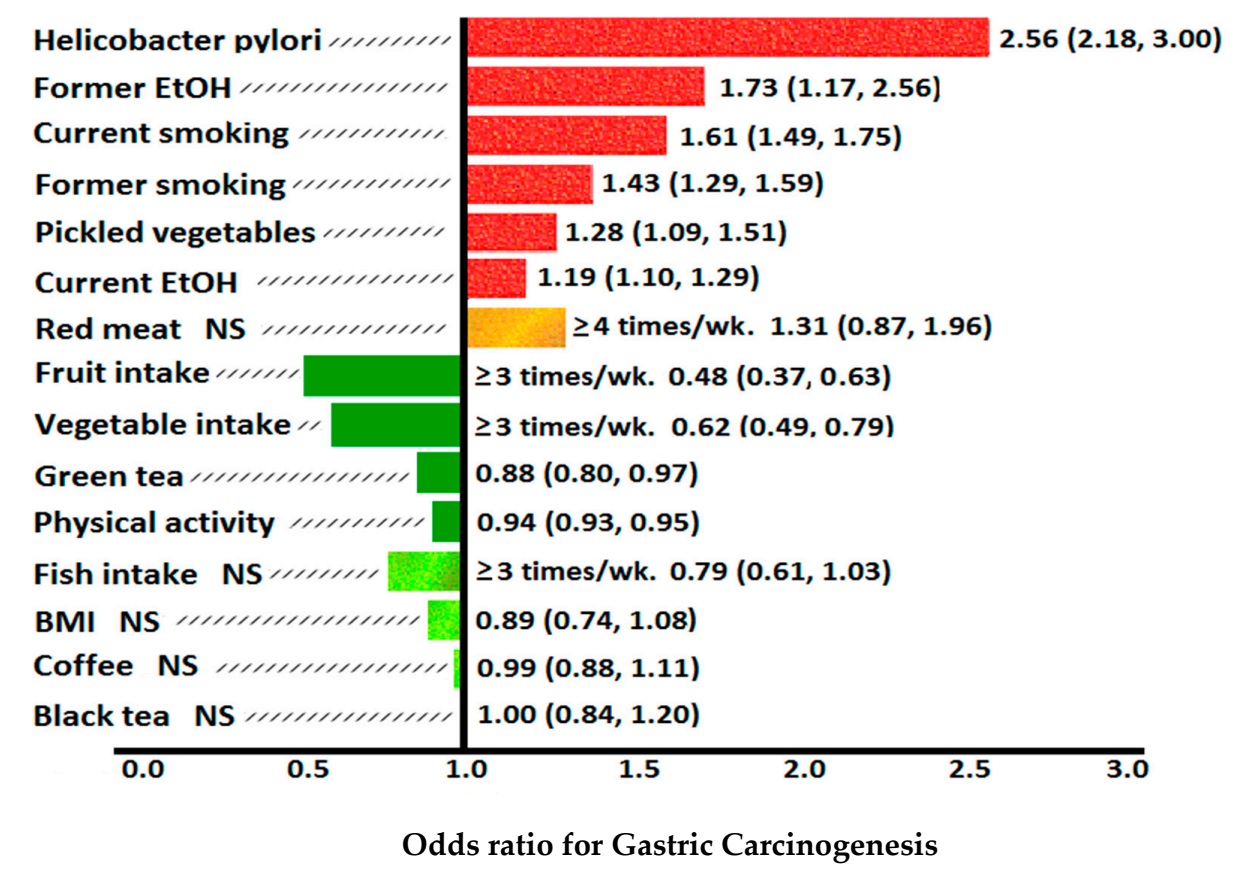

Figure 8. Odds ratios for risk factors and protective factors in gastric carcinogenesis (associations with $95 \%$ confidence intervals). Protective factors are shown in green (dark green, significant; light green, non-significant (NS)) and risk factors are shown in red (red, significant; orange, non significant). BMI: body mass index, EtOH: alcohol. Adapted from Poorolajal et al. [164]. 


\subsection{Dietary Nitrosamines}

Nitrosamines are formed by the reaction of nitrites with secondary amines. Nitrosamines and other N-nitroso compounds (NOCs) are involved in gastric carcinogenesis, and can be derived from exogenous sources (e.g., during cooking, preservation, fermentation or smoking of foods; cigarette smoking), or created endogenously in the stomach. Endogenous synthesis of nitrosamines (ENOCs) accounts for the majority (45-75\%) of overall exposure. Consumption of a diet high in pre-formed nitrosamines such as nitrosodimethylamine (NDMA) was shown to increase the risk of gastric cancer (in Swedish women) [165]. However, exogenous NDMA was not shown to be a risk factor (HR, 1.00; 95\% CI, 0.7-1.43) in the EPIC-EURGAST study. There are over 300 NOCs, and 90\% of nitrosamines are carcinogenic [166]. Stillwell and Correa (1991) measured urinary excretion of nitrate and N-nitrosoproline in 160 subjects in a Colombian population and performed gastric biopsies in 118 of these individuals. The study showed a highly significant association between urinary nitrate, N-nitrosoproline, and intestinal metaplasia and dysplasia, supporting evidence for the role of nitrosamines and other N-NOCs in gastric carcinogenesis [167].

Nitroso compounds can be categorized as C-nitroso compounds (e.g., nitrosoalkanes; $\mathrm{R}-\mathrm{N}=\mathrm{O}$ ), S-nitroso compounds (nitrosothiols; $\mathrm{RS}-\mathrm{N}=\mathrm{O}$ ), $\mathrm{N}$-nitroso compounds (e.g., nitrosamines; $\mathrm{R} 2 \mathrm{~N}-\mathrm{N}=\mathrm{O}$ ), and O-nitroso compounds (alkyl nitrites; $\mathrm{RO}-\mathrm{N}=\mathrm{O}$ ). $\mathrm{N}$-nitroso compounds can be categorised into nitrosamines and nitrosoamides (includes nitrosocarbamate and nitrosoureas).

Apart from dietary preformed N-nitroso compounds such as nitrosamines, dietary nitrites $\left(\mathrm{NO}_{2}{ }^{-}\right)$, used as preservatives in cured meats, beer, bacon, ham and some sausages, have also been implicated in gastric carcinogenesis [168]. Nitrites can produce nitrosylation or nitrosation in the stomach. Nitrosylation leads to the formation of non $\mathrm{N}$-nitroso compounds (adding a nitrosyl ion $\mathrm{NO}^{-}$to a metal such as iron or a thiol). Nitrosation adds a nitrosonium ion $\mathrm{NO}^{+}$to an amine $-\mathrm{NH} 2$ leading to formation of nitrosamines such as NDMA or nitrosoproline. This occurs in acidic $\mathrm{pH}$ environments, particularly in the stomach $(\mathrm{pH}<4)$; or when intragastric ascorbic acid levels are low. H. pylori increases NOS and nitric oxide levels, which promotes the formation of endogenous nitrosamines. H. pylori stimulates the macrophage system through the l-arginine/nitric oxide (NO) pathway. Chronic H. pylori gastritis may thus increase endogenous NO formation. Subsequent oxidation of NO by ROS results in formation of the nitrosating agents $\mathrm{N}_{2} \mathrm{O}_{3}$ (dinitrogen trioxide) and $\mathrm{N}_{2} \mathrm{O}_{4}$, which can produce nitrosamines or cause other types of DNA damage or lipid peroxidation [169]. Nitric oxide can react directly in the stomach with myoglobin and haemoglobin from red or processed meat to form ENOCs. This does not occur with non-meat protein or inorganic iron. The EPIC-EURGAST study found that the association between ENOCs and non-cardia gastric cancer was only significant in $H$. pylori sero-positive patients (HR, 1.82; 95\% CI, 1.32-2.51), and not in H. pylori sero-negative patients [170].

Dietary nitrates $\left(\mathrm{NO}_{3}{ }^{-}\right)$and nitrites can lead to formation of N-NOCs and nitrosamines. Nitrites are added to cured meats as preservatives, colour fixatives and inhibitors of spoilage bacteria and food borne pathogens (Clostridium botulinum). Nitrates are ubiquitous in foods, particularly leafy green vegetables (spinach, lettuce, beetroot, arugula, kale, celery). Nitrates are not in themselves carcinogenic but may be partially reduced in the oral cavity by bacteria to nitrites [171,172]. Nitrite does not circulate in the bloodstream because it is oxidized by oxyhemoglobin to nitrate. Nitrates can be converted to nitrites immediately following ingestion. Nitrates can also be absorbed in the small intestines, circulated in the bloodstream, concentrated in the salivary glands (by 10 fold over plasma), secreted in saliva and reduced by anaerobic buccal bacteria to nitrites at a later stage. This is the more common pathway, known as the enterosalivary circulation of nitrates [171]. Approximately $25 \%$ of ingested nitrates undergo enterosalivary circulation, which occurs in humans but not in mice or rats. An estimated $20 \%$ of the salivary nitrates are converted to nitrites, which, when swallowed, deliver large amounts of post-prandial nitrites to the gastric mucosa. Nitrites can react with gastric acid $(\mathrm{HCl})$ to produce nitrous acid $\left(\mathrm{HNO}_{2}\right)$ which actively nitrosate amides to form nitrosamides $\left(\mathrm{HN}_{2} \mathrm{O}_{2}\right)$. Two molecules of $\mathrm{HNO}_{2}$ can form $\mathrm{N}_{2} \mathrm{O}_{3}$ in the stomach, and then nitrosate amines to form gastric nitrosamines $\left(\mathrm{H}_{2} \mathrm{~N}_{2} \mathrm{O}\right)$. Ascorbate reduces $\mathrm{HNO}_{2}$ to $\mathrm{NO}$, and also reacts more rapidly with $\mathrm{N}_{2} \mathrm{O}_{3}$ than 
amines, thereby inhibiting nitrosation. The rate of chemical nitrosation in the stomach increases as the gastric ascorbate/nitrite ratio decreases [161].

Alterations in resident gastric anaerobic microbiota also contribute to nitrosation, in association with the gastric achlorhydria induced by H. pylori, AG or long-term proton pump inhibitor use [161]. Commensal bacterial fermentation in the stomach can create high levels of nitrite, particularly in AG when the gastric secretion, or the dissociation, of gastric luminal ascorbic acid is too low to offer protection [139]. At a $\mathrm{pH}$ of $>5$ during gastric achlorhydria, bacterial derived nitrate reductase is thus more important than gastric $\mathrm{HCl}$ in the formation of nitrites. This leads to endogenously formed NOCs, and may contribute to gastric carcinogenesis [136]. Gastric microbial dysbiosis, associated with AG, IM and epithelial dysplasia and diagnosed by 16S rRNA gene sequencing, can be reversed after successful $H$. pylori eradication treatment. This suggests that $H$. pylori and altered gastric microbiota have synergistic contributions to gastric carcinogenesis [173] (Figure 5).

\subsection{Vitamin C, Allium Vegetables and Nitrosamines}

The allium vegetables (onions, garlic, shallots) contain allyl sulfur compounds. These inhibit the spontaneous and bacterial mediated formation of nitrosamines (eg nitrosoproline) by favouring the formation of nitrosothiols and decreasing the availability of nitrites. They also block the alkylation of DNA by nitrosamines, which reduces the risk of N-NOC gastric carcinogenesis. The 2007 World Cancer Research Fund meta-analysis of allium vegetable ingestion showed dose related significant decreases in the risk of gastric cancer, but this was not confirmed in the EPIC study. Similarly, vitamin C inhibits the endogenous nitrosation of amines by nitrites in the formation of gastric nitrosamines by $87-100 \%$ at a normal gastric $\mathrm{pH}$ of 2.5 , and promotes nitrosylation of red meat derived heme to nitrosyl-heme, a compound which is not carcinogenic $[174,175]$. The EPIC-EURGAST study showed the risk of non-cardia gastric cancer from ENOCs correlated with plasma levels of vitamin C. In patients with low plasma levels of vitamin $\mathrm{C}(<40 \mu \mathrm{mol} / \mathrm{L})$, the associated odds ratio of ENOCs and non-cardia cancer was 3.24 (95\% CI, 1.77-5.93), but there was no association in patients with plasma vitamin $\mathrm{C}>40 \mu \mathrm{mol} / \mathrm{L}$ (OR, 1.10; 95\% CI, 0.63-1.93). This was thought to be possibly related to lower vitamin $\mathrm{C}$ levels in $\mathrm{H}$. pylori infected patients. Indeed, when the analysis of the risk of ENOCs and low plasma vitamin $\mathrm{C}$ was restricted to $H$. pylori positive patients, the non-cardia gastric cancer risk was even higher (OR, 3.52; 95\% CI, 1.8-8.9) [170] (Figure 5).

\subsection{Heterocyclic Amines}

Heterocyclic amines are mutagens formed during the cooking of protein rich foods, particularly meat and fish cooked at high temperature. This process involves protein pyrolysis or the Maillard reaction [118]. Ohgaki et al. showed heterocyclic amines in cooked foods were carcinogenic in mice, rats and monkeys [162]. HCAs are associated with gastric cancer, and also liver, lung, blood vessel, colon and mammary gland cancers, lymphomas and leukaemia.

The consumption of fruit and vegetables rich in antioxidants, polyphenols and other phytochemicals can decrease the formation, bioactivation and carcinogenicity of HCAs and nitrosamines. For example, adding garlic or onions to red meat prior to cooking decreased the formation of the HCAs 2-amino-3,8-dimethylimidazo (4,5-f) quinoxaline (MeIQx) by $66.2-88 \%$ and 2-amino-1-methyl-6phenylimidazo(4,5-b)pyridine (PhIP) by 79-94.3\%. After ingestion, HCAs are activated by N-oxidation via cytochrome P4501A2, sulfotransferases and $\mathrm{N}$-acetyltransferases (NAT), to reactive electrophilic species with greater overall genotoxicity than parent HCAs. The activity of NAT mRNA expression in humans can be suppressed by the allium vegetables (e.g., onions, garlic) [174].

Poplawski et al. [118] found that DNA damage induced by HCAs was significantly higher in subjects with $H$. pylori than those who were not infected, suggesting that $H$. pylori facilitates the mutagenic effect of HCAs. However, vitamin $C$ can reduce the toxic effects of HCAs on gastric mucosal cells regardless of $H$. pylori status. HCAs can also be conjugated and detoxified by glutathione which, like ascorbic acid, is a strong antioxidant. VacA produced by H. pylori is able to deplete levels of 
cellular GSH, and therefore increase the exposure of the gastric mucosa to the mutagenic effects of HCAs $[58,118]$.

\subsection{Salt and H. pylori}

Salt has been identified as a risk factor for gastric cancer since 1959, related to the consumption of large amounts of cured meat, soy sauce, salted fish, pickled vegetables and other salt-preserved foods (Figure 8). A meta-analysis by D'Elia et al. of 268,718 subjects showed an increased risk of gastric cancer with increased salt intake [176]. "High" and "moderately high" versus "low" salt intake were both respectively associated with increased risk of gastric cancer ( $R R=1.68$ [95\% C.I. 1.17-2.41], $p=0.005$ and $\mathrm{RR}=1.41$ [1.03-1.93], $p=0.032$ ). This was particularly so in Japanese subjects and those who had a higher consumption of selected salt-rich foods such as salt fermented fish, fermented soy paste or Korean kimchi (pickled cabbage).

Salt damages the mucous membrane of the stomach leading to inflammation and facilitating colonisation by $H$. pylori. Other reviews have suggested that high salt conditions are involved in gastric carcinogenesis by inducing hypergastrinaemia, endogenous mutations, gastric epithelial cell proliferation, altered gastric mucus viscosity, and potentiating the effects of $H$. pylori CagA and nitrosamines (e.g., $N$-methyl- $N$-nitro- $N$-nitrosoguanidine (MNNG)) [26,177]. Indeed, a 3 fold higher variation in gastric cancer mortality in Japanese prefectures (e.g., Akita (high salt) vs. Okinawa (low salt)), despite similar patient genetic makeup and Helicobacter strains, has been ascribed to large differences in dietary salt intake [178]. A significant association between dietary salt and gastric cancer was only observed in Japanese subjects who had both $H$. pylori infection and atrophic gastritis (HR, 2.87 [1.14-7.24]) [179]. In a 2015 meta-analysis of 76 prospective cohort studies of dietary risk factors for gastric cancer, every increment of $5 \mathrm{~g} /$ day intake of salt was found to increase the risk of gastric cancer by $12 \%$ [146] (Figure 5).

Recently, it was found that salt regulated multiple genes encoding $H$. pylori outer membrane proteins (HOP family), including adhesins (SabA, HopQ) and proteins involved in iron acquisition (FecA2 and FecA3). Transcript levels of H. pylori sabA, hopA, and hopQ are increased under high-salt conditions, whereas transcript levels of $H$. pylori fec $A 2$ and fec $A 3$ are decreased under high-salt conditions [180].

\subsection{Tobacco Smoking, Vitamin C and H. pylori}

Tobacco smoking is a significant risk factor for gastric cancer due to ingestion of toxic mutagenic chemicals such as tar (quinone-hydroquinone radicals), cyanide, heavy metals (e.g., cadmium, chromium, nickel); aromatic carcinogens, nitrosamines and nicotine, generation of ROS/RNS and lipid peroxidation $[34,180]$. Nicotine induced free radicals react with biomembranes causing oxidative destruction of polyunsaturated fatty acid (PUFA), producing cytotoxic aldehydes via lipid peroxidation. Thiocyanates generated from tobacco smoke are secreted in saliva and increase chemical nitrosation in the acidic stomach, particularly at the gastric cardia. The EPIC study found a 73-87\% increased risk from smoking, including gastric cardia adenocarcinoma $(\mathrm{OR}=4.1)$, the risk increasing with the intensity and duration of cigarettes smoked. Smoking was also a risk factor in non-cardia gastric adenocarcinoma $(\mathrm{OR}=1.94)$ [181].

Whilst the EPIC study showed smoking was a risk factor for both males and females, Zaridze et al. found smoking increased the risk of developing gastric cancer in males, but not in females [181,182]. The study also showed a dose response relationship, with patients with higher pack year histories being at greater risk. In a Japanese study performed by Koizumi et al. [183], risk of gastric cancer persisted for 14 years after cessation of smoking. Valavanidis et al. [184] suggested that $11 \%$ of gastric cancers are associated with smoking. Fruit consumption increased total plasma antioxidant levels in non-smokers but not in smokers, indicating that vitamin $C$ protective effects were attenuated by smoking. However, Bohn et al. showed antioxidant levels were improved by consumption of antioxidant rich foods, even in smokers [185]. Some of the mechanisms by which smoking promotes gastric cancer include reduction 
of the protective effects of prostaglandin (PGE2) production and gastric mucus integrity [186], GSH and intragastric vitamin C levels [187]. Gonzalez et al. [188] showed smokers had a higher incidence of H. pylori infection, which may be the result of, or contributes to, lower gastric luminal vitamin C [187]. Wang et al. [189] demonstrated increased ROS in rat gastric mucosa when exposed to cigarette smoke, suggesting that smoking increased free radical production and absorption. Tobacco smoking doubles the gastric epithelial dysplasia risk compared to non-smokers [190], the risk being greatest in the region of the gastric cardia [181].

Tobacco smoking and H. pylori infection may be synergistic in gastric carcinogenesis. A recent prospective study of the association of smoking and $H$. pylori status with gastric cancer risk was performed in 1446 non-cardia gastric cancer cases and 1796 controls from China, Japan and Korea. It was found that current smoking and $H$. pylori sero-positivity increased the risk of non-cardia gastric cancer $(\mathrm{OR}=1.46 ; 95 \% \mathrm{CI}, 1.10-1.93)$ as opposed to no increased gastric cancer risk amongst $H$. pylori sero-negative current smokers ( $\mathrm{OR}=0.93 ; 95 \% \mathrm{CI}, 0.65-1.33)$ [191].

Jarosz et al. [187] measured plasma and gastric juice total vitamin C levels using spectrophotometry in 86 Polish subjects divided into four groups:

1. non-smokers/H. pylori negative: mean gastric vit $\mathrm{C}=17.1 \mathrm{mcg} / \mathrm{mL}$,

2. non-smokers/H. pylori positive: mean gastric vit $\mathrm{C}=12.6 \mathrm{mcg} / \mathrm{mL}$,

3. smokers/H. pylori negative: mean gastric vit $\mathrm{C}=5.8 \mathrm{mcg} / \mathrm{mL}$,

4. smokers/H. pylori positive: mean gastric vit $\mathrm{C}=3.9 \mathrm{mcg} / \mathrm{mL}$.

The concentration of vitamin $C$ in gastric juice was significantly lower in smokers than in non-smokers $(p<0.05)$ and H. pylori infection in smokers was associated with the lowest gastric luminal vitamin C levels [187]. Pasupathi [34] suggested that ingestion of cigarette smoke containing nicotine, nitrosamines, tar and other mutagenic toxins increased oxidative damage and attenuated the effects of antioxidants such as vitamin $C$, vitamin $E$, glutathione and $\beta$-carotene.

Smokers may have lower vitamin $C$ levels than non-smokers due to:

1. Consumption of ascorbic acid to DHA by ROS and oxidative stress in the stomach and other tissues exposed to cigarette smoke/tar.

2. Vitamin $C$ is used for regeneration of vitamin $E, \beta$-carotene or glutathione which have been directly oxidized during scavenging of free radicals and ROS from cigarette smoke.

3. Smokers have lower dietary consumption of vitamin C containing foods.

4. Cigarette smoke induced oxidative damage of proteins and peroxidation of lipids are accompanied by a marked drop in tissue ascorbate levels.

5. Increased H. pylori infection in smokers vs. non-smokers.

6. Failure of regeneration of ascorbate from DHA by GSH-dependent reductases.

As such, the protective effect of ascorbic acid supplementation may only be appreciated in smokers after H. pylori eradication, or after smoking cessation. Comparatively large amounts of vitamin C are also required to counteract the high levels of free radicals, lipid peroxidation, thiobarbituric acid, NDMA and F2-isoprostane generated from tobacco smoking (Box 1) [34].

\subsection{Alcohol}

Consumption of alcohol is a risk factor for gastric cancer. In a 2017 meta-analysis of 23 prospective cohort studies published from 1987-2016, every increment of $10 \mathrm{~g}$ of alcohol consumed per day increased the gastric cancer risk by $7 \%\left(95 \%\right.$ CI $\left.1.02-1.12 ; I^{2}=28.9 \%, p=0.002\right)$. The authors commented that there was only one study of alcohol consumption in gastric cancer which adjusted the relative risk of alcohol consumption and gastric cancer relative to H. pylori status [192].

The EPIC study showed heavy alcohol consumption ( $>60 \mathrm{~g} /$ day) increased the risk of non-cardia intestinal type gastric cancer $(\mathrm{OR}=1.65)$. This has been supported by evidence from Chinese and Russian studies. Ma et al. found heavy drinking ( 7 times a week), and binge drinking ( $>55 \mathrm{~g}$ alcohol 
intake per occasion) produced a 3.48-fold (95\% CI, 1.13-10.73) and 3.27-fold (95\% CI, 1.01-10.56) higher risk in $H$. pylori negative subjects. In patients who were $H$. pylori IgG sero-positive, there was no significant association found between drinking pattern and gastric cancer risk [193].

Zaridze et al. [182] showed in a case control study consisting of over 800 subjects that hard liquor consumption, particularly vodka, increased the risk of gastric cardia cancer in males $(\mathrm{OR}=3.4$, $\mathrm{CI}=1.2-10.2)$ and non-cardia cancer in females $(\mathrm{OR}=1.5, \mathrm{CI}=1.0-2.3)$. Vodka consumption increased the respective gastric cancer risk 2.0 -fold $(95 \%$ CI, $1.2-3.1)$ and 2.3 -fold $(95 \%$ CI, $1.4-3.7)$ in subjects who were negative or positive for $H$. pylori infection, compared to their non-drinking counterparts. Moy et al. [194] showed in 391 subjects that $>50 \mathrm{~g} /$ day of alcohol increased the risk of gastric cancer $(\mathrm{HR}=1.4)$. Metabolites of alcohol (acetaldehyde and acetate) cause a direct toxic effect on the gastric mucosa and also increase the absorption of nitrosamines, including those from tobacco smoke [195]. In a prospective population-based study of 69,962 Norwegian subjects from 1984-2002, combined high use of cigarettes ( $>20 /$ day) and alcohol ( $>5$ occasions/14 days) increased the risk of non-cardia gastric adenocarcinoma almost 5 -fold $(\mathrm{HR}=4.90,95 \% \mathrm{CI}=1.90-12.62)$. The confounding effect of $H$. pylori was an unknown factor in this study [196].

Polymorphisms in the Aldehyde Dehydrogenase 2 Family Member (ALDH2) gene have been demonstrated to increase the risk of gastric cancer in a Korean population of current or ex-alcohol consumers, as compared to never/rare consumers. This was particularly so in $A L D H 2^{*} 1 /{ }^{*} 2$ carriers [5].

\section{Family History and Genetic Mutations}

Genomic instability caused by various environmental and genetic factors is characterized by microsatellite or chromosomal instability. It has been proposed that greater than 4.2 genomic alterations results in a significant risk of gastric cancer [197]. Gonzalez et al. identified mutations in genes including XPG, PLCE1, HFE, ERCC5, EZH2, DOC2, CYP19A1, ALDH2, and CDH1 to be linked with gastric cancer [198]. The risk of gastric cancer is higher in subjects with pre-existing familial cancer syndromes such as:

1. Hereditary Diffuse Gastric Cancer ( $C D H 1$ germline mutation)

2. Breast cancer syndrome (BRCA2)

3. Hereditary non-polyposis colorectal cancer (HNPCC, Lynch II) syndrome (MSH2/MLH1/MSH6 mutation),

4. Li Fraumeni syndrome (TP53 mutation)

5. Familial adenomatous polyposis (FAP) syndrome (APC mutation).

In patients with Hereditary Diffuse Gastric Cancer who were negative for the CDH1 mutation, other germline mutations have been discovered including BRCA2, STK11 (serine/threonine kinase 11; Peutz-Jeghers syndrome), ATM (Ataxia-Telangiectasia mutated), SDHB (succinate dehydrogenase complex iron sulfur subunit B), PRSS1 (Serine protease 1; Hereditary pancreatitis syndrome), MSR1 (macrophage scavenger receptor 1), CTNNA1 (catenin alpha 1) and PALB2 (Partner and localizer of BRCA2) [5,12].

\subsection{Sodium Dependent Ascorbic Acid Transporters}

Mutations in sodium dependent ascorbic acid transporters are associated with an increased risk of gastric cancer. Solute carrier family 23 member 1 (SLC23A1) and SLC23A2 are genes that respectively encode SVCT1 and SVCT2. Wright et al. found single nucleotide gene polymorphisms in SLC23A1 and SLC23A2 resulted in low serum ascorbic acid levels, and was associated with a $41 \%$ increase in gastric cancer [199]. Another study showed SLC23A2 polymorphism was associated with gastric cancer but SLC23A1 polymorphism was not [200]. 


\subsection{Glutathione and Gastric Cancer}

Genetic aberrations in critical glutathione pathways also increase gastric cancer risk. Zhang et al. [201] showed mutations of the gene expressing glutathione S-transferase P1 (GSTP1), a critical enzyme in the formation of glutathione, resulted in a higher risk of gastric cancer. The most common polymorphism of the GSTP1 gene is A-> G at nucleotide 313, a mutation which results in substitution of an amino acid (Ile105Val). The risk of gastric cancer was higher in patients with the GSTP1 substitution mutation, showing that low levels of glutathione increased gastric cancer risk. Subjects with GSTP1 mutation had further additive risks for gastric cancer with smoking $(\mathrm{OR}=1.64)$, alcohol $(\mathrm{OR}=1.64)$ or H. pylori infection (OR =3.7). CPG hypermethylation of GSTP1 is an epigenetic modification which is commonly found in EBV related gastric cancer (20\%), but rare (0.4\%) in EBV-negative gastric cancer [202].

Other important mutations associated with glutathione include polymorphisms of GSTT1 and GSTM1. GSTT1 is important for the conjugation of toxins by glutathione to detoxify compounds in the cytosol, mitochondria and microsomes. Conjugation allows the body to escort toxins out of body via urine or bile. It has been demonstrated that null allele polymorphism of GSTT1 (22q11.2) increases the risk of gastric cancer because this prevents conjugation of toxins by glutathione. GSTM1 synthesizes and recycles glutathione. Polymorphisms of GSTM1 have also been shown to increase gastric cancer risk. The GST family members, including GSTM1, are required for the detoxification of carcinogens generated from burning cigarettes, and also metabolites of alcohol. Patients with mutations in both GSTT1 and GSTM1 had a significantly increased risk of gastric cancer over those with both wild type genotypes (OR $=1.95,95 \%$ CI: $1.42-2.67 ; \mathrm{I}^{2}=0 \%$ ) [202,203].

\section{Gastric MALT Lymphoma and H. pylori Eradication}

The majority of gastric MALT lymphomas (92\%) have been shown to be associated with $\mathrm{H}$. pylori infection [204]. The H. pylori strains involved in gastric MALT lymphomas are less virulent than those associated with gastric adenocarcinoma, in that they contain the vacA $\mathrm{m} 2$ allele and lack the cag pathogenicity island (cagPAI). CagA positive strains are more likely to be associated with diffuse large B-cell lymphoma (DLBCL) [205]. Marginal zone B cell lymphomas develop in the mucosa of the stomach and are often found to harbour the translocation $\mathrm{t}(11 ; 18)(\mathrm{q} 21 ; \mathrm{q} 21)$ - this in fact predicts poor response to treatment. Complete remission (CR) of gastric MALT lymphoma with Helicobacter eradication alone has been reported in up to $85 \%$ of patients who are H. pylori positive. Interestingly, patients who are H. pylori negative can also respond to antibiotic therapy for gastric MALT lymphoma, and achieve a CR of up to $57 \%$. Helicobacter eradication was successful regardless of the MALT stage or the involvement of bone marrow. MALT lymphoma relapse can occur some years following a $\mathrm{CR}$, and, because of the associated risk of development of gastric cancer, endoscopic surveillance is recommended [204-213].

\section{Prevention of Gastric Cancer by H. pylori Eradication}

\subsection{Helicobacter pylori Eradication and Gastric Cancer}

Successful eradication of $H$. pylori results in significant reduction of future incident rates of gastric cancer in both asymptomatic $H$. pylori positive individuals (pooled incidence rate ratio, 0.62; 95\% CI: 0.49-0.79) and post-endoscopic resection of early gastric cancers (pooled incidence rate ratio, 0.46; 95\% CI: 0.35-0.60) [213]. In the 2016 meta-analysis of 21 RCTs, H. pylori eradication decreased the pooled incidence rate of gastric cancer in a non-linear way with increasing baseline incidence of gastric cancer $(p=0.018)$ [214]. A 2017 meta-analysis of seven RCTs in prevention of primary gastric cancer with $H$. pylori eradication showed a similar reduction in overall relative risk of 0.67 (95\% CI: 0.48 to 0.95 ). However, the respective overall risk difference (RD) was 0.00 ([95\% CI: -0.01 to 0.00$]$ and number needed to treat was 125.5 [95\% CI: 70.0 to 800.9]). It was thought that the discrepancy between the pooled relative risk (RR) and the RD was because data of rare events was used, and the relative risk overestimated the actual effect [215]. 
A further 2019 meta-analysis of 31 RCTs showed a significant reduction in future gastric cancer after $H$. pylori eradication $(\mathrm{OR}=0.46)$ in Eastern Asia. On subset analysis this effect was most pronounced in Japanese $(\mathrm{OR}=0.39)$ and Korean $(\mathrm{OR}=0.47)$ patients [216]. Other beneficial effects of $H$. pylori eradication beyond gastric adenocarcinoma prevention include decreased peptic ulcer disease, MALT lymphoma, functional dyspepsia, atrophic gastritis, vitamin B12 and iron deficiency, and idiopathic thrombocytopenia purpura. Due to the potential benefits of H. pylori eradication in endemic countries, population based testing commenced in Taiwan in 2004 and Japan in 2013 [4].

Extending population based $H$. pylori testing to countries with a low prevalence of gastric cancer is controversial [217]. There are differences in H. pylori strain virulence and dietary and environmental risk factors in developed nations; and modern guidelines recommend patients found to be infected with $H$. pylori should be treated. This may potentially increase the risk of antibiotic resistance, change gastrointestinal microecology or increase costs. A retrospective cohort study of H. pylori diagnosed in 371,813 symptomatic USA Veterans was recently reported [218]. Successful eradication reduced the future risk of non-cardia gastric cancer by 76\% (SHR, 0.24; 95\% CI, $0.15-0.41 ; p<0.001$ ) in 38,535 patients with proven $H$. pylori infection on urea breath testing, faecal antigen testing or histopathology. Eradication was only attempted in $75 \%$ of these patients $(28,818 / 38,535)$, which unintentionally provided a sub-group of untreated patients with which to compare outcomes. The overall incidence of gastric cancer in untreated patients was relatively low, respectively $0.37 \%, 0.5 \%$, and $0.65 \%$ at 5,10 , and 20 years after diagnosis of $H$. pylori infection. However, the gastric cancer risk was higher in patients of Black (SHR, 2.0) Hispanic (SHR, 1.59) and Asian (SHR, 2.52) race or ethnicity when compared to Caucasian patients. Male sex, older age (SHR, 1.13) and smoking (SHR, 1.39) were additional significant risk factors [218].

One of the limitations of the study was only 8020 of the 28,818 patients $(28 \%)$ who received H. pylori treatment had post treatment testing. Of these, $90.9 \%$ (7292/8020) achieved successful eradication. It was thought that this study could inform future decisions about population based $H$. pylori screening in Western countries with low overall gastric cancer incidence, but higher risk in some demographic subgroups [218]. Post treatment testing to confirm H. pylori eradication in the present era of $H$. pylori clarithromycin and metronidazole resistance is emphasized. This is so the preventative effect of Helicobacter treatment is not diluted in prospective trials [219].

\subsection{H. pylori Eradication, Intestinal Metaplasia and Gastric Cancer}

A more targeted approach in high risk patients before they develop gastric precancerous changes, as compared to population based $H$. pylori eradication may potentially be more efficacious in the prevention of gastric cancer. Early, successful H. pylori eradication may lead to regression of atrophic gastritis but not established intestinal metaplasia $[74,219,220]$. For example, the preventative effect of H. pylori eradication in 1676 H. pylori positive, first degree relatives of Korean patients with gastric cancer was recently reported in a double blind, placebo controlled trial with a median follow-up of 9.2 years. Gastric cancer occurred in 5/608 $(0.8 \%)$ of participants in whom $H$. pylori infection was successfully eradicated and in 28/979 (2.9\%) of participants who had persistent infection (HR, 0.27; $95 \%$ CI, 0.10 to 0.70 ) [221]. The observation that $H$. pylori eradication may not improve the risk of future gastric cancer development after long-term follow up in patients with established IM is supported by the finding that CIMP is reduced by H. pylori eradication in patients with AG and non-IM mucosa, but not in IM. The incidence of CIMP also appears to progress from AG to gastric cancer, in parallel with the histological changes of the Correa pathway [222] (Figure 5). However, the concept of IM being a "point of no return" in the prevention of gastric cancer is still debated, particularly with the recent reporting from the Shandong Intervention trial $[214,223]$.

\subsection{Shandong Intervention Trial}

The Shandong Intervention Trial was a blinded, randomized, placebo controlled gastric cancer prevention trial involving 3365 participants who underwent initial gastroscopy and $H$. pylori serological 
testing [223]. The study was commenced in 1995 and conducted in rural Linqu County, Shandong province, northern China, which has a high incidence of gastric cancer mortality $\left(55 / 10^{5}\right.$ males, $19 / 10^{5}$ females). Linqu county also has a high prevalence of $H$. pylori infection and vitamin C and selenium deficiency. The study evaluated the long-term effect of $H$. pylori eradication (omeprazole and amoxicillin for two weeks), and/or oral $250 \mathrm{mg}$ vitamin C, $100 \mathrm{IU}$ vitamin E, $37.5 \mu \mathrm{g}$ selenium (taken for 7.3 years) and/or garlic supplementation or their placebos (taken for 7.3 years) on gastric cancer development in $2258 \mathrm{H}$. pylori seropositive people in a $2 \times 2 \times 2$ factorial design. This was compared to 1107 H. pylori seronegative people who were given vitamin and/or garlic supplementation or their placebos in a $2 \times 2$ factorial design. Follow-up urea 13C breath testing in 1996 found 382 of the original 2258 seropositive participants $(17 \%)$ had persistent $H$. pylori, and they received a further two weeks of Helicobacter eradication therapy [223].

In 2019, the study group reported their 22.3 year follow-up results, which found H. pylori eradication treatment significantly decreased gastric cancer incidence (OR, 0.48, 95\% CI: 0.32-0.71, $p<0.001)$. Gastric cancer incidence also decreased significantly with vitamin supplementation (OR, 0.64 , 95\% CI: 0.46-0.91, $p=0.01$ ) but not garlic supplementation (OR, 0.81, CI: 0.57-1.13, $p=0.22$ ). All three interventions showed statistically significant reductions in gastric cancer mortality: H. pylori eradication $\mathrm{HR}=0.62$ (95\% CI: 0.39-0.99, $p=0.05$ ), vitamin supplementation HR $=0.48$ (95\% CI: 0.31-0.75, $p=0.001$ ), and garlic supplementation HR $=0.66$ (95\% CI: 0.43 to 1.00, $p=0.05$ ). Hazard ratios were adjusted for baseline histology (moderate chronic atrophic gastritis or less severe gastric lesions, severe chronic atrophic gastritis or superficial intestinal metaplasia, deep intestinal metaplasia, or dysplasia), age, sex, history of ever using alcohol, and history of ever smoking. The beneficial effect of $H$. pylori eradication on gastric cancer incidence and mortality was evident even in older patients (55-71 years), and even in those with intestinal metaplasia and dysplasia at baseline endoscopic assessment. The preventative effect of vitamin supplementation on gastric cancer and gastric cancer mortality was more evident in younger patients ( $<45$ years) or those with more favourable baseline histology (normal, superficial gastritis, chronic atrophic gastritis). Combining vitamin supplementation with $\mathrm{H}$. pylori eradication in seropositive subjects appeared to be synergistic in preventing gastric cancer incidence $\mathrm{OR}=0.30$ (95\% CI: 0.16-0.55) and gastric cancer mortality HR $=0.31$ (95\% CI: 0.15-0.66). The joint effect of garlic administration and $H$. pylori eradication was also greater than the individual effects on gastric cancer incidence $\mathrm{OR}=0.38$ (95\% CI: $0.21-0.69)$, and gastric cancer related mortality $\mathrm{HR}=0.44$ (95\% CI: $0.23-0.84)$ [223].

The finding that a long carcinogen-free period was necessary for regression of premalignant mucosal changes and prevention of cancer progression is supported by mouse studies of gastric cancer and Helicobacter felis, Mongolian gerbil studies of gastric cancer and Helicobacter pylori, and also clinical studies of $H$. pylori eradication. These studies show that early Helicobacter eradication was more effective in gastric cancer prevention, and that prolonged anti-oxidant protection (vitamin $C$, vitamin E, $\beta$-carotene, selenium) without cessation was required after initial Helicobacter eradication [134,223]. The progression of intestinal metaplasia to dysplasia in the stomach appears to be faster in older patients ( $>40$ years) than in younger patients ( 4.0 per 100 patient years vs. 2.1/100 patient years, respectively). Correa described the fall in risk of development of gastric cancer after removal of the major carcinogen (H. pylori) followed a sigmoid quadratic curve, and paralleled in reverse the progressive Correa pathway of gastric carcinogenesis [134].

\section{Conclusions}

Gastric carcinogenesis is a multifactorial and multistep process involving genetic susceptibility, environmental factors, H. pylori bacterial and Epstein Barr virus infection and epigenetics. Antioxidant systems and ingested phytochemicals can provide cytoprotection for the gastric epithelium against oxidative stress, ingested carcinogens, mutagens and chronic Helicobacter pylori infection. Ascorbic acid may be protective against gastric cancer through its antioxidant effect, by regenerating active vitamin $\mathrm{E}$ and glutathione, inhibiting endogenous $\mathrm{N}$-nitrosation, reducing the somatic mutagenic effects of 
ingested nitrites, nitrosamines and heterocyclic amines, inhibiting damage from ROS and preventing H. pylori infection (or re-infection following eradication). Ascorbic acid is also an important co-factor in the demethylation of DNA suppressor genes.

It may be possible to prevent the progression of chronic atrophic gastritis and intestinal metaplasia to gastric cancer by Helicobacter eradication, risk reduction and gastric cytoprotection. The "point of no return" in Helicobacter pylori related gastric intestinal metaplasia may be important in the timing of H. pylori eradication programs in high risk groups. The effectiveness of gastric cytoprotection is closely related to the virulence of $H$. pylori strains, particularly CagA subtypes. Both intestinal and diffuse subtypes of gastric cancer share risk factors including $H$. pylori gastritis, blood group A, smoking and alchohol consumption. However, genetics (e.g., $C D H 1$ germline mutations) and female sex are important in diffuse gastric cancer. Recent transcriptomic and proteomic analysis has demonstrated that gastric cancer is a complex, heterogeneous disease, with substantial intra-tumoural, intra-patient and inter-patient variability. Eradication of H. pylori may lead to recovery of Vitamin C secretion by gastric epithelium and enable regression of premalignant gastric lesions, thereby interrupting the Correa pathway of gastric carcinogenesis.

Box 1. Summary of Vitamin C actions in prevention of gastric carcinogenesis.

- $\quad$ Scavenging of superoxide anion radical $\left(\mathrm{O}_{2}^{-} \cdot\right)$, singlet oxygen $\left(\mathrm{O}_{2}\right)$, hydroxyl radical $(\mathrm{OH} \cdot)$

- Regeneration of vitamin $\mathrm{E}$ and glutathione

- Inhibition of lipid peroxidation in conjunction with catechins

- $\quad$ Enhanced activity of HIF- $\alpha$ Prolyl hydroxylase

- $\quad$ Enhanced activity of $\alpha$-KGDD TET DNA hydroxylases

- $\quad$ Enhanced activity of JHDMs

- $\quad$ Decreased DNA CPG hypermethylation (CIMP)

- Upregulation of transmembrane protein with epidermal growth factor (EGF)-like and two follistatin motifs 2 (TMEFF2)

- Inhibition of endogenous gastric N-nitrosation

- $\quad$ Reduced toxicity of ingested heterocyclic amines/NDMA

- Inhibition of $H$. pylori urease

- Inhibition of $H$. pylori colonization

- Improved H. pylori eradication rates

- Inhibition of H. pylori mediated activation of NF-kB and STAT3

- Increased synthesis of PGE2 and gastric mucus production.

Author Contributions: Conceptualization, R.B.W.; methodology, R.B.W. and J.W.T.T.; software, J.W.T.T.; validation, R.B.W.; formal analysis, R.B.W.; investigation, R.B.W. and J.W.T.T.; resources, R.B.W.; writing-original draft preparation, R.B.W. and J.W.T.T.; writing-review and editing, R.B.W. and J.W.T.T.; visualization, R.B.W.; project administration, R.B.W.; funding acquisition, R.B.W. All authors have read and agreed to the published version of the manuscript.

Funding: This research received no external funding.

Acknowledgments: The authors would like to acknowledge the illustrations by Emoka Bailey.

Conflicts of Interest: The authors declare no conflict of interest.

\section{Abbreviations}

$\begin{array}{ll}\text { 5-FU } & 5 \text {-fluorouracil } \\ \alpha \text {-KGDDs } & \alpha \text {-ketoglutarate-dependent dioxygenases } \\ \text { AG } & \text { Atrophic gastritis } \\ \text { AGE } & \text { Advanced glycation end product } \\ \text { AGS } & \text { Human gastric adenocarcinoma hyperdiploid cell line } \\ \text { ALDH2 } & \text { Aldehyde Dehydrogenase 2 Family Member } \\ \text { ALE } & \text { Advanced lipid peroxidation end product }\end{array}$




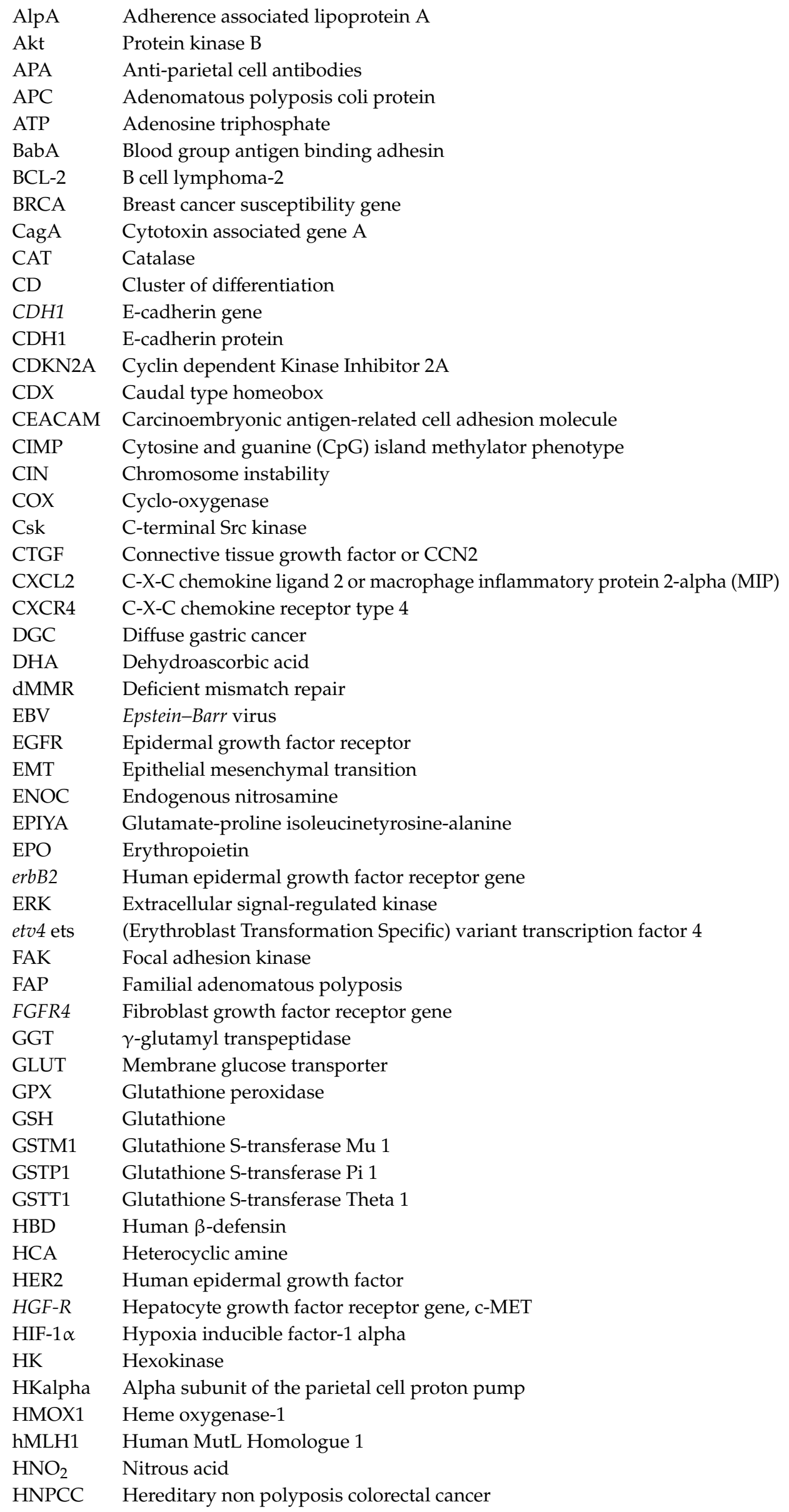




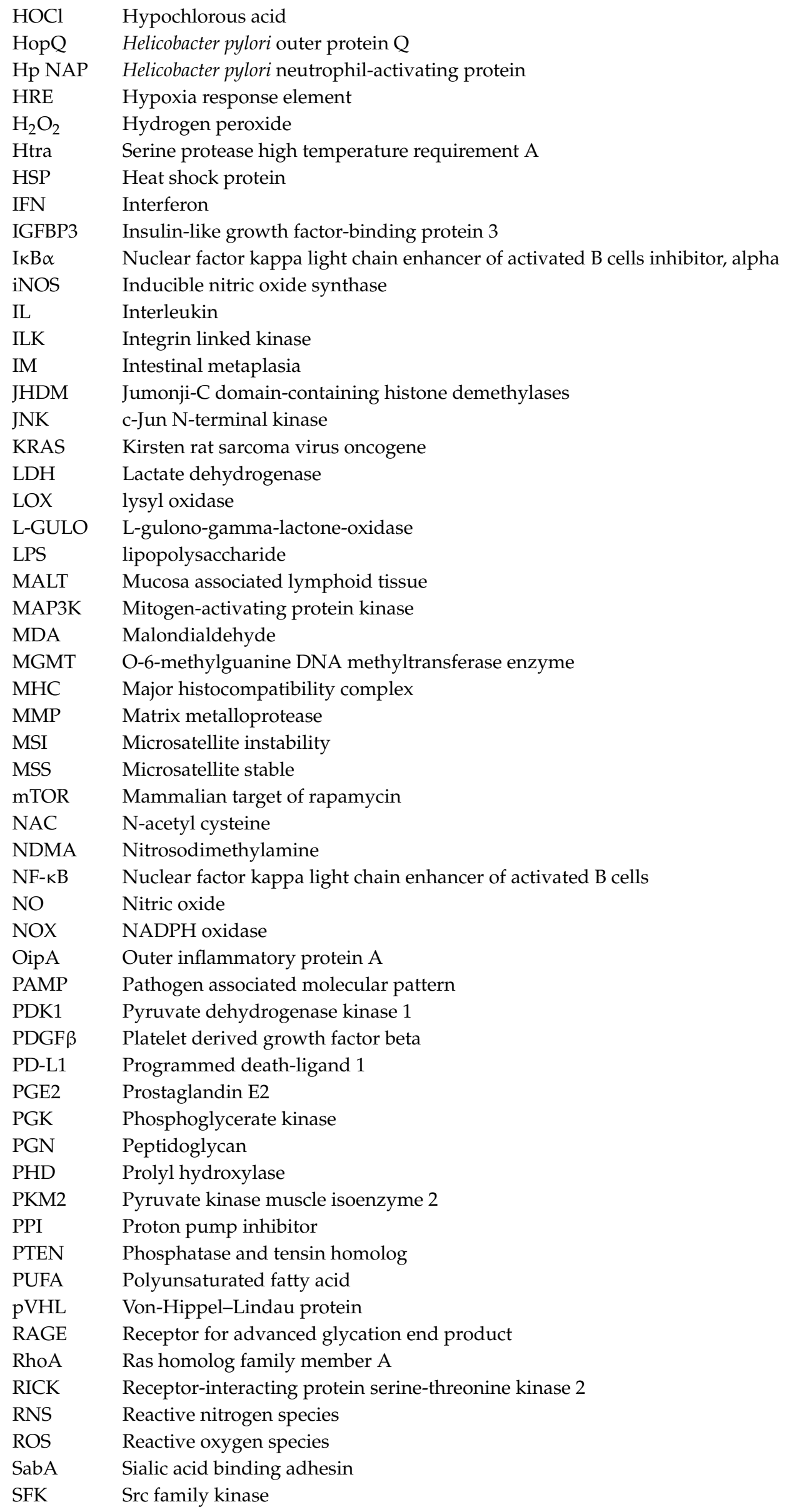




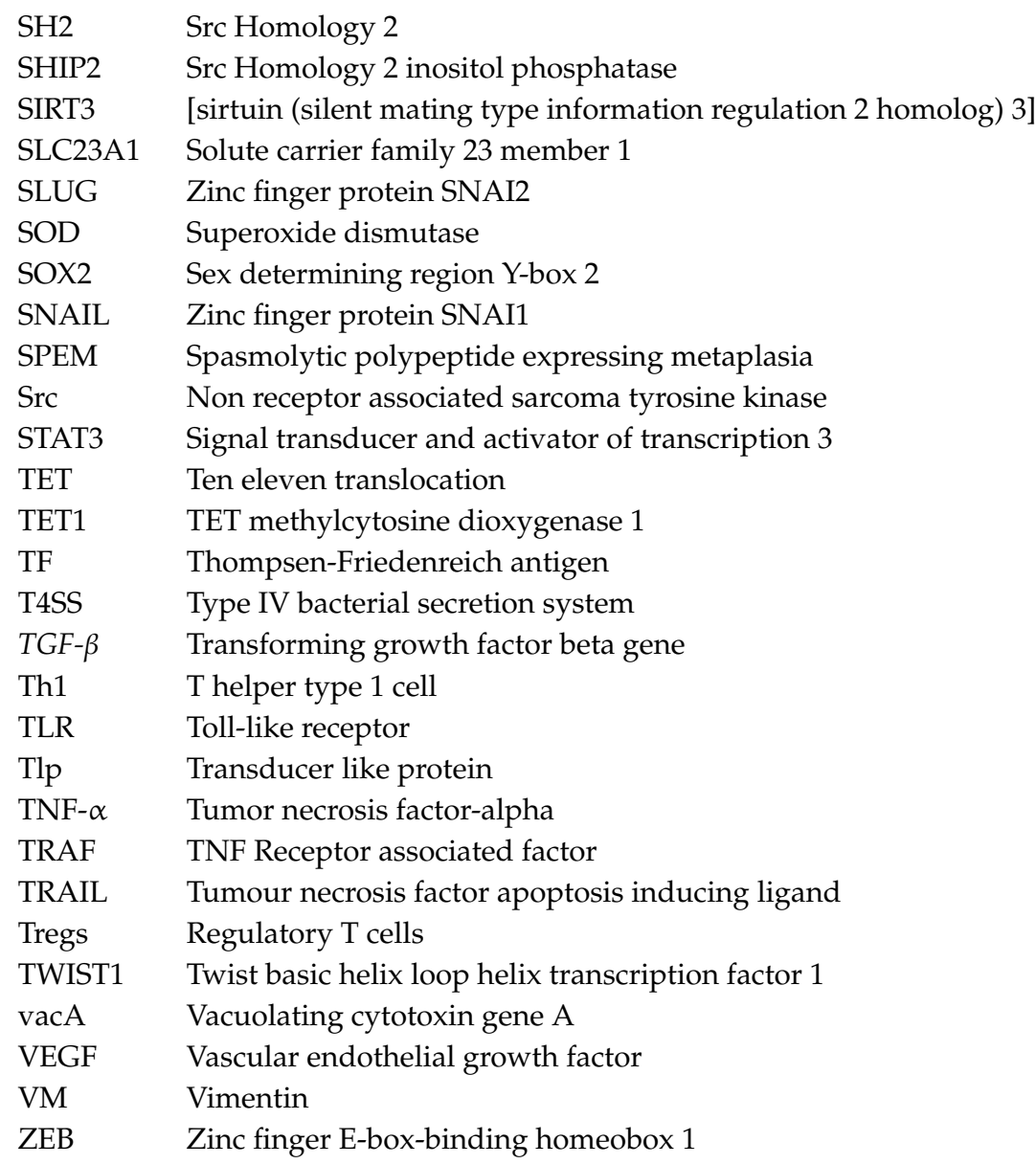

\section{References}

1. Bray, F.; Ferlay, J.; Soerjomataram, I.; Siegel, R.L.; Torre, L.A.; Jemal, A. Global cancer statistics 2018: GLOBOCAN estimates of incidence and mortality worldwide for 36 cancers in 185 countries. CA A Cancer J. Clin. 2018, 68, 394-424. [CrossRef]

2. Parkin, D.M.; Bray, F.; Ferlay, J.; Pisani, P. Global cancer statistics, 2002. CA A Cancer J. Clin. 2005, 55, 74-108. [CrossRef] [PubMed]

3. Jemal, A.; Bray, F.; Center, M.M.; Ferlay, J.; Ward, E.; Forman, D. Global cancer statistics. CA A Cancer J. Clin. 2011, 61, 69-90. [CrossRef] [PubMed]

4. Wu, J.Y.; Lee, Y.C.; Graham, D.Y. The eradication of Helicobacter pylori to prevent gastric cancer: A critical appraisal. Expert Rev. Gastroenterol. Hepatol. 2019, 13, 17-24. [CrossRef] [PubMed]

5. Machlowska, J.; Baj, J.; Sitarz, M.; Maciejewski, R.; Sitarz, R. Gastric Cancer: Epidemiology, Risk Factors, Classification, Genomic Characteristics and Treatment Strategies. Int. J. Mol. Sci. 2020, 21, 4012. [CrossRef] [PubMed]

6. Park, Y.H.; Kim, N. Review of atrophic gastritis and intestinal metaplasia as a premalignant lesion of gastric cancer. J. Cancer Prev. 2015, 20, 25-40. [CrossRef] [PubMed]

7. Schistosomes, Liver Flukes and Helicobacter Pylori. IARC Working Group on the Evaluation of Carcinogenic Risks to Humans. Lyon, 7-14 June 1994. Int. Agency Res. Cancer 1994, 61, 1-241.

8. Correa, P. Human gastric carcinogenesis: A multistep and multifactorial process-First American Cancer Society Award Lecture on Cancer Epidemiology and Prevention. Cancer Res. 1992, 52, 6735-6740.

9. Jencks, D.S.; Adam, J.D.; Borum, M.L.; Koh, J.M.; Stephen, S.; Doman, D.B. Overview of Current Concepts in Gastric Intestinal Metaplasia and Gastric Cancer. Gastroenterol. Hepatol. (N. Y.) 2018, 14, 92-101.

10. Kinoshita, H.; Hayakawa, Y.; Koike, K. Metaplasia in the Stomach-Precursor of Gastric Cancer? Int. J. Mol. Sci. 2017, 18, 2063. [CrossRef] 
11. Banks, M.; Graham, D.; Jansen, M.; Gotoda, T.; Coda, S.; di Pietro, M.; Uedo, N.; Bhandari, P.; Pritchard, D.M.; Kuipers, E.J.; et al. British Society of Gastroenterology guidelines on the diagnosis and management of patients at risk of gastric adenocarcinoma. Gut 2019, 68, 1545-1575. [CrossRef] [PubMed]

12. Ansari, S.; Gantuya, B.; Tuan, V.P.; Yamaoka, Y. Diffuse Gastric Cancer: A Summary of Analogous Contributing Factors for Its Molecular Pathogenicity. Int. J. Mol. Sci. 2018, 19, 2424. [CrossRef] [PubMed]

13. Lee, H.E.; Smyrk, T.C.; Zhang, L. Histologic and immunohistochemical differences between hereditary and sporadic diffuse gastric carcinoma. Hum. Pathol. 2018, 74, 64-72. [CrossRef]

14. Compare, D.; Rocco, A.; Nardone, G. Risk factors in gastric cancer. Eur. Rev. Med. Pharmacol. Sci. 2010, 14, 302-308.

15. Rawla, P.; Barsouk, A. Epidemiology of gastric cancer: Global trends, risk factors and prevention. Prz. Gastroenterol. 2019, 14, 26-38. [CrossRef] [PubMed]

16. Reed, P.I. Vitamin C Helicobacter pylori infection and gastric carcinogenesis. Int. J. Vitam. Nutr. Res. 1999, 69, 220-227. [CrossRef] [PubMed]

17. Nouraie, M.; Pietinen, P.; Kamangar, F.; Dawsey, S.M.; Abnet, C.C.; Albanes, D.; Virtamo, J.; Taylor, P.R. Fruits, vegetables, and antioxidants and risk of gastric cancer among male smokers. Cancer Epidemiol. Biomark. Prev. 2005, 14, 2087-2092. [CrossRef]

18. Hoang, B.V.; Lee, J.; Choi, I.J.; Kim, Y.W.; Ryu, K.W.; Kim, J. Effect of dietary vitamin C on gastric cancer risk in the Korean population. World J. Gastroenterol. WJG 2016, 22, 6257-6267. [CrossRef]

19. Moss, S.F. The Clinical Evidence Linking Helicobacter pylori to Gastric Cancer. Cell. Mol. Gastroenterol. Hepatol. 2017, 3, 183-191. [CrossRef]

20. Forman, D. Gastric cancer and Helicobacter pylori: A combined analysis of 12 case control studies nested within prospective cohorts. Gut 2001, 49, 347-353.

21. Ma, J.; Shen, H.; Kapesa, L.; Zeng, S. Lauren classification and individualized chemotherapy in gastric cancer. Oncol. Lett. 2016, 11, 2959-2964. [CrossRef] [PubMed]

22. Nishikawa, J.; Iizasa, H.; Yoshiyama, H.; Shimokuri, K.; Kobayashi, Y.; Sasaki, S.; Nakamura, M.; Yanai, H.; Sakai, K.; Suehiro, Y.; et al. Clinical Importance of Epstein-Barr Virus-Associated Gastric Cancer. Cancers 2018, 10, 167. [CrossRef] [PubMed]

23. Tavera, G.; Morgan, D.R.; Williams, S.M. Tipping the Scale toward Gastric Disease: A Host-Pathogen Genomic Mismatch? Curr. Genet. Med. Rep. 2018, 6, 199-207. [CrossRef] [PubMed]

24. Ho, S.W.T.; Tan, P. Dissection of gastric cancer heterogeneity for precision oncology. Cancer Sci. 2019, 110, 3405-3414. [CrossRef]

25. Lott, P.C.; Carvajal-Carmona, L.G. Resolving gastric cancer aetiology: An update in genetic predisposition. Lancet Gastroenterol. Hepatol. 2018, 3, 874-883. [CrossRef]

26. Nagini, S. Carcinoma of the stomach: A review of epidemiology, pathogenesis, molecular genetics and chemoprevention. World J. Gastrointest. Oncol. 2012, 4, 156-169. [CrossRef]

27. Wang, Q.; Liu, G.; Hu, C. Molecular Classification of Gastric Adenocarcinoma. Gastroenterol. Res. 2019, 12, 275-282. [CrossRef]

28. Avila, F.; Theoduloz, C.; Lopez-Alarcon, C.; Dorta, E.; Schmeda-Hirschmann, G. Cytoprotective Mechanisms Mediated by Polyphenols from Chilean Native Berries against Free Radical-Induced Damage on AGS Cells. Oxidative Med. Cell. Longev. 2017, 2017, 9808520. [CrossRef]

29. Kanner, J.; Selhub, J.; Shpaizer, A.; Rabkin, B.; Shacham, I.; Tirosh, O. Redox homeostasis in stomach medium by foods: The Postprandial Oxidative Stress Index (POSI) for balancing nutrition and human health. Redox Biol. 2017, 12, 929-936. [CrossRef]

30. Aggarwal, V.; Tuli, H.S.; Varol, A.; Thakral, F.; Yerer, M.B.; Sak, K.; Varol, M.; Jain, A.; Khan, M.A.; Sethi, G. Role of Reactive Oxygen Species in Cancer Progression: Molecular Mechanisms and Recent Advancements. Biomolecules 2019, 9, 735. [CrossRef]

31. Everett, S.M.; Singh, R.; Leuratti, C.; White, K.L.; Neville, P.; Greenwood, D.; Marnett, L.J.; Schorah, C.J.; Forman, D.; Shuker, D.; et al. Levels of malondialdehyde-deoxyguanosine in the gastric mucosa: Relationship with lipid peroxidation, ascorbic acid, and Helicobacter pylori. Cancer Epidemiol. Biomark. Prev. 2001, 10, 369-376.

32. Deng, R.; Mo, F.; Chang, B.; Zhang, Q.; Ran, H.; Yang, S.; Zhu, Z.; Hu, L.; Su, Q. Glucose-derived AGEs enhance human gastric cancer metastasis through RAGE/ERK/Sp1/MMP2 cascade. Oncotarget 2017, 8, 104216-104226. [CrossRef] [PubMed] 
33. Zoidis, E.; Seremelis, I.; Kontopoulos, N.; Danezis, G.P. Selenium-Dependent Antioxidant Enzymes: Actions and Properties of Selenoproteins. Antioxidants 2018, 7, 66. [CrossRef] [PubMed]

34. Pasupathi, P.; Saravanan, G.; Chinnaswamy, P.; Bakthavathsalam, G. Effect of chronic smoking on lipid peroxidation and antioxidant status in gastric carcinoma patients. Indian J. Gastroenterol. Off. J. Indian Soc. Gastroenterol. 2009, 28, 65-67. [CrossRef]

35. Abotaleb, M.; Liskova, A.; Kubatka, P.; Büsselberg, D. Therapeutic Potential of Plant Phenolic Acids in the Treatment of Cancer. Biomolecules 2020, 10, 221. [CrossRef]

36. Carr, A.C.; Vissers, M.C. Synthetic or food-derived vitamin C-Are they equally bioavailable? Nutrients 2013, 5, 4284-4304. [CrossRef]

37. Kamiya, Y.; Ohta, Y.; Imai, Y.; Arisawa, T.; Nakano, H. A critical role of gastric mucosal ascorbic acid in the progression of acute gastric mucosal lesions induced by compound 48/80 in rats. World J. Gastroenterol. WJG 2005, 11, 1324-1332. [CrossRef]

38. Blaszczak, W.; Barczak, W.; Masternak, J.; Kopczyński, P.; Zhitkovich, A.; Rubiś, B. Vitamin C as a Modulator of the Response to Cancer Therapy. Molecules 2019, 24, 453. [CrossRef]

39. Carr, A.; Frei, B. Does vitamin C act as a pro-oxidant under physiological conditions? FASEB J. Off. Publ. Fed. Am. Soc. Exp. Biol. 1999, 13, 1007-1024. [CrossRef]

40. Cui, J.; Pan, Y.H.; Zhang, Y.; Jones, G.; Zhang, S. Progressive pseudogenization: Vitamin C synthesis and its loss in bats. Mol. Biol. Evol. 2011, 28, 1025-1031. [CrossRef]

41. Aditi, A.; Graham, D.Y. Vitamin C, gastritis, and gastric disease: A historical review and update. Dig. Dis. Sci. 2012, 57, 2504-2515. [CrossRef] [PubMed]

42. Tuo, B.G.; Yan, Y.H.; Ge, Z.L.; Ou, G.W.; Zhao, K. Ascorbic acid secretion in the human stomach and the effect of gastrin. World J. Gastroenterol. WJG 2000, 6, 704-708. [CrossRef] [PubMed]

43. Wohlrab, C.; Phillips, E.; Dachs, G.U. Vitamin C Transporters in Cancer: Current Understanding and Gaps in Knowledge. Front. Oncol. 2017, 7, 74. [CrossRef] [PubMed]

44. Rood, J.C.; Ruiz, B.; Fontham, E.T.; Malcom, G.T.; Hunter, F.M.; Sobhan, M.; Johnson, W.D.; Correa, P. Helicobacter pylori-associated gastritis and the ascorbic acid concentration in gastric juice. Nutr. Cancer 1994, 22, 65-72. [CrossRef]

45. Grollman, A.P.; Lehninger, A.L. Enzymic synthesis of L-ascorbic acid in different animal species. Arch. Biochem. Biophys. 1957, 69, 458-467. [CrossRef]

46. Drouin, G.; Godin, J.R.; Page, B. The genetics of vitamin C loss in vertebrates. Curr. Genom. 2011, 12, 371-378. [CrossRef]

47. Tsujii, M.; Kawano, S.; Tsuji, S.; Fusamoto, H.; Kamada, T.; Sato, N. Mechanism of gastric mucosal damage induced by ammonia. Gastroenterology 1992, 102, 1881-1888. [CrossRef]

48. Valenzuela-Valderrama, M.; Cerda-Opazo, P.; Backert, S.; González, M.F.; Carrasco-Véliz, N.; Jorquera-Cordero, C.; Wehinger, S.; Canales, J.; Bravo, D.; Quest, A.F.G. The Helicobacter pylori Urease Virulence Factor Is Required for the Induction of Hypoxia-Induced Factor- $1 \alpha$ in Gastric Cells. Cancers 2019, 11, 799. [CrossRef]

49. Wen, Y.; Scott, D.R.; Vagin, O.; Tokhtaeva, E.; Marcus, E.A.; Sachs, G. Measurement of Internal pH in Helicobacter pylori by Using Green Fluorescent Protein Fluorimetry. J. Bacteriol. 2018, 200. [CrossRef]

50. Scott, D.R.; Marcus, E.A.; Wen, Y.; Singh, S.; Feng, J.; Sachs, G. Cytoplasmic histidine kinase (HP0244)-regulated assembly of urease with UreI, a channel for urea and its metabolites, CO2, NH3, and NH4(+), is necessary for acid survival of Helicobacter pylori. J. Bacteriol. 2010, 192, 94-103. [CrossRef]

51. Stingl, K.; Uhlemann, E.M.; Schmid, R.; Altendorf, K.; Bakker, E.P. Energetics of Helicobacter pylori and its implications for the mechanism of urease-dependent acid tolerance at $\mathrm{pH}$ 1. J. Bacteriol. 2002, 184, 3053-3060. [CrossRef] [PubMed]

52. McGee, D.J.; Zabaleta, J.; Viator, R.J.; Testerman, T.L.; Ochoa, A.C.; Mendz, G.L. Purification and characterization of Helicobacter pylori arginase, RocF: Unique features among the arginase superfamily. Eur. J. Biochem. 2004, 271, 1952-1962. [CrossRef] [PubMed]

53. Schoep, T.D.; Fulurija, A.; Good, F.; Lu, W.; Himbeck, R.P.; Schwan, C.; Choi, S.S.; Berg, D.E.; Mittl, P.R.; Benghezal, M.; et al. Surface properties of Helicobacter pylori urease complex are essential for persistence. PLoS ONE 2010, 5, e15042. [CrossRef] [PubMed]

54. Beil, W.; Sewing, K.F.; Busche, R.; Wagner, S. Helicobacter pylori augments the acid inhibitory effect of omeprazole on parietal cells and gastric $\mathrm{H}(+) / \mathrm{K}(+)$-ATPase. Gut 2001, 48, 157-162. [CrossRef] [PubMed] 
55. Waldum, H.L.; Kleveland, P.M.; Sørdal, Ø.F. Helicobacter pylori and gastric acid: An intimate and reciprocal relationship. Ther. Adv. Gastroenterol. 2016, 9, 836-844. [CrossRef]

56. Yao, X.; Smolka, A.J. Gastric Parietal Cell Physiology and Helicobacter pylori-Induced Disease. Gastroenterology 2019, 156, 2158-2173. [CrossRef]

57. Bockerstett, K.A.; Osaki, L.H.; Petersen, C.P.; Cai, C.W.; Wong, C.F.; Nguyen, T.M.; Ford, E.L.; Hoft, D.F.; Mills, J.C.; Goldenring, J.R.; et al. Interleukin-17A Promotes Parietal Cell Atrophy by Inducing Apoptosis. Cell. Mol. Gastroenterol. Hepatol. 2018, 5, 678-690.e1. [CrossRef]

58. Ling, S.S.; Khoo, L.H.; Hwang, L.A.; Yeoh, K.G.; Ho, B. Instrumental Role of Helicobacter pylori gamma-Glutamyl Transpeptidase in VacA-Dependent Vacuolation in Gastric Epithelial Cells. PLoS ONE 2015, 10, e0131460. [CrossRef]

59. Keilberg, D.; Ottemann, K.M. How Helicobacter pylori senses, targets and interacts with the gastric epithelium. Environ. Microbiol. 2016, 18, 791-806. [CrossRef]

60. Haley, K.P.; Gaddy, J.A. Nutrition and Helicobacter pylori: Host Diet and Nutritional Immunity Influence Bacterial Virulence and Disease Outcome. Gastroenterol. Res. Pract. 2016, 2016, 3019362. [CrossRef]

61. Machuca, M.A.; Johnson, K.S.; Liu, Y.C.; Steer, D.L.; Ottemann, K.M.; Roujeinikova, A. Helicobacter pylori chemoreceptor TlpC mediates chemotaxis to lactate. Sci. Rep. 2017, 7, 14089. [CrossRef] [PubMed]

62. Perkins, A.; Tudorica, D.A.; Amieva, M.R.; Remington, S.J.; Guillemin, K. Helicobacter pylori senses bleach $(\mathrm{HOCl})$ as a chemoattractant using a cytosolic chemoreceptor. PLoS Biol. 2019, 17, e3000395. [CrossRef] [PubMed]

63. Huang, J.Y.; Goers Sweeney, E.; Guillemin, K.; Amieva, M.R. Multiple Acid Sensors Control Helicobacter pylori Colonization of the Stomach. PLoS Pathog. 2017, 13, e1006118. [CrossRef] [PubMed]

64. Schreiber, S.; Konradt, M.; Groll, C.; Scheid, P.; Hanauer, G.; Werling, H.O.; Josenhans, C.; Suerbaum, S. The spatial orientation of Helicobacter pylori in the gastric mucus. Proc. Natl. Acad. Sci. USA 2004, 101, 5024-5029. [CrossRef]

65. Wilson, R.B. Hypoxia, cytokines and stromal recruitment: Parallels between pathophysiology of encapsulating peritoneal sclerosis, endometriosis and peritoneal metastasis. Pleura Peritoneum. 2018, 3, 20180103. [CrossRef]

66. Marshall, B.J. One Hundred Years of Discovery and Rediscovery of Helicobacter pylori and Its Association with Peptic Ulcer Disease. In Helicobacter Pylori: Physiology and Genetics; Mobley, H.L.T., Mendz, G.L., Hazell, S.L., Eds.; ASM Press: Washington, DC, USA, 2001.

67. Uemura, N.; Okamoto, S.; Yamamoto, S.; Matsumura, N.; Yamaguchi, S.; Yamakido, M.; Taniyama, K.; Sasaki, N.; Schlemper, R.J. Helicobacter pylori infection and the development of gastric cancer. N. Engl. J. Med. 2001, 345, 784-789. [CrossRef]

68. Furuta, T.; El-Omar, E.M.; Xiao, F.; Shirai, N.; Takashima, M.; Sugimura, H. Interleukin $1 \beta$ polymorphisms increase risk of hypochlorhydria and atrophic gastritis and reduce risk of duodenal ulcer recurrence in Japan. Gastroenterology 2002, 123, 92-105. [CrossRef]

69. Bang, C.S.; Lee, J.J.; Baik, G.H. Prediction of Chronic Atrophic Gastritis and Gastric Neoplasms by Serum Pepsinogen Assay: A Systematic Review and Meta-Analysis of Diagnostic Test Accuracy. J. Clin. Med. 2019, 8, 657. [CrossRef]

70. Eslick, G.D. Helicobacter pylori infection causes gastric cancer? A review of the epidemiological, meta-analytic, and experimental evidence. World J. Gastroenterol. WJG 2006, 12, 2991-2999. [CrossRef]

71. Gonzalez, C.A.; Megraud, F.; Buissonniere, A.; Lujan Barroso, L.; Agudo, A.; Duell, E.J.; Boutron-Ruault, M.C.; Clavel-Chapelon, F.; Palli, D.; Krogh, V.; et al. Helicobacter pylori infection assessed by ELISA and by immunoblot and noncardia gastric cancer risk in a prospective study: The Eurgast-EPIC project. Ann. Oncol. Off. J. Eur. Soc. Med. Oncol. ESMO 2012, 23, 1320-1324. [CrossRef]

72. Kim, S.S.; Ruiz, V.E.; Carroll, J.D.; Moss, S.F. Helicobacter pylori in the pathogenesis of gastric cancer and gastric lymphoma. Cancer Lett. 2011, 305, 228-238. [CrossRef] [PubMed]

73. Jain, A.; Kaczanowska, S.; Davila, E. IL-1 Receptor-Associated Kinase Signaling and Its Role in Inflammation, Cancer Progression, and Therapy Resistance. Front. Immunol. 2014, 5, 553. [CrossRef]

74. Peleteiro, B.; Lunet, N. Gastritis and Gastric Cancer-New Insights into Gastroprotection, Diagnosis and Treatment; Tonino, P., Ed.; InTech: London, UK, 2011. Available online: https://www.researchgate.net/publication/2593914 26_Gastritis_and_Gastric_Cancer_-_New_Insights_in_Gastroprotection_Diagnosis_and_Treatments_Edited _by_Paola_Tonino_ISBN_978-953-307-375-0_296_pages_Publisher_InTech_Chapters_published_September_ 15_2011_u (accessed on 8 February 2020). 
75. Youn, H.S.; Ko, G.H.; Chung, M.H.; Lee, W.K.; Cho, M.J.; Rhee, K.H. Pathogenesis and prevention of stomach cancer. J. Korean Med. Sci. 1996, 11, 373-385. [CrossRef] [PubMed]

76. Knaapen, A.M.; Güngör, N.; Schins, R.P.; Borm, P.J.; Van Schooten, F.J. Neutrophils and respiratory tract DNA damage and mutagenesis: A review. Mutagenesis 2006, 21, 225-236. [CrossRef] [PubMed]

77. Marcus, E.A.; Sachs, G.; Scott, D.R. Acid-regulated gene expression of Helicobacter pylori: Insight into acid protection and gastric colonization. Helicobacter 2018, 23, e12490. [CrossRef] [PubMed]

78. Li, H.; Yang, T.; Liao, T.; Debowski, A.W.; Nilsson, H.O.; Fulurija, A.; Haslam, S.M.; Mulloy, B.; Dell, A.; Stubbs, K.A.; et al. The redefinition of Helicobacter pylori lipopolysaccharide O-antigen and core-oligosaccharide domains. PLoS Pathog. 2017, 13, e1006280. [CrossRef]

79. Allison, C.C.; Ferrero, R.L. Role of virulence factors and host cell signaling in the recognition of Helicobacter pylori and the generation of immune responses. Future Microbiol. 2010, 5, 1233-1255. [CrossRef]

80. Yao, Y.; Tao, H.; Park, D.I.; Sepulveda, J.L.; Sepulveda, A.R. Demonstration and characterization of mutations induced by Helicobacter pylori organisms in gastric epithelial cells. Helicobacter 2006, 11, 272-286. [CrossRef]

81. Wang, Y.K.; Chiang, W.C.; Kuo, F.C.; Wu, M.C.; Shih, H.Y.; Wang, S.S.W.; Liu, C.J.; Chen, Y.H.; Wu, D.C.; $\mathrm{Su}, \mathrm{W} . W . ;$ et al. Levels of malondialdehyde in the gastric juice: Its association with Helicobacter pylori infection and stomach diseases. Helicobacter 2018, 23, e12460. [CrossRef]

82. Ding, S.Z.; Goldberg, J.B.; Hatakeyama, M. Helicobacter pylori infection, oncogenic pathways and epigenetic mechanisms in gastric carcinogenesis. Future Oncol. 2010, 6, 851-862. [CrossRef]

83. Muhammad, J.S.; Eladl, M.A.; Khoder, G. Helicobacter pylori-induced DNA Methylation as an Epigenetic Modulator of Gastric Cancer: Recent Outcomes and Future Direction. Pathogens 2019, 8, 23. [CrossRef] [PubMed]

84. Han, H.; Xu, J.; Ji, W.; Wang, L.; Wang, A. Upregulation of TMEFF2 is involved in the antiproliferative effects of vitamin C and tyrphostin AG490 on GES-1 and AGS cells. Oncol. Lett. 2019, 17, 652-659. [CrossRef] [PubMed]

85. Park, Y.; Lee, H.; Lim, J.W.; Kim, H. Inhibitory Effect of $\beta$-Carotene on Helicobacter pylori-Induced TRAF Expression and Hyper-Proliferation in Gastric Epithelial Cells. Antioxidants 2019, 8, 637. [CrossRef] [PubMed]

86. da Costa, D.M.; Pereira Edos, S.; Rabenhorst, S.H. What exists beyond cagA and vacA? Helicobacter pylori genes in gastric diseases. World J. Gastroenterol. WJG 2015, 21, 10563-10572. [CrossRef]

87. Chang, C.C.; Kuo, W.S.; Chen, Y.C.; Perng, C.L.; Lin, H.J.; Ou, Y.H. Fragmentation of CagA Reduces Hummingbird Phenotype Induction by Helicobactor pylori. PLOS ONE 2016, 11, e0150061. [CrossRef]

88. Vaziri, F.; Peerayeh, S.N.; Alebouyeh, M.; Maghsoudi, N.; Azimzadeh, P.; Siadat, S.D.; Zali, M.R. Novel effects of Helicobacter pylori CagA on key genes of gastric cancer signal transduction: A comparative transfection study. Pathog. Dis. 2015, 73. [CrossRef]

89. Roebuck, K.A. Regulation of interleukin-8 gene expression. J. Interferon Cytokine Res. Off. J. Int. Soc. Interferon Cytokine Res. 1999, 19, 429-438. [CrossRef]

90. Tegtmeyer, N.; Wessler, S.; Necchi, V.; Rohde, M.; Harrer, A.; Rau, T.T.; Asche, C.I.; Boehm, M.; Loessner, H.; Figueiredo, C.; et al. Helicobacter pylori Employs a Unique Basolateral Type IV Secretion Mechanism for CagA Delivery. Cell Host. Microbe 2017, 22, 552-560.e5. [CrossRef]

91. Pero, R.; Coretti, L.; Nigro, E.; Lembo, F.; Laneri, S.; Lombardo, B.; Daniele, A.; Scudiero, O. $\beta$-Defensins in the Fight against Helicobacter pylori. Molecules 2017, 22, 424. [CrossRef]

92. Vergara, D.; Simeone, P.; Damato, M.; Maffia, M.; Lanuti, P.; Trerotola, M. The Cancer Microbiota: EMT and Inflammation as Shared Molecular Mechanisms Associated with Plasticity and Progression. J. Oncol. 2019, 2019, 1253727. [CrossRef]

93. Schneider, B.G.; Peng, D.F.; Camargo, M.C.; Piazuelo, M.B.; Sicinschi, L.A.; Mera, R.; Romero-Gallo, J.; Delgado, A.G.; Bravo, L.E.; Wilson, K.T.; et al. Promoter DNA hypermethylation in gastric biopsies from subjects at high and low risk for gastric cancer. Int. J. Cancer 2010, 127, 2588-2597. [CrossRef] [PubMed]

94. Chan, A.O.; Peng, J.Z.; Lam, S.K.; Lai, K.C.; Yuen, M.F.; Cheung, H.K.; Kwong, Y.L.; Rashid, A.; Chan, C.K.; Wong, B.C. Eradication of Helicobacter pylori infection reverses E-cadherin promoter hypermethylation. Gut 2006, 55, 463-468. [CrossRef] [PubMed]

95. Zhang, B.; Zhang, X.; Jin, M.; Hu, L.; Zang, M.; Qiu, W.; Wang, S.; Liu, B.; Liu, S.; Guo, D. CagA increases DNA methylation and decreases PTEN expression in human gastric cancer. Mol. Med. Rep. 2019, 19, 309-319. [CrossRef] [PubMed] 
96. Starczak, M.; Zarakowska, E.; Modrzejewska, M.; Dziaman, T.; Szpila, A.; Linowiecka, K.; Guz, J.; Szpotan, J.; Gawronski, M.; Labejszo, A.; et al. In vivo evidence of ascorbate involvement in the generation of epigenetic DNA modifications in leukocytes from patients with colorectal carcinoma, benign adenoma and inflammatory bowel disease. J. Transl. Med. 2018, 16, 204. [CrossRef]

97. Pawlowska, E.; Szczepanska, J.; Blasiak, J. Pro- and Antioxidant Effects of Vitamin C in Cancer in correspondence to Its Dietary and Pharmacological Concentrations. Oxidative Med. Cell. Longev. 2019, 2019, 7286737. [CrossRef]

98. Lee Chong, T.; Ahearn, E.L.; Cimmino, L. Reprogramming the Epigenome With Vitamin C. Front. Cell Dev. Biol. 2019, 7, 128. [CrossRef]

99. Zeng, X.Q.; Wang, J.; Chen, S.Y. Methylation modification in gastric cancer and approaches to targeted epigenetic therapy (Review). Int. J. Oncol. 2017, 50, 1921-1933. [CrossRef]

100. Chichirau, B.E.; Diechler, S.; Posselt, G.; Wessler, S. Tyrosine Kinases in Helicobacter pylori Infections and Gastric Cancer. Toxins 2019, 11, 591. [CrossRef]

101. Takahashi-Kanemitsu, A.; Knight, C.T.; Hatakeyama, M. Molecular anatomy and pathogenic actions of Helicobacter pylori CagA that underpin gastric carcinogenesis. Cell. Mol. Immunol. 2020, 17, 50-63. [CrossRef]

102. Shi, J.; Qu, Y.P.; Hou, P. Pathogenetic mechanisms in gastric cancer. World J. Gastroenterol. WJG 2014, 20, 13804-13819. [CrossRef]

103. Baj, J.; Korona-Głowniak, I.; Forma, A.; Maani, A.; Sitarz, E.; Rahnama-Hezavah, M.; Radzikowska, E.; Portincasa, P. Mechanisms of the Epithelial-Mesenchymal Transition and Tumor Microenvironment in Helicobacter pylori-Induced Gastric Cancer. Cells 2020, 9, 1055. [CrossRef] [PubMed]

104. Choi, S.I.; Yoon, C.; Park, M.R.; Lee, D.; Kook, M.C.; Lin, J.X.; Kang, J.H.; Ashktorab, H.; Smoot, D.T.; Yoon, S.S.; et al. CDX1 Expression Induced by CagA-Expressing Helicobacter pylori Promotes Gastric Tumorigenesis. Mol. Cancer Res. 2019, 17, 2169-2183. [CrossRef]

105. Murata-Kamiya, N.; Kurashima, Y.; Teishikata, Y.; Yamahashi, Y.; Saito, Y.; Higashi, H.; Aburatani, H.; Akiyama, T.; Peek, R.M., Jr.; Azuma, T.; et al. Helicobacter pylori CagA interacts with E-cadherin and deregulates the beta-catenin signal that promotes intestinal transdifferentiation in gastric epithelial cells. Oncogene 2007, 26, 4617-4626. [CrossRef] [PubMed]

106. Buda, A.; Pignatelli, M. E-cadherin and the cytoskeletal network in colorectal cancer development and metastasis. Cell Commun. Adhes 2011, 18, 133-143. [CrossRef] [PubMed]

107. Devaux, C.A.; Mezouar, S.; Mege, J.L. The E-Cadherin Cleavage Associated to Pathogenic Bacteria Infections Can Favor Bacterial Invasion and Transmigration, Dysregulation of the Immune Response and Cancer Induction in Humans. Front Microbiol. 2019, 10, 2598. [CrossRef]

108. Zhang, X.Y.; Zhang, P.Y.; Aboul-Soud, M.A. From inflammation to gastric cancer: Role of Helicobacter pylori. Oncol. Lett. 2017, 13, 543-548. [CrossRef]

109. Molina Castro, S.E.; Tiffon, C.; Giraud, J.; Boeuf, H.; Sifre, E.; Giese, A.; Belleannee, G.; Lehours, P.; Bessede, E.; Megraud, F.; et al. The Hippo Kinase LATS2 Controls Helicobacter pylori-Induced Epithelial-Mesenchymal Transition and Intestinal Metaplasia in Gastric Mucosa. Cell. Mol. Gastroenterol. Hepatol. 2020, 9, 257-276. [CrossRef]

110. Wada, Y.; Takemura, K.; Tummala, P.; Uchida, K.; Kitagaki, K.; Furukawa, A.; Ishige, Y.; Ito, T.; Hara, Y.; Suzuki, T.; et al. Helicobacter pylori induces somatic mutations in TP53 via overexpression of CHAC1 in infected gastric epithelial cells. FEBS Open Bio 2018, 8, 671-679. [CrossRef]

111. Ruggiero, P. Helicobacter pylori infection: What's new. Curr. Opin. Infect. Dis. 2012, 25, 337-344. [CrossRef]

112. Lee, D.Y.; Jung, D.E.; Yu, S.S.; Lee, Y.S.; Choi, B.K.; Lee, Y.C. Regulation of SIRT3 signal related metabolic reprogramming in gastric cancer by Helicobacter pylori oncoprotein CagA. Oncotarget 2017, 8, 78365-78378. [CrossRef]

113. Kido, M.; Watanabe, N.; Aoki, N.; Iwamoto, S.; Nishiura, H.; Maruoka, R.; Ikeda, A.; Azuma, T.; Chiba, T. Dual roles of CagA protein in Helicobacterpylori-induced chronic gastritis in mice. Biochem. Biophys. Res. Commun. 2011, 412, 266-272. [CrossRef] [PubMed]

114. Zhang, Z.W.; Patchett, S.E.; Perrett, D.; Katelaris, P.H.; Domizio, P.; Farthing, M.J. The relation between gastric vitamin $\mathrm{C}$ concentrations, mucosal histology, and CagA seropositivity in the human stomach. Gut 1998, 43, 322-326. [CrossRef] [PubMed] 
115. Meliț, L.E.; Mărginean, C.O.; Mărginean, C.D.; Mărginean, M.O. The Relationship between Toll-like Receptors and Helicobacter pylori-Related Gastropathies: Still a Controversial Topic. J. Immunol. Res. 2019, 2019, 8197048. [CrossRef] [PubMed]

116. Li, S.; Cong, X.; Gao, H.; Lan, X.; Li, Z.; Wang, W.; Song, S.; Wang, Y.; Li, C.; Zhang, H.; et al. Tumor-associated neutrophils induce EMT by IL-17a to promote migration and invasion in gastric cancer cells. J. Exp. Clin. Cancer Res. 2019, 38, 6. [CrossRef] [PubMed]

117. Wang, Z.; Zhang, L.; Guo, Z.; Liu, L.; Ji, J.; Zhang, J.; Chen, X.; Liu, B.; Zhang, J.; Ding, Q.; et al. A unique feature of iron loss via close adhesion of Helicobacter pylori to host erythrocytes. PLoS ONE 2012, 7, e50314. [CrossRef]

118. Poplawski, T.; Chojnacki, C.; Czubatka, A.; Klupinska, G.; Chojnacki, J.; Blasiak, J. Helicobacter pylori infection and antioxidants can modulate the genotoxic effects of heterocyclic amines in gastric mucosa cells. Mol. Biol. Rep. 2013, 40, 5205-5212. [CrossRef]

119. Fahimi, F.; Tohidkia, M.R.; Fouladi, M.; Aghabeygi, R.; Samadi, N.; Omidi, Y. Pleiotropic cytotoxicity of VacA toxin in host cells and its impact on immunotherapy. Bioimpacts 2017, 7, 59-71. [CrossRef]

120. Bridge, D.R.; Merrell, D.S. Polymorphism in the Helicobacter pylori CagA and VacA toxins and disease. Gut Microbes 2013, 4, 101-117. [CrossRef]

121. Palframan, S.L.; Kwok, T.; Gabriel, K. Vacuolating cytotoxin A (VacA), a key toxin for Helicobacter pylori pathogenesis. Front. Cell. Infect. Microbiol. 2012, 2, 92. [CrossRef]

122. Mahdavi, J.; Sonden, B.; Hurtig, M.; Olfat, F.O.; Forsberg, L.; Roche, N.; Angstrom, J.; Larsson, T.; Teneberg, S.; Karlsson, K.A.; et al. Helicobacter pylori SabA adhesin in persistent infection and chronic inflammation. Science 2002, 297, 573-578. [CrossRef]

123. Su, Y.L.; Huang, H.L.; Huang, B.S.; Chen, P.C.; Chen, C.S.; Wang, H.L.; Lin, P.H.; Chieh, M.S.; Wu, J.J.; Yang, J.C.; et al. Combination of OipA, BabA, and SabA as candidate biomarkers for predicting Helicobacter pylori-related gastric cancer. Sci. Rep. 2016, 6, 36442. [CrossRef] [PubMed]

124. Wiener, A.S. Blood-groups and disease. A critical review. Lancet 1962, 1, 813-816. [CrossRef]

125. Horwich, L.; Evans, D.A.; McConnell, R.B.; Donohoe, W.T. ABO blood groups in gastric bleeding. Gut 1966, 7, 680-685. [CrossRef] [PubMed]

126. Edgren, G.; Hjalgrim, H.; Rostgaard, K.; Norda, R.; Wikman, A.; Melbye, M.; Nyren, O. Risk of gastric cancer and peptic ulcers in relation to ABO blood type: A cohort study. Am. J. Epidemiol. 2010, 172, 1280-1285. [CrossRef] [PubMed]

127. Alkout, A.M.; Blackwell, C.C.; Weir, D.M. Increased inflammatory responses of persons of blood group O to Helicobacter pylori. J. Infect. Dis. 2000, 181, 1364-1369. [CrossRef]

128. Nakao, M.; Matsuo, K.; Ito, H.; Shitara, K.; Hosono, S.; Watanabe, M.; Ito, S.; Sawaki, A.; Iida, S.; Sato, S.; et al. ABO genotype and the risk of gastric cancer, atrophic gastritis, and Helicobacter pylori infection. Cancer Epidemiol. Biomark. Prev. 2011, 20, 1665-1672. [CrossRef]

129. Kurtenkov, O.; Klaamas, K. Hidden IgG Antibodies to the Tumor-Associated Thomsen-Friedenreich Antigen in Gastric Cancer Patients: Lectin Reactivity, Avidity, and Clinical Relevance. Biomed. Res. Int. 2017, 2017, 6097647. [CrossRef]

130. Jaff, M.S. Relation between ABO blood groups and Helicobacter pylori infection in symptomatic patients. Clin. Exp. Gastroenterol. 2011, 4, 221-226. [CrossRef]

131. Sievers, M.L. Hereditary aspects of gastric secretory function; race and ABO blood groups in relationship to acid and pepsin production. Am. J. Med. 1959, 27, 246-255. [CrossRef]

132. Akatsuka, S.; Yamashita, Y.; Ohara, H.; Liu, Y.T.; Izumiya, M.; Abe, K.; Ochiai, M.; Jiang, L.; Nagai, H.; Okazaki, Y.; et al. Fenton reaction induced cancer in wild type rats recapitulates genomic alterations observed in human cancer. PLoS ONE 2012, 7, e43403. [CrossRef]

133. Conteduca, V.; Sansonno, D.; Lauletta, G.; Russi, S.; Ingravallo, G.; Dammacco, F. H. pylori infection and gastric cancer: State of the art (review). Int. J. Oncol. 2013, 42, 5-18. [CrossRef] [PubMed]

134. Correa, P.; Houghton, J. Carcinogenesis of Helicobacter pylori. Gastroenterology 2007, 133, 659-672. [CrossRef] [PubMed]

135. Minalyan, A.; Benhammou, J.N.; Artashesyan, A.; Lewis, M.S.; Pisegna, J.R. Autoimmune atrophic gastritis: Current perspectives. Clin. Exp. Gastroenterol. 2017, 10, 19-27. [CrossRef] [PubMed]

136. Cavalcoli, F.; Zilli, A.; Conte, D.; Massironi, S. Micronutrient deficiencies in patients with chronic atrophic autoimmune gastritis: A review. World J. Gastroenterol. WJG 2017, 23, 563-572. [CrossRef] [PubMed] 
137. Hussain, A.; Tabrez, E.; Peela, J.; Honnavar, P.D.; Tabrez, S.S.M. Vitamin C: A Preventative, Therapeutic Agent Against Helicobacter pylori. Cureus 2018, 10, e3062. [CrossRef]

138. Feiz, H.R.; Mobarhan, S. Does vitamin C intake slow the progression of gastric cancer in Helicobacter pylori-infected populations? Nutr. Rev. 2002, 60,34-36. [PubMed]

139. Waring, A.J.; Drake, I.M.; Schorah, C.J.; White, K.L.; Lynch, D.A.; Axon, A.T.; Dixon, M.F. Ascorbic acid and total vitamin C concentrations in plasma, gastric juice, and gastrointestinal mucosa: Effects of gastritis and oral supplementation. Gut 1996, 38, 171-176. [CrossRef]

140. Rokkas, T.; Papatheodorou, G.; Karameris, A.; Mavrogeorgis, A.; Kalogeropoulos, N.; Giannikos, N. Helicobacter pylori infection and gastric juice vitamin C levels. Impact of eradication. Dig. Dis. Sci. 1995, 40, 615-621. [CrossRef]

141. Banerjee, S.; Hawksby, C.; Miller, S.; Dahill, S.; Beattie, A.D.; McColl, K.E. Effect of Helicobacter pylori and its eradication on gastric juice ascorbic acid. Gut 1994, 35, 317-322. [CrossRef]

142. Sobala, G.M.; Schorah, C.J.; Shires, S.; Lynch, D.A.; Gallacher, B.; Dixon, M.F.; Axon, A.T. Effect of eradication of Helicobacter pylori on gastric juice ascorbic acid concentrations. Gut 1993, 34, 1038-1041. [CrossRef]

143. Annibale, B.; Capurso, G.; Lahner, E.; Passi, S.; Ricci, R.; Maggio, F.; Delle Fave, G. Concomitant alterations in intragastric $\mathrm{pH}$ and ascorbic acid concentration in patients with Helicobacter pylori gastritis and associated iron deficiency anaemia. Gut 2003, 52, 496-501. [CrossRef] [PubMed]

144. Gao, H.J.; Yu, L.Z.; Bai, J.F.; Peng, Y.S.; Sun, G.; Zhao, H.L.; Miu, K.; Lu, X.Z.; Zhang, X.Y.; Zhao, Z.Q. Multiple genetic alterations and behavior of cellular biology in gastric cancer and other gastric mucosal lesions: H. pylori infection, histological types and staging. World J. Gastroenterol. WJG 2000, 6, 848-854. [CrossRef] [PubMed]

145. Mao, Q.Q.; Xu, X.Y.; Shang, A.; Gan, R.Y.; Wu, D.T.; Atanasov, A.G.; Li, H.B. Phytochemicals for the Prevention and Treatment of Gastric Cancer: Effects and Mechanisms. Int. J. Mol. Sci. 2020, 21, 570. [CrossRef] [PubMed]

146. Fang, X.; Wei, J.; He, X.; An, P.; Wang, H.; Jiang, L.; Shao, D.; Liang, H.; Li, Y.; Wang, F.; et al. Landscape of dietary factors associated with risk of gastric cancer: A systematic review and dose-response meta-analysis of prospective cohort studies. Eur. J. Cancer 2015, 51, 2820-2832. [CrossRef] [PubMed]

147. Kong, P.; Cai, Q.; Geng, Q.; Wang, J.; Lan, Y.; Zhan, Y.; Xu, D. Vitamin intake reduce the risk of gastric cancer: Meta-analysis and systematic review of randomized and observational studies. PLoS ONE 2014, 9, e116060. [CrossRef]

148. Sasazuki, S.; Sasaki, S.; Tsubono, Y.; Okubo, S.; Hayashi, M.; Kakizoe, T.; Tsugane, S. The effect of 5-year vitamin C supplementation on serum pepsinogen level and Helicobacter pylori infection. Cancer Sci. 2003, 94, 378-382. [CrossRef]

149. Mera, R.; Fontham, E.T.; Bravo, L.E.; Bravo, J.C.; Piazuelo, M.B.; Camargo, M.C.; Correa, P. Long term follow up of patients treated for Helicobacter pylori infection. Gut 2005, 54, 1536-1540. [CrossRef]

150. Bjelakovic, G.; Nikolova, D.; Simonetti, R.G.; Gluud, C. Antioxidant supplements for prevention of gastrointestinal cancers: A systematic review and meta-analysis. Lancet 2004, 364, 1219-1228. [CrossRef]

151. López-Carrillo, L.; López-Cervantes, M.; Ward, M.H.; Bravo-Alvarado, J.; Ramírez-Espitia, A. Nutrient intake and gastric cancer in Mexico. Int. J. Cancer 1999, 83, 601-605. [CrossRef]

152. Pelucchi, C.; Tramacere, I.; Bertuccio, P.; Tavani, A.; Negri, E.; La Vecchia, C. Dietary intake of selected micronutrients and gastric cancer risk: An Italian case-control study. Ann. Oncol. Off. J. Eur. Soc. Med. Oncol. ESMO 2009, 20, 160-165. [CrossRef]

153. Epplein, M.; Shu, X.O.; Xiang, Y.B.; Chow, W.H.; Yang, G.; Li, H.L.; Ji, B.T.; Cai, H.; Gao, Y.T.; Zheng, W. Fruit and vegetable consumption and risk of distal gastric cancer in the Shanghai Women's and Men's Health studies. Am. J. Epidemiol. 2010, 172, 397-406. [CrossRef] [PubMed]

154. Wang, T.; Cai, H.; Sasazuki, S.; Tsugane, S.; Zheng, W.; Cho, E.R.; Jee, S.H.; Michel, A.; Pawlita, M.; Xiang, Y.B.; et al. Fruit and vegetable consumption, Helicobacter pylori antibodies, and gastric cancer risk: A pooled analysis of prospective studies in China, Japan, and Korea. Int. J. Cancer 2017, 140, 591-599. [CrossRef] [PubMed]

155. Kamiya, S.; Yonezawa, H.; Osaki, T. Role of Probiotics in Eradication Therapy for Helicobacter pylori Infection. Adv. Exp. Med. Biol. 2019, 1149, 243-255. [PubMed]

156. Eslami, M.; Yousefi, B.; Kokhaei, P.; Jazayeri Moghadas, A.; Sadighi Moghadam, B.; Arabkari, V.; Niazi, Z. Are probiotics useful for therapy of Helicobacter pylori diseases? Comp. Immunol. Microbiol. Infect. Dis. 2019, 64, 99-108. [CrossRef] 
157. Song, H.; Zhou, L.; Liu, D.; Ge, L.; Li, Y. Probiotic effect on Helicobacter pylori attachment and inhibition of inflammation in human gastric epithelial cells. Exp. Med. 2019, 18, 1551-1562. [CrossRef]

158. Ji, J.; Yang, H. Using Probiotics as Supplementation for Helicobacter pylori Antibiotic Therapy. Int. J. Mol. Sci. 2020, 21, 1136. [CrossRef]

159. Elangovan, A.; Fischer, M. When to use probiotics in luminal gastrointestinal disorders? Curr. Opin. Clin. Nutr. Metab. Care 2020, 23, 336-343. [CrossRef]

160. Russo, F.; Linsalata, M.; Orlando, A. Probiotics against neoplastic transformation of gastric mucosa: Effects on cell proliferation and polyamine metabolism. World J. Gastroenterol. WJG 2014, 20, 13258-13272. [CrossRef]

161. Lijinsky, W. N-Nitroso compounds in the diet. Mutat. Res. 1999, 443, 129-138. [CrossRef]

162. Ohgaki, H.; Takayama, S.; Sugimura, T. Carcinogenicities of heterocyclic amines in cooked food. Mutat. Res. 1991, 259, 399-410. [CrossRef]

163. Tsugane, S. Salt, salted food intake, and risk of gastric cancer: Epidemiologic evidence. Cancer Sci. 2005, 96, 1-6. [CrossRef] [PubMed]

164. Poorolajal, J.; Moradi, L.; Mohammadi, Y.; Cheraghi, Z.; Gohari-Ensaf, F. Risk factors for stomach cancer: A systematic review and meta-analysis. Epidemiol. Health 2020, 42, e2020004. [CrossRef] [PubMed]

165. Larsson, S.C.; Bergkvist, L.; Wolk, A. Processed meat consumption, dietary nitrosamines and stomach cancer risk in a cohort of Swedish women. Int. J. Cancer 2006, 119, 915-919. [CrossRef] [PubMed]

166. Wynder, E.L.; Bross, I.J. A study of etiological factors in cancer of the esophagus. Cancer 1961, 14, $389-413$. [CrossRef]

167. Stillwell, W.G.; Glogowski, J.; Xu, H.X.; Wishnok, J.S.; Zavala, D.; Montes, G.; Correa, P.; Tannenbaum, S.R. Urinary excretion of nitrate, $\mathrm{N}$-nitrosoproline, 3-methyladenine, and 7-methylguanine in a Colombian population at high risk for stomach cancer. Cancer Res. 1991, 51, 190-194. [PubMed]

168. Bouvard, V.; Loomis, D.; Guyton, K.Z.; Grosse, Y.; Ghissassi, F.E.; Benbrahim-Tallaa, L.; Guha, N.; Mattock, H.; Straif, K. Carcinogenicity of consumption of red and processed meat. Lancet Oncol. 2015, 16, 1599-1600. [CrossRef]

169. Mard, S.A.; Khadem Haghighian, H.; Sebghatulahi, V.; Ahmadi, B. Dietary Factors in Relation to Helicobacter pylori Infection. Gastroenterol. Res. Pract. 2014, 2014, 826910. [CrossRef]

170. Jakszyn, P.; Bingham, S.; Pera, G.; Agudo, A.; Luben, R.; Welch, A.; Boeing, H.; Del Giudice, G.; Palli, D.; Saieva, C.; et al. Endogenous versus exogenous exposure to N-nitroso compounds and gastric cancer risk in the European Prospective Investigation into Cancer and Nutrition (EPIC-EURGAST) study. Carcinogenesis 2006, 27, 1497-1501. [CrossRef]

171. Tannenbaum, S.R.; Sinskey, A.J.; Weisman, M.; Bishop, W. Nitrite in human saliva. Its possible relationship to nitrosamine formation. J. Natl. Cancer Inst. 1974, 53, 79-84. [CrossRef]

172. Tannenbaum, S.R.; Archer, M.C.; Wishnok, J.S.; Bishop, W.W. Nitrosamine formation in human saliva. J. Natl. Cancer Inst. 1978, 60, 251-253. [CrossRef]

173. Guo, Y.; Zhang, Y.; Gerhard, M.; Gao, J.J.; Mejias-Luque, R.; Zhang, L.; Vieth, M.; Ma, J.L.; Bajbouj, M.; Suchanek, S.; et al. Effect of Helicobacter pylori on gastrointestinal microbiota: A population-based study in Linqu, a high-risk area of gastric cancer. Gut 2019. [CrossRef]

174. Nicastro, H.L.; Ross, S.A.; Milner, J.A. Garlic and onions: Their cancer prevention properties. Cancer Prev. Res. (Phila) 2015, 8, 181-189. [CrossRef] [PubMed]

175. Kyrtopoulos, S.A.; Pignatelli, B.; Karkanias, G.; Golematis, B.; Esteve, J. Studies in gastric carcinogenesis. V. The effects of ascorbic acid on N-nitroso compound formation in human gastric juice in vivo and in vitro. Carcinogenesis 1991, 12, 1371-1376. [CrossRef] [PubMed]

176. D'Elia, L.; Rossi, G.; Ippolito, R.; Cappuccio, F.P.; Strazzullo, P. Habitual salt intake and risk of gastric cancer: A meta-analysis of prospective studies. Clin. Nutr. 2012, 31, 489-498. [CrossRef]

177. Fox, J.G.; Wang, T.C. Dietary factors modulate Helicobacter-associated gastric cancer in rodent models. Toxicol. Pathol. 2014, 42, 162-181. [CrossRef] [PubMed]

178. Zaidi, S.F. Helicobacter pylori associated Asian enigma: Does diet deserve distinction? World J. Gastrointest. Oncol. 2016, 8, 341-350. [CrossRef] [PubMed]

179. Shikata, K.; Kiyohara, Y.; Kubo, M.; Yonemoto, K.; Ninomiya, T.; Shirota, T.; Tanizaki, Y.; Doi, Y.; Tanaka, K.; Oishi, Y.; et al. A prospective study of dietary salt intake and gastric cancer incidence in a defined Japanese population: The Hisayama study. Int. J. Cancer 2006, 119, 196-201. [CrossRef] 
180. Loh, J.T.; Beckett, A.C.; Scholz, M.B.; Cover, T.L. High-Salt Conditions Alter Transcription of Helicobacter pylori Genes Encoding Outer Membrane Proteins. Infect. Immun. 2018, 86. [CrossRef]

181. Gonzalez, C.A.; Pera, G.; Agudo, A.; Palli, D.; Krogh, V.; Vineis, P.; Tumino, R.; Panico, S.; Berglund, G.; Siman, H.; et al. Smoking and the risk of gastric cancer in the European Prospective Investigation Into Cancer and Nutrition (EPIC). Int. J. Cancer 2003, 107, 629-634. [CrossRef]

182. Zaridze, D.; Borisova, E.; Maximovitch, D.; Chkhikvadze, V. Alcohol consumption, smoking and risk of gastric cancer: Case-control study from Moscow, Russia. Cancer Causes Control CCC 2000, 11, 363-371. [CrossRef]

183. Koizumi, Y.; Tsubono, Y.; Nakaya, N.; Kuriyama, S.; Shibuya, D.; Matsuoka, H.; Tsuji, I. Cigarette smoking and the risk of gastric cancer: A pooled analysis of two prospective studies in Japan. Int. J. Cancer 2004, 112, 1049-1055. [CrossRef] [PubMed]

184. Valavanidis, A.; Vlachogianni, T.; Fiotakis, K. Tobacco smoke: Involvement of reactive oxygen species and stable free radicals in mechanisms of oxidative damage, carcinogenesis and synergistic effects with other respirable particles. Int. J. Environ. Res. Public Health 2009, 6, 445-462. [CrossRef] [PubMed]

185. Bohn, S.K.; Myhrstad, M.C.; Thoresen, M.; Holden, M.; Karlsen, A.; Tunheim, S.H.; Erlund, I.; Svendsen, M.; Seljeflot, I.; Moskaug, J.O.; et al. Blood cell gene expression associated with cellular stress defense is modulated by antioxidant-rich food in a randomised controlled clinical trial of male smokers. BMC Med. 2010, 8, 54. [CrossRef] [PubMed]

186. McCready, D.R.; Clark, L.; Cohen, M.M. Cigarette smoking reduces human gastric luminal prostaglandin E2. Gut 1985, 26, 1192-1196. [CrossRef]

187. Jarosz, M.; Dzieniszewski, J.; Dabrowska-Ufniarz, E.; Wartanowicz, M.; Ziemlanski, S. Tobacco smoking and vitamin $\mathrm{C}$ concentration in gastric juice in healthy subjects and patients with Helicobacter pylori infection. Eur. J. Cancer Prev. 2000, 9, 423-428. [CrossRef]

188. Gonzalez, C.A.; Lopez-Carrillo, L. Helicobacter pylori, nutrition and smoking interactions: Their impact in gastric carcinogenesis. Scand. J. Gastroenterol. 2010, 45, 6-14. [CrossRef]

189. Wang, H.; Ma, L.; Li, Y.; Cho, C.H. Exposure to cigarette smoke increases apoptosis in the rat gastric mucosa through a reactive oxygen species-mediated and p53-independent pathway. Free Radic. Biol. Med. 2000, 28, 1125-1131. [CrossRef]

190. Kneller, R.W.; You, W.C.; Chang, Y.S.; Liu, W.D.; Zhang, L.; Zhao, L.; Xu, G.W.; Fraumeni, J.F., Jr.; Blot, W.J. Cigarette smoking and other risk factors for progression of precancerous stomach lesions. J. Natl. Cancer Inst. 1992, 84, 1261-1266. [CrossRef]

191. Butt, J.; Varga, M.G.; Wang, T.; Tsugane, S.; Shimazu, T.; Zheng, W.; Abnet, C.C.; Yoo, K.Y.; Park, S.K.; Kim, J.; et al. Smoking, Helicobacter Pylori Serology, and Gastric Cancer Risk in Prospective Studies from China, Japan, and Korea. Cancer Prev. Res. (Phila) 2019, 12, 667-674. [CrossRef]

192. Han, X.; Xiao, L.; Yu, Y.; Chen, Y.; Shu, H.H. Alcohol consumption and gastric cancer risk: A meta-analysis of prospective cohort studies. Oncotarget 2017, 8, 83237-83245. [CrossRef]

193. Ma, S.H.; Jung, W.; Weiderpass, E.; Jang, J.; Hwang, Y.; Ahn, C.; Ko, K.P.; Chang, S.H.; Shin, H.R.; Yoo, K.Y.; et al. Impact of alcohol drinking on gastric cancer development according to Helicobacter pylori infection status. Br. J. Cancer 2015, 113, 1381-1388. [CrossRef] [PubMed]

194. Moy, K.A.; Fan, Y.; Wang, R.; Gao, Y.T.; Yu, M.C.; Yuan, J.M. Alcohol and tobacco use in relation to gastric cancer: A prospective study of men in Shanghai, China. Cancer Epidemiol. Biomark. Prev. 2010, 19, 2287-2297. [CrossRef] [PubMed]

195. Bartsch, H.; Nair, J. Accumulation of lipid peroxidation-derived DNA lesions: Potential lead markers for chemoprevention of inflammation-driven malignancies. Mutat. Res. 2005, 591, 34-44. [CrossRef] [PubMed]

196. Sjodahl, K.; Lu, Y.; Nilsen, T.I.; Ye, W.; Hveem, K.; Vatten, L.; Lagergren, J. Smoking and alcohol drinking in relation to risk of gastric cancer: A population-based, prospective cohort study. Int. J. Cancer 2007, 120, 128-132. [CrossRef] [PubMed]

197. Nishimura, T. Total number of genome alterations in sporadic gastrointestinal cancer inferred from pooled analyses in the literature. Tumour Biol. J. Int. Soc. Oncodev. Biol. Med. 2008, 29, 343-350. [CrossRef]

198. Gonzalez, C.A.; Sala, N.; Rokkas, T. Gastric cancer: Epidemiologic aspects. Helicobacter 2013, 18, 34-38. [CrossRef] [PubMed] 
199. Wright, M.E.; Andreotti, G.; Lissowska, J.; Yeager, M.; Zatonski, W.; Chanock, S.J.; Chow, W.H.; Hou, L. Genetic variation in sodium-dependent ascorbic acid transporters and risk of gastric cancer in Poland. Eur. J. Cancer 2009, 45, 1824-1830. [CrossRef]

200. Duell, E.J.; Lujan-Barroso, L.; Llivina, C.; Munoz, X.; Jenab, M.; Boutron-Ruault, M.C.; Clavel-Chapelon, F.; Racine, A.; Boeing, H.; Buijsse, B.; et al. Vitamin C transporter gene (SLC23A1 and SLC23A2) polymorphisms, plasma vitamin $C$ levels, and gastric cancer risk in the EPIC cohort. Genes Nutr. 2013, 8, 549-560. [CrossRef]

201. Zhang, Y.; Sun, L.P.; Xing, C.Z.; Xu, Q.; He, C.Y.; Li, P.; Gong, Y.H.; Liu, Y.P.; Yuan, Y. Interaction between GSTP1 Val allele and H. pylori infection, smoking and alcohol consumption and risk of gastric cancer among the Chinese population. PLoS ONE 2012, 7, e47178. [CrossRef]

202. Kim, J.; Lee, H.S.; Bae, S.I.; Lee, Y.M.; Kim, W.H. Silencing and CpG island methylation of GSTP1 is rare in ordinary gastric carcinomas but common in Epstein-Barr virus-associated gastric carcinomas. Anticancer Res. 2005, 25, 4013-4019.

203. Lao, X.; Peng, Q.; Lu, Y.; Li, S.; Qin, X.; Chen, Z.; Chen, J. Glutathione S-transferase gene GSTM1, gene-gene interaction, and gastric cancer susceptibility: Evidence from an updated meta-analysis. Cancer Cell Int. 2014, 14, 127. [CrossRef] [PubMed]

204. Gong, E.J.; Ahn, J.Y.; Jung, H.Y.; Park, H.; Ko, Y.B.; Na, H.K.; Jung, K.W.; Kim, D.H.; Lee, J.H.; Choi, K.D.; et al. Helicobacter pylori Eradication Therapy Is Effective as the Initial Treatment for Patients with $\mathrm{H}$. pylori-Negative and Disseminated Gastric Mucosa-Associated Lymphoid Tissue Lymphoma. Gut Liver 2016, 10, 706-713. [CrossRef] [PubMed]

205. Floch, P.; Mégraud, F.; Lehours, P. Helicobacter pylori Strains and Gastric MALT Lymphoma. Toxins 2017, 9, 132. [CrossRef] [PubMed]

206. Wündisch, T.; Stolte, M. Current status of gastric MALT lymphoma. Curr. Gastroenterol. Rep. 2006, 8, 343-346. [CrossRef] [PubMed]

207. Santacroce, L.; Cagiano, R.; Del Prete, R.; Bottalico, L.; Sabatini, R.; Carlaio, R.G.; Prejbeanu, R.; Vermesan, H.; Dragulescu, S.I.; Vermesan, D.; et al. Helicobacter pylori infection and gastric MALTomas: An up-to-date and therapy highlight. Clin. Ter. 2008, 159, 457-462.

208. Mazloom, A.; Rodriguez, A.; Ha, C.S.; Medeiros, L.J.; Wogan, C.; Shihadeh, F.; Allen, P.; Fowler, N.; Dabaja, B. Incidence of gastric involvement in patients with nongastrointestinal extranodal marginal zone lymphoma. Cancer 2011, 117, 2461-2466. [CrossRef]

209. Pervez, S.; Ali, N.; Aaqil, H.; Mumtaz, K.; Siddiq Ullah, S.; Akhtar, N. Gastric MALT lymphoma: A rarity. J. Coll. Physicians Surg. Pak. 2011, 21, 171-172.

210. Saito, Y.; Suzuki, H.; Tsugawa, H.; Imaeda, H.; Matsuzaki, J.; Hirata, K.; Hosoe, N.; Nakamura, M.; Mukai, M.; Saito, H.; et al. Overexpression of miR-142-5p and miR-155 in gastric mucosa-associated lymphoid tissue (MALT) lymphoma resistant to Helicobacter pylori eradication. PLoS ONE 2012, 7, e47396. [CrossRef]

211. Zucca, E.; Copie-Bergman, C.; Ricardi, U.; Thieblemont, C.; Raderer, M.; Ladetto, M. Gastric marginal zone lymphoma of MALT type: ESMO Clinical Practice Guidelines for diagnosis, treatment and follow-up. Ann. Oncol. Off. J. Eur. Soc. Med. Oncol. ESMO 2013, 24, vi144-vi148. [CrossRef]

212. Raderer, M.; Wöhrer, S.; Kiesewetter, B.; Dolak, W.; Lagler, H.; Wotherspoon, A.; Muellauer, L.; Chott, A. Antibiotic treatment as sole management of Helicobacter pylori-negative gastric MALT lymphoma: A single center experience with prolonged follow-up. Ann. Hematol. 2015, 94, 969-973. [CrossRef]

213. Hatakeyama, M. Malignant Helicobacter pylori-Associated Diseases: Gastric Cancer and MALT Lymphoma. Adv. Exp. Med. Biol. 2019, 1149, 135-149. [PubMed]

214. Lee, Y.C.; Chiang, T.H.; Chou, C.K.; Tu, Y.K.; Liao, W.C.; Wu, M.S.; Graham, D.Y. Association Between Helicobacter pylori Eradication and Gastric Cancer Incidence: A Systematic Review and Meta-analysis. Gastroenterology 2016, 150, 1113-1124.e5. [CrossRef] [PubMed]

215. Seta, T.; Takahashi, Y.; Noguchi, Y.; Shikata, S.; Sakai, T.; Sakai, K.; Yamashita, Y.; Nakayama, T. Effectiveness of Helicobacter pylori eradication in the prevention of primary gastric cancer in healthy asymptomatic people: A systematic review and meta-analysis comparing risk ratio with risk difference. PLoS ONE 2017, 12, e0183321. [CrossRef] [PubMed]

216. Sugano, K. Effect of Helicobacter pylori eradication on the incidence of gastric cancer: A systematic review and meta-analysis. Gastric Cancer 2019, 22, 435-445. [CrossRef] [PubMed]

217. Ford, A.C.; Yuan, Y.; Forman, D.; Hunt, R.; Moayyedi, P. Helicobacter pylori eradication for the prevention of gastric neoplasia. Cochrane Database Syst. Rev. 2020, 7, Cd005583. 
218. Kumar, S.; Metz, D.C.; Ellenberg, S.; Kaplan, D.E.; Goldberg, D.S. Risk Factors and Incidence of Gastric Cancer After Detection of Helicobacter pylori Infection: A Large Cohort Study. Gastroenterology 2020, 158, 527-536.e7. [CrossRef]

219. Malfertheiner, P.; Megraud, F.; O’Morain, C.A.; Gisbert, J.P.; Kuipers, E.J.; Axon, A.T.; Bazzoli, F.; Gasbarrini, A.; Atherton, J.; Graham, D.Y.; et al. Management of Helicobacter pylori infection-the Maastricht V/Florence Consensus Report. Gut 2017, 66, 6-30. [CrossRef]

220. Lee, Y.C.; Chen, T.H.; Chiu, H.M.; Shun, C.T.; Chiang, H.; Liu, T.Y.; Wu, M.S.; Lin, J.T. The benefit of mass eradication of Helicobacter pylori infection: A community-based study of gastric cancer prevention. Gut 2013, 62, 676-682. [CrossRef]

221. Choi, I.J.; Kim, C.G.; Lee, J.Y.; Kim, Y.I.; Kook, M.C.; Park, B.; Joo, J. Family History of Gastric Cancer and Helicobacter pylori Treatment. N. Engl. J. Med. 2020, 382, 427-436. [CrossRef]

222. Michigami, Y.; Watari, J.; Ito, C.; Nakai, K.; Yamasaki, T.; Kondo, T.; Kono, T.; Tozawa, K.; Tomita, T.; Oshima, T.; et al. Long-term effects of H. pylori eradication on epigenetic alterations related to gastric carcinogenesis. Sci. Rep. 2018, 8, 14369. [CrossRef]

223. Li, W.Q.; Zhang, J.Y.; Ma, J.L.; Li, Z.X.; Zhang, L.; Zhang, Y.; Guo, Y.; Zhou, T.; Li, J.Y.; Shen, L.; et al. Effects of Helicobacter pylori treatment and vitamin and garlic supplementation on gastric cancer incidence and mortality: Follow-up of a randomized intervention trial. BMJ (Clin. Res. Ed.) 2019, 366, 15016. [CrossRef] [PubMed]

(C) 2020 by the authors. Licensee MDPI, Basel, Switzerland. This article is an open access article distributed under the terms and conditions of the Creative Commons Attribution (CC BY) license (http://creativecommons.org/licenses/by/4.0/). 